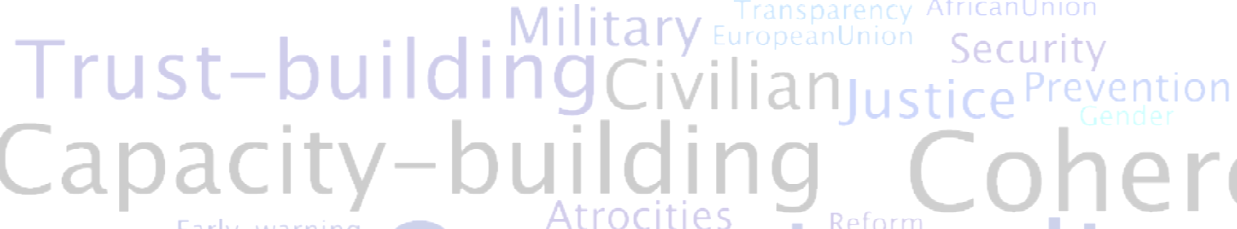 Operationalise zing the \\ Operationalizing gectegin \\ Operationalizing
}

Responsibility to

Protect

A Contribution to the pacity-building Third Pillar Approach 


\title{
Operationalizing the Responsibility to Protect
}

\author{
A Contribution to the Third Pillar Approach
}

Edited by

Daniel Fiott

Robert Zuber

Joachim Koops

ISSN: $2033-7574$

Brussels, 2012.

Published by the Madariaga - College of Europe Foundation, Global Action to Prevent War, the Global Governance Institute and the International Coalition for the Responsibility to Protect.

Cover Photo: Abyei, Sudan (28 May 2011). UN Photo/Stuart Price - Photo \# 474285. 
1. Note on the Contributors 4

2. Preface 6

3. Acronyms $\quad 7$

4. Introduction $\quad 8$

DANIEL FIOTT

5. Building Confidence and Trust in the United Nations Third Pillar Response Capacities ROBERT ZUBER

6. The Regionalization of the Responsibility to Protect KATE SEAMAN

7. A Reluctant Actor: China's Dilemmas in the Responsibility to Protect PEIRAN WANG

8. An Examination of the Level of Standby Effectiveness in the EU for Responsibility to Protect Style Deployments DAVID CURRAN

9. Operationalizing the Responsibility to Protect's "Sharp End": Towards a No Footprint Approach ROBERT SCHÜTTE

10. A Common Approach to the Application of the Responsibility to Protect SHERI ROSENBERG E EKKEHARD STRAUSS

11. Libya and the Responsibility to Protect: Pillar Three and the Prevention of Mass Atrocity Crimes RUBEN REIKE

12. The Business Society and the Responsibility to Protect CONOR SEYLE E EAMON ALOYO

13. Gender Dimensions of Third Pillar Capacities: Women's Contributions to Conflict Prevention, Early Warning and Rapid Response MELINA LITO

14. Sanctions, Trials and Peace: Promises and Pitfalls of Responsibility to Protect's Civilian

Dimension

CAROLINE FEHL

15. Index 


\section{Note on the Contributors}

Dr. Eamon Aloyo is a Research Associate at the One Earth Future Foundation and a Senior Analyst in the Global Justice section at the Global Governance Institute. His publications and expertise span the topics of human rights, global institutional responsibility, international criminal law, transitional justice, and international development. Aloyo holds a Ph.D. in Political Science from the University of Colorado at Boulder and a B.A. in economics with honours from Lehigh University.

Dr. David Curran is a lecturer at the Department of Peace Studies, University of Bradford, specializing in the fields of peacekeeping and peacebuilding. His main area of research is into the role of conflict resolution theory and practices in the training of military personnel for peacekeeping deployments. He has also researched the development of standing peacekeeping forces in the UN, AU and the EU. Curran received his M.Phil. from the Department of Peace Studies and holds a Ph.D. from the same department.

Dr. Caroline Fehl is currently a Post-Doctoral Research Fellow and Assistant Professor at Goethe University Frankfurt where, among other subjects, she teaches international institutions and law. Fehl was previously an ESRC Post-Doctoral Research Fellow at the University of Oxford and she studied Political Science at Albert Ludwigs Universität Freiburg and Columbia University, New York, before earning her D.Phil. in International Relations from the University of Oxford.

Daniel Fiott has been a Research Fellow with the Madariaga - College of Europe Foundation since 2009 where he has focused his research work, events and publications on conflict prevention, European foreign and defence policies and the Responsibility to Protect. He has a B.Sc. (Hons) in International Studies and an M.Phil. in International Relations from the University of Cambridge. He currently heads the Foundation's work on RtoP and European foreign and defence policies.

Prof. Dr. Joachim Koops is the Director of the Global Governance Institute. He is Assistant Professor of Political Science at Vesalius College, Free University of Brussels (VUB) and a Senior Associate Researcher at the Institute for European Studies. He has advised the German Ministry of Foreign Affairs on EU and UNrelated security issues. Koops read Philosophy, Politics and Economics at the University of Oxford and completed his Ph.D. at the University of Kiel.

Melina Lito is Programme Director for Women, Peace and Security at Global Action to Prevent War where she works on issues of gender equality and their connection to disarmament, development and the prevention of mass atrocities. Lito received a B.A. in International Relations from the James Madison College of Public Affairs, Michigan State University, and holds a Juris Doctor degree in Law from Wayne State University Law School.

Ruben Reike is a Senior Analyst in the Global Governance Institute's Peace \& Security Section where he works on RtoP. He holds an M.A. in International Relations from the University of Queensland, Australia, where he worked with Professor Alex Bellamy and the Asia-Pacific Centre for the Responsibility to Protect on the RtoP's legal foundations. Reike is currently reading for a D.Phil. in International Relations at the University of Oxford where he works with Prof. Jennifer Welsh on the preventive dimension of RtoP.

Prof. Sheri Rosenberg is the Director of the Human Rights and Genocide Clinic and the Programme in Holocaust and Human Rights Studies at the Cardozo Law School. Professor Rosenberg has worked in the areas of civil rights and international human rights with a specific focus on issues of discrimination, equality and genocide. She has worked with several human rights organizations and the UN, as a civil rights litigator in private practice and as an Assistant Corporation Counsel to the New York City Law Department. 
Robert Schütte is President of the human rights NGO "Genocide Alert" and has published extensively on RtoP, the protection of civilians and robust peace operations. Schuette is also an Affiliate of the Harvard Humanitarian Initiative. He studied political science at the University of Cologne and Sciences Po Paris, spent several research stays at Harvard University and Friedrich-Ebert-Stiftung's New York office. He is completing a Ph.D. on the protection of civilians in armed conflict at the University of Cologne.

Dr. Kate Seaman is a Post-Doctoral Fellow in United States Politics at the Department of Political, Social and International Studies at the University of East Anglia, United Kingdom. She completed her Ph.D. entitled "Bridging the Gap: The United Nations, Global Governance and Peacekeeping in Crisis" at Lancaster University in 2011. Her research interests include peacekeeping, global security governance, the regionalization of norms of security governance and the development of RtoP.

Dr. Conor Seyle is an Associate Director of Research at the One Earth Future Foundation. Before this Seyle worked as a research for NGOs including the Charles F. Kettering Foundation, Issues Deliberation Australia/America, and Psychology Beyond Borders. His research has included predictors of successful interventions in communities affected by natural disasters or war. Seyle is a political psychologist and holds a Ph.D. in Social Psychology from the University of Texas.

Dr. Ekkehard Strauss holds a PhD in international law and human rights from the University of Potsdam, Germany. His professional experience includes academia, government and the private sector. He worked for the OSCE from 1998-2001 and the UN from 2001-2011, including the Office of the Special Adviser on the Prevention of Genocide. In 2011, he was appointed adjunct professor at Griffith University, Australia. Currently, Strauss works as consultant and researcher from Rabat, Morocco.

Peiran Wang is a Ph.D. candidate of International Relations at the School of Advanced International and Area Studies at East China Normal University, Shanghai, China. He previously studied Comparative Politics at East China University of Science and Technology. Since 2010 he has served as a Visiting Fellow at the Centre for Economic Law and Governance at the Vrije Universiteit Brussel, Belgium. Peiran Wang was also a Visiting Researcher at the Brussels Institute of Contemporary China Studies.

Dr. Robert Zuber is Director of the UN-based Global Action to Prevent War and the Project for a UN Emergency Peace Service. He also serves as consultant, adviser or board member to a wide variety of nonprofit, policy and educational organizations, including Green Map system, Our Humanity in the Balance, and the Paris-based human rights organization FIACAT. Dr Zuber has degrees from Yale and Columbia Universities and has written and spoken extensively on diverse human security issues and has organized workshops and conferences in over 30 countries. 


\section{Preface}

This collection of papers is a response and contribution to the challenges of the third pillar of the Responsibility to Protect principle. This pillar focuses on the international responsibility to take timely and decisive action to prevent and halt genocide, ethnic cleansing, war crimes and crimes against humanity in those instances where a state is unable or unwilling to protect its own population. As RtoP moves further away from discussions on norms towards operationalization, and following the concerns raised by the intervention in Libya, further thinking and clarity needs to be developed on the capacities needed for a timely and decisive response under pillar three.

Indeed, NATO's activities over Libya in pursuit of UN Resolution 1973 have again raised questions over the timeliness, legitimacy, proportionality and effectiveness of military action. Such issues have now been made more acute given the emphasis on the operationalisation of the RtoP principle, which has strong support from regional actors such as the European Union. There is a need to analyse the consistency, legitimacy and effectiveness of pillar three tools such as economic sanctions, diplomacy and civilian and military responses, especially in terms of how they impact on and complement preventive and re-building strategies.

These questions become all the more important given the United Nations report on the "The Role of Regional and Sub-Regional Arrangements in Implementing the Responsibility to Protect" (27 June 2011), plus the upcoming 2012 UN General Assembly interactive dialogue on 'third pillar' operationalisation of RtoP. This is an essential time to open up a policy and scholarly debate on the extant capacities of the UN and regional actors to effectively engage in pillar three of RtoP, as required. The collection of papers aims to provide substantive input for that interactive dialogue.

This collection of papers also forms the basis of a public event held on the $26^{\text {th }}$ April 2012 in Brussels at the Global Governance Institute - Vesalius College, Vrije Universiteit Brussel. The workshop was organized by the Madariaga - College of Europe Foundation, Global Action to Prevent War, the Global Governance Institute and the International Coalition for the Responsibility to Protect. The workshop provided an opportunity for policy experts and scholars to discuss their findings and recommendations and encouraged further debate on RtoP's third pillar with a diverse group of civil society partners. This collection of papers was presented first to the Office of the Special Advisor to the UN Secretary General on RtoP.

The organizers wish to thank all of the authors in this collection for their respective contributions and dedication. Each paper offers a rich contribution to the debate on RtoP's "third pillar". The organizers would also like to thank the UN Office of the Special Adviser on the Prevention of Genocide, the European Union and Vesalius College - Vrije Universiteit Brussel for their assistance and input. Finally, special thanks must go to the International Coalition for the Responsibility to Protect for their generous contribution to this project.

Daniel Fiott, Robert Zuber and Joachim Koops

Brussels

25 April 2012. 


\section{Acronyms}

\begin{tabular}{|c|c|}
\hline AU & African Union \\
\hline CEDAW & Committee on the Elimination of Discrimination against Women \\
\hline CSDP & Common Security and Defence Policy \\
\hline CSecR & Corporate Security Responsibility \\
\hline CSR & Corporate Social Responsibility \\
\hline DPKO & UN Department of Peacekeeping Operations \\
\hline DRC & Democratic Republic of Congo \\
\hline ECOWAS & Economic Organisation of West African States \\
\hline EU & European Union \\
\hline GAPW & Global Action to Prevent War and Armed Conflict \\
\hline GDP & Gross Domestic Product \\
\hline ICC & International Criminal Court \\
\hline ICISS & International Commission on Intervention and State Sovereignty \\
\hline ICRC & International Committee of the Red Cross \\
\hline ICRtoP & International Coalition for the Responsibility to Protect \\
\hline ICTY & International Tribunal for the Former Yugoslavia \\
\hline IGOs & Intergovernmental Organizations \\
\hline INTERFET & International Force for East Timor \\
\hline LRA & Lord's Resistance Army \\
\hline MAROs & Mass Atrocity Reaction Operations \\
\hline MINUSTAH & UN Stabilization Mission in Haiti \\
\hline MONUSCO & UN Mission to the Democratic Republic of Congo \\
\hline NATO & North Atlantic Treaty Organization \\
\hline NGOs & Non-Governmental Organizations \\
\hline NGOWG & NGO Working Group on Women, Peace and Security \\
\hline OCHA & Office for the Coordination of Humanitarian Affairs \\
\hline P5 & Permanent Members of the Security Council \\
\hline PoC & Protection of Civilians \\
\hline PKOs & UN Peacekeeping Operations \\
\hline PLA & People's Liberation Army \\
\hline PLAAF & People’s Liberation Army Air Force \\
\hline PRC & People's Republic of China \\
\hline RTLM & Radio Télévision Libre Des Mille Collines \\
\hline RtoP & Responsibility to Protect \\
\hline SCR & UN Security Council Resolution \\
\hline SGBV & Sexual and Gender-Based Violence \\
\hline SRSG & UN Special Representative of the Secretary-General \\
\hline UAV & Unmanned Aerial Vehicles \\
\hline UN & United Nations \\
\hline UNAMID & United Nations-African Union Mission in Darfur \\
\hline UNAMSIL & UN Mission in Sierra Leone \\
\hline UNEPS & UN Emergency Peace Service \\
\hline UNGA & UN General Assembly \\
\hline UNOCI & UN Operation in Côte d'Ivoire \\
\hline UNIFIL & UN Interim Force in Lebanon \\
\hline UNPROFOR & UN Protection Force \\
\hline UNSC & UN Security Council \\
\hline UNSCR & UN Security Council Resolution \\
\hline UNSG & UN Secretary General \\
\hline UNSMIL & UN Support Mission in Libya \\
\hline WPS & Women, Peace and Security \\
\hline WTO & World Trade Organization \\
\hline
\end{tabular}




\section{Introduction}

\section{DANIEL FIOTT}

Diplomatic, economic and military intervention remains one of the most contentious issues in international relations. Justifying intervention for the protection of civilians, even with the consent of the Security Council, makes the issue no less controversial or complex. This is hardly a new phenomenon. The humanists and Thomists once debated the justifications for and merits of intervention. The humanists were more inclined to justify intervention to halt "barbaric acts", whereas the Thomists questioned under whose authority the right to intervene could be given. ${ }^{1}$ The enduring tension was - and remains - between the sovereign right of a nation to be "free" from external interference and the "right" of other states to uphold human protection and dignity on a global basis. This tension has been greatly exacerbated by the processes of globalization. This is an era where globalized markets and finance, not to speak of challenges such as climate change, continue to test the resilience and authority of the state. The traditional unit in international politics is undergoing a long and drawn out crisis of identity and purpose. Added to this existential crisis are increased global media coverage of mass atrocities and the participation of civil society: "empathy without borders". These factors have made debates about intervention all the more acute and controversial.

The RtoP principle has been both an intellectual and practical response to the crisis of sovereignty. RtoP seeks to stress the importance of "shared sovereignty" by entrusting states with the primary responsibility to protect populations with the support of concerted international action, and, should states be unable or unwilling to protect populations, to mobilise political and diplomatic tools - including, as a last resort, the use of force - to restore responsible sovereignty. This is an approach that was accepted by a majority of states at the 2005 World Summit. Yet critics of the principle point to the need to maintain traditional concepts of sovereignty: with the emphasis on non-interference. This claim partly derives from the perceived insecurity that might result from the undermining of the rules of the international system, at least as they have been enshrined since the signing of the UN Charter in 1945. Sovereignty is a precious element in the lives of governments and individual rulers, yet sovereign recognition occurs both at the domestic and the international levels. ${ }^{2}$ While it is true that notions such as "sovereignty as responsibility" cannot exist without a system of sovereign states, when sovereign power is contested or when it is concentrated in the hands of those who would abuse it the potential atrocities remains.

The development of RtoP as a norm has seen it increase in complexity. This is particularly the case when one considers the moves to operationalize RtoP and its 'third pillar' approach; this pillar being geared to timely and decisive responses by the international community should a state be unable or unwilling to protect civilians from mass atrocities. While the third pillar approach is not just restricted to military intervention, the recent example of the NATO-led intervention of Libya (2011) has again raised the importance and contentiousness of using force to protect civilians. Indeed, the implementation of Resolution 1973 in Libya has highlighted concerns related to the timeliness, legitimacy, proportionality and effectiveness of military action. Furthermore, military action in Libya has raised questions about how the use of force sits alongside other pillar three tools such as preventive diplomacy, economic sanctions and restrictions and civilian protection missions. There is also the question of how pillar three tools in turn complement measures that are aimed at ensuring states meet their sovereign responsibilities in the first instance (pillar one) and to assist states in this task if needed (pillar two).

This collection of papers provides a greater understanding of the range of peaceful and military measures and tools used under the third pillar of RtoP. The collection is a contribution to the development of further thinking and clarity on the capacities needed for timely and decisive responses to mass atrocity crimes. The contributions offer the reader methods and policy options for improving the legitimacy and consistency of the third pillar approach.

\footnotetext{
${ }^{1}$ R. Tuck, The Rights of War and Peace: Political Thought and the International Order from Grotius to Kant (Oxford: Oxford University Press, 2002).

${ }^{2}$ S. Krasner, Sovereignty: Organized Hypocrisy (Princeton: Princeton University Press, 1999).
} 
Robert Zuber's chapter on building confidence and trust in third pillar response capacities provides a valuable perspective on the role of trust-building in developing a viable toolkit that would enhance the UN's capacity to prevent mass atrocities. Drawing on direct interaction with UN delegations, Zuber explores diverse options for trust-building to enhance the critical third pillar of RtoP. Following on with the issue of trust and legitimacy, Kate Seaman's chapter focuses on the shift in focus to regional organizations and the increased tendency to subcontract peacekeeping and peace enforcement missions from the UN to a variety of regional organizations including the EU, the NATO and the African Union. The chapter then examines the inherent dangers in removing international control of these operations including the challenges of legitimacy, accountability, resources, and capabilities. Peiran Wang's chapter on China's role in implementing RtoP discusses the reasons for China's persistent cautiousness to non-consensual force, and its reticence about applying sanctions, particularly when these measures are not fully backed by relevant regional organizations.

Discussion then moves on to capabilities. David Curran's chapter on the level of standby effectiveness of the EU for RtoP deployments is illuminating in this regard. After giving an overview of how the EU has been envisaged as a vehicle for the spread of Human Security, and an examination of how well prepared military and civilian peacekeepers are for intervention in RtoP-style operations, the chapter asks whether there exists an "expectations/capacities gap" between the values and capabilities of the EU. Looking at the prospects for and challenges to a robust civilian protection doctrine, Robert Schütte's chapter argues that neither the UN nor NATO have a comprehensive civilian protection doctrine, which could guide future Mass Atrocity Reaction Operations. Schütte's chapter makes an interesting exploration into the potential problems associated with the use of airborne capabilities as opposed to ground forces.

Sheri Rosenberg's and Ekkehard Strauss' chapter articulates a standard for the implementation of the RtoP that strikes at the mid-term prevention level. They show how this point is one where risk factors can be assessed with sufficient certainty to predict future developments and prevention tools are known to us. This standard, the authors argue, will narrow the boundaries within which decisions over the appropriate practical policy responses can occur. In his chapter on the lessons learned from the case of Libya, Ruben Reike argues that the Libya crisis provides the opportunity to clarify the role of pillar three in RtoP's under-developed preventive dimension. The chapter also argues that the Libya crisis suggests that the tools that are usually listed under pillar three might be of key importance for preventing mass atrocities in an immediate phase.

In the chapter by Conor Seyle and Eamon Aloyo the premise is that business is particularly relevant to RtoP. Drawing on historic cases as well as more recent business participation in democratic movements and the RtoP intervention in Libya, this chapter argues that business has the capacity to bolster the effectiveness of third pillar interventions and moral, legal, and economic reasons to do so. Looking at the gender dimension, Melina Lito's chapter argues that little attention has been given to how women can become full partners in prevention and implementation. Given RtoP's growing prominence as a key focus of the UN's security responsibilities, the chapter suggests that it is important to look at ways for women to become full participants in the formulation of RtoP policy and in the implementation of broad ranging RtoP mandates to halt mass atrocities and protect civilians. In the final chapter Caroline Fehl discusses the theoretical rationale for using two non-military - sanctions and criminal prosecution - strategies under RtoP and highlights the potential pitfalls inherent in both. Fehl argues that where criminal prosecution is concerned there may be a risk of counterproductive and destabilizing effects on conflicts and peace processes and that there is a danger that sanctions and trials are instrumentalized as symbolic responses to atrocities.

The chapters to come then are ambitious in scope and cover a broad array of subjects related to the implementation of RtoP's "third pillar". Owing to issues of time and space, however, there are a number of areas which this publication has been unable to fully address including: the views of major players like India, Russia and Brazil; an analysis of region-based capacities and leadership on third pillar tool development and implementation; a contribution on the role and limits of the UN Security Council's norm setting on atrocity crime prevention; a connection between RtoP's "third pillar" and the "second" and "third" pillars; and an international law perspective looking at issues such as "just war". Given the breadth of issues related to RtoP, there will undoubtedly be more subjects to consider. That said, each contributor in this publication has something interesting to say on the topics covered, which will undoubtedly give rise to further thinking on the operationalization of the norm. The editors of this publication feel certain that this is a constructive contribution of recommendations to continuing efforts aimed at further understanding and debating Responsibility to Protect's third pillar. 


\title{
A Living Trust: Strategies for Sustaining and Growing Support for Third Pillar Response to Threats of Mass Atrocities
}

\author{
ROBERT ZUBER
}

\author{
Introduction
}

The issue of trust has been an important one for both our organization and our partners for some time. As noted in a paper that we wrote recently for the Brisbane-based journal, Global Responsibility to Protect, 'whether we wish to acknowledge it or not, trust issues permeate all security policy deliberations, including recent discussions at UN headquarters focused on building acceptance of the RtoP norm and laying out plans for the full implementation of all three of its programmatic pillars.'

While we celebrate the strategic efforts that have allowed the norm to find its place in the mainstream of UN security concerns, we also believe that serious obstacles to full implementation remain that can only be addressed through sustained attention to 'softer' forms of diplomatic engagement. This must be focused less on dividing states by alleged levels of support and more on helping states overcome reasonable concerns related to the capacity of the UN to provide fair, transparent and robust response to atrocity crimes across a spectrum of threats. Specifically, we believe that more attention must be paid to providing reassurances that the UN system is prepared to do whatever is needed to ensure that our responses to the threat of mass atrocities are as principled as our aspirations to address such crimes in the first place.

In light of the upcoming General Assembly debate on the "third pillar" of RtoP, this unique opportunity must be seized in all global regions for collective examination and assessment of "third pillar", last-resort, coercive responses to threats of atrocity crimes. Moreover, the potential long-term implications of this examination, including building more durable and dependable bonds of trust between RtoP advocates, diplomats and policymakers, will only grow in importance.

The priority of Global Action to Prevent War and Armed Conflict (GAPW) on trust-building had its genesis in the context of our project to develop a UN Emergency Peace Service (UNEPS). The UNEPS project calls for a standing, complementary, service integrated, rapid response capacity. UNEPS is being designed to more effectively energize what are often insufficient diplomatic engagements and more coercive responses that are often controversial in their mandates, late arriving in the field, and with insufficient capacity to address violence which often evolves and escalates in the gap between mandate and deployment.

UNEPS is the latest iteration of a long line of proposals to create standing peacekeeping capacity at the UN. Juan Mendez, former Special Advisor to the Secretary General on the Prevention of Genocide, has noted that 'UNEPS [could be] to protection what the International Criminal Court is to accountability'. While a UNEPS-style service might well turn out to be a "game changer" in terms of UN capacity, it evokes considerable caution and even consternation from governments. For the most powerful states, the thought of the UN having direct access to deployment capacity not under their full control raises suspicion. And for the less powerful, providing the Security Council with another coercive option when the Council has not demonstrated its ability to handle existing options with sufficient fairness and care evokes great unease. Thus, while many policymakers and diplomats we have interviewed actually welcome the idea of UNEPS, they cannot easily overcome the multiple trust barriers that impede progress towards its eventual adoption.

Our work in the area of "trust-building and the third pillar" has led us to organize many regional meetings and produce some publications, largely inspired by a former GAPW staff person, Kavitha Suthanthiraraj, and by an affiliated researcher in Australia, Annie Herro. Using our regional meetings as opportunities to conduct interviews and arrange for others, Suthanthiraraj and Herro examined the multiple levels of trust that must be addressed if states are to feel comfortable endorsing (and paying for) a "third

\footnotetext{
${ }^{1}$ R. Zuber \& A. Carolina Barry Laso, “Trust but Verify: Building Cultures of Support for the Responsibility to Protect Norm”, Global Responsibility to Protect, Vol. 3 (2011) pp. 286-300.

${ }^{2}$ J. Méndez "Standing for Change in Peacekeeping Operations", UNEPS Secretariat (2009), p. 46. See:

www.globalactionpw.org/wp/wp-content/uploads/standing-for-change-final-09.pdf. (Accessed 12 April 2012).
} 
pillar" tool such as UNEPS. Their research conclusions found their way into a paper, Trust and the Development of a United Nations Emergency Peace Service ${ }^{3}$ that elevates a dimension of social change often overlooked (and at times even scorned) by academics, policymakers and even some civil society advocates the need to cultivate trusting relationships to enhance the feasibility of new security ideas, tools and policies within multilateral frameworks.

Their findings and recommendations for GAPW and our network have been tweaked several times over, but the course on which they have set us is one we are pledged to keep. At the end of the day, as members of civil society with a clear vested interest in RtoP effectiveness, our wish list for the "third pillar" is predicated on our determination and willingness to partner with state actors, academics and other policy stakeholders in the creation of political conditions conducive to response options on atrocity crimes worthy of broad and sustainable government support. In the end, a more robust culture of trust is at least as important to successful "third pillar" capacity development as technical competence.

\section{Pillars of Trust}

From the outset we acknowledge, as we have done in other speeches and publications, that trust is difficult to quantify. It relies on the willingness of some to offer assurances and demonstrate due diligence in policy formulation and implementation, in part by eschewing policy short cuts and in part by striving for policy inclusiveness. But it also requires others to accept the assurance offered and to respond in kind where appropriate; in the case of RtoP, giving up what Mendez referred to as 'excuses for refusing to rescue lives at risk. ${ }^{14}$ In the multilateral setting of the $\mathrm{UN}$, trust is more about effectiveness than friendship, but both are challenging to define and promote. Given the lack of clear benchmarks when it comes to trust-building, many decide to stick with narrow policy priorities and eschew more complex, more complementary and perhaps more "personal" engagements. But relevant categories and principles do exist that can guide the trust-building pursuit, help remove incentives to hide behind excuses, and enhance opportunities for open assessments of challenging or controversial response options, such as many proposed for the "third pillar" of RtoP.

We have identified three inter-related "pillars" of trust to complement the three pillars of RtoP response: trust in the effectiveness of the norm and its diverse tool kits; trust in the sincerity and diversity of those promoting the norm and its tools; and trust in the independence and transparency of the organization or organizations that are tasked with "hosting" and nourishing the norm and strategies for implementation. We will offer a brief analysis of each.

i. The first pillar of trust relates to levels of confidence in the norm and its existing and proposed implementation tools. While there is still skepticism regarding strategies and commitments for its implementation, the norm itself has won broad (if not always active) support from a wide range of states. While perhaps too much was made of the consensus adoption of the norm at the 2005 World Summit, there is little doubt that UN officials and RtoP advocates have successfully nullified much of the original, overt concern about the norm, in part by pointing to the growing consensus that in certain instances sovereignty must 'soften' enough to embrace collective security frameworks that include protection of civilians. This success is also tied, we believe, to the deep resonance of a "responsibility to protect" with so much in our lives beyond policy. Our language, especially within the contexts of family and school, is replete with protection references. Symbolically, we place versions of "protect and serve" on our police and emergency vehicles. Safety has become such a preoccupation that, at least in the US, we could easily be accused of fostering a culture that minimizes challenge and suppresses risk-taking.

\footnotetext{
${ }^{3}$ A. Herro and K. Suthanthiraraj, Trust and the Development of a United Nations Emergency Peace Service, paper first delivered at the International Studies Association Annual Conference in New Orleans, (18 February 2010). See: http://sydney.edu.au/arts/peace_conflict/docs/reports/UNEPS_report.pdf. (Accessed 12 April 2012).

${ }^{4}$ Op.Cit., "Standing for Change in Peacekeeping Operation", p. 44.
} 
The point for us is that, thankfully, the norm is now firmly established. The lingering trust questions for states and others mostly relate to the gaps between these protection values we affirm and the tools and policy actions that flow from those values. Most of us have had bad experiences with people and institutions claiming a value "high road" but acting in ways more akin to a roadside ditch. And diplomats sometimes use value-laden language as much to brand a government interest as to commit to actually improve circumstances on the ground. Given these mixed priorities, the RtoP community must insist that proposed "third pillar" capacities to address the threat of mass atrocities are governed by the values underlying the norm itself. We equally question any attempts to use the norm as "cover" for hastily conceived responses to the threat of mass atrocities, or as justification for inaction.

ii. The second pillar of trust relates to those primarily responsible for defining, refining, promoting and operationalizing the norm. Up until recently, this group has been modest in size and largely western in orientation, training and physical appearance. There is a small group of advocacy and policy organizations which has become almost synonymous with the defense and application of the norm, at least within the RtoP community itself if not beyond. Part of this is related to the natural evolution of norms, which are proposed first by a small group and then struggle to find broad based endorsements. But there has also been concern expressed to us often that we in the RtoP community (including GAPW as well) are more intent on maintaining our place at the table than doing what is needed to make the norm as universally accepted and effectively implemented as possible. We have spent too much time selling a norm we don't own and too little building bridges with persons and institutions with complementary mandates and policy concerns. We have acted as gatekeepers for involvement instead of investing energy in creating larger and more representative spheres of interest and engagement.

In building this broader community, there are two issues about which we need to be cognizant. First, we must acknowledge the degree to which current capacity levels are ill equipped to deal with the wide ranging challenges associated with synchronizing all aspects of our preventive and reactive toolkit and then subsequently demonstrating the legitimacy, fairness and effectiveness of those tools to often wary global audiences. Even with a recent and most welcome burst of attention by younger scholars and policymakers to the norm and its potential, we are woefully short of resources to handle all of the challenging political and technical responsibilities needed to instill state and civil society trust in a stillevolving framework.

Second, there is an expressed need to ensure that the "toolmakers" represent, as much as possible, the full spectrum of state and civil society interests. It really does matter which persons are on stage and whose faces are in front of the camera. The more controversial and profound the matter at hand - and "third pillar" implementation capacities and strategies would certainly qualify - the more important it is to insist on diverse leadership in all phases of policy and practice. In the context of RtoP, we can do more to ensure that states and their citizens most likely to become the object of "third pillar" response have every relevant opportunity to contribute to and help assess existing and proposed "third pillar" capacities. For us, this upcoming GA debate is merely the latest opportunity to help broaden and diversify participation.

iii. The final pillar of trust is related to the capacity of the host institution - in this instance the UN - as a reliable 'home base' to handle the grave responsibilities of timely and decisive response. On this point, the jury is still out. The multilateral system in which we do most of our work is one in which trust-building and integrated security concerns seem forever subsidiary to state priorities and discrete policy interests. It is also a system with some fundamental security-related inequities, including the dominance of the five permanent members (P5) of the Security Council and the wildly divergent staff capacities of diplomatic missions that make it almost impossible for smaller countries to keep track of issues - from illicit arms to civilian protection - on which they should have the opportunity (and the incentive) to weigh in. All of this reinforces systemic imbalances at the UN which, as noted by Henry Farrell, highlight difficulties in maintaining conditions of trust in situations of extreme power disparities. ${ }^{5}$ Furthermore, the UN represents a system - from largely unaccountable major powers to NGOs content to "swim in their own

\footnotetext{
${ }^{5}$ H. Farrell, “Trust, Distrust and Power” in Russell Hardin (ed.), Distrust, (Russell Sage Foundation, 2004), esp. pp. 8-15.
} 
policy lane", that often appears closed to the full range of voices that have a direct stake in ensuring that the international community acts as an honest, trustworthy broker for global security interests, including applications of the "third pillar" norm tasked with preventing and, if necessary, halting atrocity crimes against vulnerable civilian populations.

The role that the UN is choosing to play in atrocity crime prevention has life saving implications with able direction from the joint office (Genocide Prevention and Responsibility to Protect) and other sectors of the secretariat as well as significant input from the state "friends" of RtoP, other governments and various NGOs. Despite several political miscalculations and needlessly stubborn capacity gaps, the UN still maintains legitimacy on security matters that regional organizations struggle even to approximate. But the responsibility embedded in our responses to mass atrocities is as grave as the crimes to which response is so often desperately needed. Many sectors of the global community still have serious reservations about the ability of the UN system to "raise its game" on atrocity crime response. Those sectors are likely to be satisfied only with "full spectrum" responsibility while protecting that considers the longer term implications of coercive measures and makes provision for robust prevention before Council authorization of coercive force is even at issue. Clearly more trust-building, grounded in transparent activities designed to "get prevention right", must be integrated into our collective strategic plan if the UN is to ensure sustainable progress on norm implementation.

\section{Lessons for Trust Builders}

There is no "playbook" for increasing reservoirs of trust with regard to "third pillar" response capacities. But there are useful guidelines. Some of these flow from the previous section, specifically the need to ensure diverse leadership and spokespersons so that people can interrogate their responsibilities under the norm from people whose word they are more inclined to trust. But there are more.

i. First, we must listen more attentively to the concerns of states and civil society rather than dismissing, categorizing or demonizing those concerns. There are many lessons to be learned about handling objections in UN contexts, but two stand out: first, articulated objections are rarely as toxic as silent ones, and thus objections shared should always be properly and even gratefully heeded. Some states, for instance, are uneasy about RtoP implementation tools that give yet more power to a Security Council that has not always been the fairest or most transparent steward of the norm and its values. And such concerns once expressed and then ignored do not easily disappear. Indeed, they tend to deepen in their reactive patterns.

At the UN, state objections to RtoP can certainly be both repetitive and tiresome. And, of course, motivated as much by political positioning as by a desire for clarity on policy or responsibility. But repetitive political rhetoric can characterize policy expressions by RtoP supporters as well. States that support the norm will also use the upcoming GA debate to rehash statements from previous years that contain no new recommendations for implementation capacities, no deep recognition of the bottlenecks in the UN system that prevent us from being seized of matters at the earliest possible stages, and no recognition of what they have learned since the last debate on the regionalization of RtoP and all of the hand-wringing over Libya and Syria.

This shortage of attentiveness and humility is not a new problem. The US theologian, Reinhold Niebuhr, like many so-called Christian realists in the mid- $20^{\text {th }}$ century, did his best work in an era of wars and rumours of wars. Niebuhr would likely have warmed quickly to the RtoP norm. This point was reinforced for me in the context of an email conversation (about UNEPS) I had a while back with Sir Brian Urquhart, one of the great statesman of the UN in its history and someone also intrigued by Niebuhr's thought. But there is a caveat amidst Niebuhr's receptivity - while endorsing the norm he would be cautious about the ability of policymakers, let alone governments, to fully grasp the staggering implications and responsibilities that the norm's implementation suggests. From our standpoint, if there is any place in the UN system where "business as usual" should yield to a sober and almost sacred sense of responsibility, it is in the area of atrocity crime prevention. There is simply too much that can go wrong, 
even at times when we are trying our very best to address wrongdoing without contributing to its toxic after effects.

But for Niebuhr, acknowledging an awesome and uncertain duty does not in any way imply shirking from its responsibilities. There are too many instances where even supportive governments make excuses of time, of resource, of will - to keep from taking a long hard look at our existing response tools and capacities and to make honest, humble and transparent assessments of what are still largely precedent setting actions.

Policy is an inexact science that seeks to blend national interest and the common interest - as well as decisive response and deep humility - that can point the way for more timely and effective relief for citizens suffering under incompetent, indifferent or even malevolent governments. As such, we must ensure careful attention to precedent as well as the need for prompt response. When Niebuhr noted during the tumultuous debates in the US about entering the second war against Germany (an entry he supported), that 'the evils against which we contend are often the fruits of illusions similar to our own', ${ }^{6}$ he was underscoring the imprecision of so many major policy decisions, the precedents we establish without our full awareness. He was also highlighting the need to listen harder and evaluate more judiciously.

ii. We must also ensure that our resources (time, talents and finances) confirm, as best as we are able, our most important institutional values. In the case of atrocity crimes prevention, there are obvious deficits in the architecture of response - especially on the "upstream" preventive capacities - that can be filled with sufficient will and resources.

As Human Rights Committee member Sir Nigel Rodley noted recently at a two-day panel at UN Headquarters on how to make human rights treaty bodies more effective (an event that was not attended by any recognized RtoP advocate), that Sixth Committee discussions on funding treaty bodies reminded him of politicians in the US who try to convince voters that they can lower taxes and provide heightened levels of service at the same time.

With all due respect to the need for resourcefulness in application, our willingness to commit funds to get implementation tools properly designed, vetted and deployed in the service of atrocity crime prevention is a major dimension of trust-building. We must be cost-effective but not stingy if we expect others to accept with confidence our jurisdiction over these critical responsibilities. It is much more expensive in currency, lives and political capital to drop bombs than to create credible information on mass atrocities and eliminate bottlenecks in the system that prevent such information from becoming actionable at earlier stages.

iii. A third issue of trust involves clarifying the opportunities and limitations of our own authority. UN headquarters is an odd place insofar as it seemingly commands great authority but without many decisionmakers actually in residence. Governments are represented in New York, but decisions on policy are largely made in capitals. UN secretariat staff members pose variable levels of challenge to governments, but most recognize that the large powers play a more formidable role in policy than all but the most charismatic, senior secretariat officials.

For their part, academics have the capacity to explore policy inconsistencies, contexts and implications in ways that generally elude policymakers, but they also tend to be more concerned with the opinions of the 'trend setters' in their academic fields and are thus often rendered more marginal to policy discussions than they could be.

And what of the NGOs? Well, we clearly are not decision-makers, nor do we as a group pay much attention to what diplomats are thinking about and committed to in order to help them make better decisions on critical security matters such as RtoP. Our institutional propensity for branding rather than collaborating, for settling for the easy political consensus at the expense of the hard political questions, for practicing relationships with diplomats predicated on solicitation rather than partnership, continues to

\footnotetext{
${ }^{6}$ Quoted in A. J. Bacevich, "Illusions of Managing History: The Enduring Relevance of Reinhold Niebuhr", (9 October 2007). (Lecture available at: http://www.pbs.org/moyers/journal/08152008/profile3.html). The reader may also wish to consult, Niebuhr, Reinhold, The Children of Light and the Children of Darkness (University of Chicago Press, 2011).
} 
rob us of what authority we have. We simply have not done enough to ensure that, on RtoP, all political and geographical contexts have been explored and duly integrated, all relevant voices have a place at the policy table, and all critical ideas that have not been put to rest have been put to work. Trust-building in the UN system is partially our responsibility as well, and we need to be more resolute in this challenge.

iv. More than anything, our primary trust-building task is to demonstrate, in word as well as deed, our commitment as a policy community to get atrocity crime prevention "right". The norm itself does not suggest obvious pathways to implementation any more than a theological principle immediately suggests a pathway for faithful living. It is an arduous task to ensure that all the tools and capacities we need - both before and after the Security Council is seized of a challenging circumstance - are in place, fully functional and sufficiently complementary. But more than arduous, it is essential to trust-building. States, like individuals, will tolerate mistakes in judgment or policy as long as they can see that robust, good-faith efforts are being undertaken. But in a system that is generally unwilling to be seized of deadly challenges at early stages, that does little assessment of its actions, and that literally bristles at the suggestion that someone might want to apologize to the global public for serious policy mis-steps, trust will be more difficult to attain than it probably should be.

Whether we like it or not, the higher the stakes regarding a particular policy challenge, the higher the bar on trust-building is likely to be. If we believe that RtoP is a permanent game changer, if we believe that we have all helped set in motion a process that can eventually bring response tools and political will and diplomatic wisdom into a decisive and harmonious engagement with the threat of atrocity crimes, then we must set high standards for trust-building. Towards that end, we must do more to help states at early stages of the challenge, in the form of capacity assistance to governments under stress, but also by our willingness to ask the difficult questions; for instance regarding standards for legitimate state responses to domestic threats to its authority. We must also do more to anticipate problems in RtoP implementation, specifically how best to effectively narrow those vast, empty spaces that so often separate early warnings and late deployments. "Getting it right" implies a process and a commitment for which the global public needs to see stakeholder determination and concrete, preventive and protective results.

\section{Conclusion}

Let me draw this to a close by repeating the obvious. We do not control this norm. It will not succeed or collapse on the basis of recommendations from formal academic colloquia or from qualitatively based research and diplomatic engagement such as we attempt through my office. Indeed, we have only begun to identify the relevant actors and their complementary issues from all parts of the globe who can and must have a place in this discussion. Terrible things usually do not happen to us here in Brussels or in New York, but horrible things are happening in many parts of the world, right now, on our watch, over our coffee breaks. These people need a policy voice, but also a response architecture that is hopeful, competent and representative.

We must do all that we can to get this right and we must do it urgently. Clearly lives are riding on policy discussions such as the one planned for the General Assembly this summer, many lives in fact. But also on notice is the credibility of the UN as an impartial defender of human dignity in those instances where governments cannot or will not offer protection to their own. If UN member states large and small continue to undermine public trust in the UN's capacity for decisive, fair and transparent action in the security field with deadlocked disarmament architecture, and civilian protection norms that fail to find the hopeful ground between rhetoric and reckless reaction - we will lose more than respect. We will lose our way.

Kofi Annan, as is commonly known, used to employ "fire department" analogies to describe the problems with peacekeeping operations - having to hold a bake sale to purchase a fire truck before there could be any response to the outbreak of fire. Timing is a key element of trust. To arrive late can be tantamount to not arriving at all. At a certain point, the homes that the fire department has pledged to protect are reduced to 
rubble. But commitments to prevention are also essential to trust on RtoP. We are fond of saying in our UNEPS network that the best deployment for rapid-response capacities is the one that we do not need to make. In the same way, the best coercive response under the "third pillar" is the one that is not necessary, because we have created a durable, sustainable framework that can identify and respond to smoke before the fire erupts.

We must use the opportunity afforded by this summer's GA debate to discuss ways to ensure that any future coercive deployment in response to the threat of mass atrocities is transparent, principled and effective. As noted in one of the other chapters of this book, we should not settle for symbolic responses that raise public expectations with little prospect of behaviour change. But we also do not principally need to coerce change at the tip of a missile. With Finnemore and Sikkink, we affirm other, less-muscular moments of persuasion that we must also be prepared to seize at the earliest possible stages and that are central to both normative influence and lasting behavioural change. ${ }^{7}$ This much is clear: once human beings have been relegated to the status of "cockroaches", the time for trust-building and tool development is compromised, and the immediate mass violence, not to mention the longer-term cycles of retribution that often follow, are that much harder to stop.

\section{Trust-Building Recommendations}

- We must ensure that our resources (time, talents and finances) amply support our RtoP commitments. There are obvious gaps in the architecture of UN response - especially regarding 'upstream' preventive capacities - that can be filled in ways that are fully functional and sufficiently complementary.

- We must develop capacities that allow stakeholders to be seized of potentially grave dangers to civilians at the earliest possible stages. This must include commitments to eliminate bottlenecks that prevent legitimate findings emanating from states or other sources from receiving full assessment and preventive response before contemplating more coercive measures.

- We must listen more to objections raised by governments and civil society to the current architecture of atrocity crime response. While not all are equally valid or helpful, such objections provide pathways to a response system that is fair, transparent and representative of diverse global interests. The less our willingness to listen, the more deeply embedded objections will likely become.

- We must do more to ensure that the Security Council conducts full and transparent assessments of all authorizations of coercive force, but especially those which might create controversial precedents. Full and transparent assessments of coercive mandates (including lessons learned) are key indicators of trustworthiness for many states and stakeholders.

- We must help promote a secure seat at the policy table for region-based groups working on RtoP especially from regions likely to be the recipients of RtoP-mandated coercive responses. Failure to facilitate diverse participation is likely to generate wary or even hostile reactions, raise questions about the legitimacy of the norm and its tools, and stifle movement towards building viable regional "audiences" for RtoP discussions.

- We must do more to ensure that smaller missions, which constitute the majority of the 193 member states, get the assistance they need to keep track of RtoP and related matters so that they can be full and active participants in all relevant policy discussions. "Related matters" include illicit small arms, international justice, and gender-based violence. This assistance to missions can come from sources including regional experts and civil society organizations.

\footnotetext{
${ }^{7}$ M. Finnemore \& K. Sikkink "Taking Stock: The Constructivist Research Program in International Relations and Comparative Politics”, Annual Review of Political Science, Vol. 4, (2001), p. 914.
} 


\title{
The Regionalization of the Responsibility to Protect
}

\author{
KATE SEAMAN
}

\section{Introduction}

In recent years regional organizations including the $\mathrm{AU}$, the $\mathrm{EU}$, the Economic Organisation of West African States (ECOWAS), and NATO, have been increasingly involved in peacekeeping missions, either independently of the UN or in coordinated operations. There has been a shift in opinion and the emphasis is now placed on viewing these organizations as an asset rather than a liability. This shift can be attributed to the fact that the UN, following several failures, came to be viewed as overburdened and unable to undertake the increasingly complex operations required of it. It can also be connected to the push for "local solutions to local problems" ${ }^{1}$ which was directly in response to and designed to reduce the perceived burden of peacekeeping; particularly in relation to the funding and troop provision for operations which had been placed on more developed countries following the end of the Cold War. Although the existence of and cooperation with regional organizations is foreseen in the UN Charter, under Chapter VIII, an increased role in peace operations for these organisations raises some difficult questions in relation to legitimacy, accountability, capacity, and resources.

The examination of these questions is made even more important when the growing role of regional organizations is coupled with the increased emphasis on the development of the RtoP. The concept of RtoP is still, in terms of development, fairly new. It has been hailed as a watershed development in international relations, a representation of a new political commitment to take timely and decisive action in the face of gross human rights violations. As emphasis has shifted away from the protection of traditional notions of sovereignty toward "sovereignty as responsibility" the international community has had to come up with new ways of resolving crises. RtoP and the application of the specific tools outlined in the third pillar have the potential to become a resolution to many of these problems, however 'a responsibility to protect must also entail a responsibility to do it right ${ }^{2}$ and before it can be done right a lot more work needs to be done on operationalizing the concept. If this work is not undertaken it risks placing increasing pressure on the UN and its peacekeepers to undertake ever more complex tasks with the same limited resources and support which have always been provided.

Whilst substantial progress has been made in relation to the first two pillars of RtoP, the third pillar focusing on civilian and military capacities for "timely and decisive action" requires much more attention in order to ensure the operationalization of the norm is successful. RtoP has the potential to be the basis for a new activism within the international community. However, the concept raises as many questions as it answers, particularly in relation to the potential use of force in interventions. There are also questions as to which situations RtoP could be applied to. Is the concept only applicable to situations occurring after the 2005 summit? Or can it be applied to ongoing crises such as the Democratic Republic of the Congo and Somalia? Alongside the lack of definition in the type of situation to which it is applicable is the lack of clarity as to how exactly it should be operationalized. How should the international community help to prevent genocide? Where are the resources going to come from? Who will be the legitimating body for action?

In this respect RtoP faces the same problems as humanitarian intervention - a lack of political will and resources. It is that same fundamental problem that confronts the UN system and is preventing the operationalization of RtoP and that is 'the gap between: i) the wisdom occasionally manifested by representatives of states assembled in UN bodies; and, ii) the conventional policies for UN participation

\footnotetext{
${ }^{1} \mathrm{UN}$, "Report of the Secretary-General on Peacebuilding in the Immediate Aftermath of Conflict", A/63/881S/2009/304, New York, (11 ${ }^{\text {th }}$ June 2009).

${ }^{2}$ G. Day \& C. Freeman, "Operationalizing the Responsibility to Protect: The Policekeeping Approach", Global Governance, Vol. 11, (2005) pp. 139-146.
} 
made in the capitals of these states. ${ }^{3}$ Given the challenges the UN has faced in the past in relation to the gap between mandates and resource provision, there has been increased focus on the abilities of regional organizations to plug the gap. The question is whether or not these organizations do represent a plausible and possible solution to the problems of operationalizing RtoP.

\section{Regional Organizations and the Responsibility to Protect}

The incorporation of regional organizations under the UN system is covered under Chapter VIII of the Charter but it was not until the 2005 report 'In Larger Freedom' that the potential these organizations represent was formally recognised. In the report, then Secretary General Kofi Annan stated that 'the time is now ripe for a decisive move forward: the establishment of an interlocking system of peacekeeping capacities that will enable the UN to work with relevant regional organizations in predictable and reliable partnerships. ${ }^{4}$ The increasing emphasis being placed on the utilisation of regional organizations stems partly from the realization that 'exclusive reliance on the UNSC to authorize intervention often erodes the credibility of threats to intervene' due to the failure of the Council to intervene in a timely and appropriate manner in some crisis situations. Regional organizations are however much better placed to intervene in a timely manner, with recent examples such as the EU's Operation Artemis in the DRC and the NATO backed air operations in Libya demonstrating this to great effect. For others sub-contracting is connected to the need to back-up or replace peacekeeping operations with more forceful interventions. ${ }^{6}$ However the somewhat sporadic use of these organizations is again an illustration of the selectivity of Council members, and the differing importance they assign to some interventions to the detriment of others. It is a clear demonstration that 'the complexities of the international political system militate against developing a predictable and reliable inter-locking system. ${ }^{, 7}$ This selectivity has been a particular problem in relation to the implementation of the principles of RtoP, and the different application of the tools available under the third pillar. One of the key factors in the successful operationalization of the concept will be consistency in application. This will require the development of a clear division of labour between the different actors involved.

Although the use of regional organizations does represent one way of remedying the gap between demand and supply, it also poses a lot of other challenging questions. The first question relates to the legal authority by which the Security Council mandates operations and whether or not the same kind of authority is attributable to regional organizations. Many of the questions relating to the Council's legitimacy stem from concerns about 'whether the UN decision-making process adequately represents the interest of actors in the region of the conflict. ${ }^{, 8}$ These questions have led to an increasing emphasis on the use of regional organizations, such as the AU, because 'they can provide legitimacy, local knowledge, and experience." For many, the sole legitimacy of the Council is questionable and in some cases regional organizations, from the basis of their makeup and on the legal authority of their agreements, may have a stronger form of legitimacy than the Security Council. In relation to the wider development of third pillar RtoP activities this can be viewed as one way of increasing the democratization and representation within

\footnotetext{
${ }^{3}$ P.F. Diehl, The Politics of Global Governance, (Lynne Rienner: USA: 2001), p. 493.

${ }^{4}$ UN, "Report of the Secretary General In larger Freedom: Towards Development, Security and Human Rights for all", A/59/2005, (21 $1^{\text {st }}$ March 2005).

${ }^{5}$ M.C. Waxman, "Intervention to Stop Genocide and Mass Atrocities" in M.C. Waxman (ed.) Intervention to Stop Genocide and Mass Atrocities, (Council on Foreign Relations, 2009), p. 16.

${ }^{6}$ N.D. White, "The UN Charter and Peacekeeping Forces: Constitutional Issues" in M. Pugh (ed.), The UN, Peace and Force, (Frank Cass, 1997), p. 58.

${ }^{7}$ A. Sarjoh Bah \& B.D. Jones, Peace Operations Partnerships: Lessons and Issues from Coordination to Hybrid Arrangements (Center for International Cooperation, 2008), p. 7.

${ }^{8}$ C. Samii \& W.P.S Sidhu, "Strengthening Regional Approaches to Peace Operations" in M. Pugh \& W.P.S Sidhu, The UN and Regional Security, (Lynne Rienner, 2003), p. 259.

${ }^{9}$ M. Alagappa, "Regional Institutions, the UN and International Security", Third World Quarterly, Vol. 18, No. 3, (1997), pp. 421-441.
} 
these operations. Local actors will provide a more nuanced and perhaps more locally acceptable solution to problems which outside organizations may not understand.

Another argument for the utilization of regional organizations is that decentralization, delegation and cooperation will lighten the burden on the UN, especially in relation to resources. But there are questions regarding the potential for regional organizations to fulfil this devolved responsibility, particularly in relation to the inherent weaknesses of many regional organizations in terms of capabilities and resources, plus the potential difficulty regional actors may face in remaining impartial in a conflict situation. ${ }^{10}$ There is also the potential risk that allowing more regional enforcement action, outside the control of the Security Council increases the risk of abuse by regional superpowers. ${ }^{11}$ Rather than making peacekeeping more representative and responsive this would then only exacerbate power politics on a regional level rather than an international level. There is also a danger that 'reliance on regional operations may mean that a greater burden is carried by those who are comparatively ill equipped to do so.'

One of the key testing grounds for the utilization of regional organizations has been Africa. It is the limitations of the UN and the challenges it has faced in several complex conflicts, which have led to arguments that the $\mathrm{AU}$ would be better 'able to do things that particularly the UN cannot do because of the greater legitimacy that comes from being Africans, and African troops and African governments. ${ }^{13}$ This greater potential legitimacy is combined with a greater willingness to intervene. A willingness most clearly demonstrated in the constitutive act of the AU which outlines 'the right of the Union to intervene in a Member State pursuant to a decision of the Assembly in respect of grave circumstances, namely: war crimes, genocide and crimes against humanity. ${ }^{14}$ Unfortunately the increased willingness to intervene is not necessarily matched by the capabilities required to do so. This then raises the issue of credibility as the 'operational difficulties raise the question of what capacity African states currently possess to conduct complex and multidimensional peace operations. ${ }^{15}$ Again the problem is the resourcing and funding of increasingly complex peacekeeping missions.

The problem is that in some cases the use of regional organizations, with their resource deficit, can also undermine the UN operation. As one field operative argues 'it undermines the UN in cases like UNAMID where you end up with some kind of hybrid. What we have ended up with is an organization which the $\mathrm{UN}$ funds and the $\mathrm{AU}$ is or members of the $\mathrm{AU}$ are providing most of the assets and that has not been helpful. ${ }^{16}$ This then leads to a blurring of lines between what the UN wants to achieve and what the $\mathrm{AU}$ is working towards on the ground. It only serves to make the operation more complex and convoluted.

Interoperability between the UN and regional organizations, and between different regional organizations is another issue that needs to be examined further. The use of regional organizations not only poses credibility issues to the UN but also practical coordination issues. ${ }^{17}$ This was particularly true in Bosnia with the coordination between UN peacekeeping troops under UNPROFOR command and the NATO air strikes. The role of NATO in Bosnia was to provide the coercive military capacity required to create a solution to the conflict. The coordination was based upon the "dual key" approach in which any NATO action had to be approved by both the UN and NATO before it could take place. This caused large delays in the ability of NATO to deploy air strikes in a timely manner. The "dual key" approach was not however the only hamper to both coordination and action between the UN and NATO:

\footnotetext{
${ }^{10}$ M. Berdal, "Whither UN Peacekeeping?", Adelphi Paper 218, (IISS, 1993).

${ }^{11}$ Op.Cit., "The UN Charter and Peacekeeping Forces: Constitutional Issues", p. 58

12 S. Forman \& A. Grene, 'Collaborating with Regional Organisations', in D. M. Malone (ed.) The UN Security Council: From the Cold War to the $21^{\text {st }}$ Century, (Lynne Reiner: London, 2004), p. 306.

${ }^{13}$ Interview with Professor Craig N. Murphy, Wellesley College, ( $3^{\text {rd }}$ September 2008).

${ }^{14}$ Constitutive Act of the African Union. See: www.au.int/en/about/constitutive act. (Accessed $4^{\text {th }}$ May 2011).

${ }^{15}$ P.D. Williams, "The African Union: Prospects for Regional Peacekeeping after Burundi and Sudan", Review of African Political Economy, Vol. 33, No. 108, (2006), pp. 352-357.

${ }^{16}$ Interview with UK Mission Official One, (27 $7^{\text {th }}$ August 2008).

${ }^{17}$ This problem was recognized by the Secretary General in his 2006 Report. See: UN, Report of the Secretary General on A regional-global security partnership: challenges and opportunities, A/61/204-S/2006/590 (28 $8^{\text {th }}$ July 2006).
} 
'NATO's inertia was, in part, a reflection of UNPROFOR's composition. Many Allies including Canada, France and the United Kingdom, had deployed their own peacekeepers in UNPROFOR and feared that a more robust approach towards the Bosnian Serbs would produce a backlash against their troops. Meanwhile, the United States, which did not have troops on the ground, was pushing a "lift and strike" policy - lifting the arms embargo against the entire region that penalised in particular the Bosnian Muslims and striking the Bosnian Serb targets from the air. ${ }^{, 18}$

There were clear disagreements over how best to proceed which were only resolved with the authorization of 'operation deliberate force ${ }^{19}$ by both the UNPROFOR commander and the NATO commander, who both held the necessary keys to instigate the air strikes. The air strikes however signalled the end of the UN peacekeeping mission in Bosnia as it essentially became a peace enforcement operation instead. This again highlights the complications of coordination with other organizations, especially organizations with a higher level of military capacity than the UN. It can lead to the UN becoming involved in operations it is not capable of undertaking, and perhaps more detrimental is the potential for the UN to become a party to the conflict in the eyes of the belligerents which leaves its troops open to attack and kidnapping, as then occurred in Bosnia. ${ }^{20}$

These challenges need to be addressed and there are a number of ways in which the problems could be mitigated. As outlined in the 2011 UNSG's report, regional organizations have the potential to act as 'political and operational bridges between global standards and local and national action.' ${ }^{21}$ Regional organizations have the potential to enhance the legitimacy of an operation by providing local context, regional ownership and appropriate operationalization. This may come in a variety of different forms, all utilising tools under the third pillar of RtoP, but perhaps focused more on the non-military tools such as good offices, mediation, investigation, and most importantly the use of personal persuasion. This has the potential to dramatically lower the footprint of RtoP operations, and make them more acceptable in the eyes of local populations.

There is a need to formalize these roles and the relationships between the different organizations in order to ensure the most is made of each organization's assets. A formalization of the roles would also avoid improve the issues of coordination, and reduce the potential for complications as outlined in the example above. The focus should be shifted to the development of more robust regional mechanisms for dealing with RtoP situations, in order to do so there should be a renewed focus on capacity building through international development assistance. This ties the responsibilities of the international community under pillar two of RtoP directly to the capabilities of regional organizations to undertake these missions, a development which is key if the potential synergies outlined by the Secretary General are to be realised. ${ }^{22}$

Alongside the focus on capacity building should be an emphasis on increased coordination between the UN, regional organizations, and regional civil society actors. For staff at the UN, NGOs and other civil society actors play a valuable advocacy role in ensuring that issues are kept on the agendas of both international organizations and states ${ }^{23}$ and whilst 'they have had a steadily growing impact on the security council $^{24}$ this impact seems to come more from their interactions with national governments 'for example Oxfam in the UK or faith based organizations in the USA' as 'they have the potential to embarrass governments into action. ${ }^{, 25}$ This influence then translates into actions taken by states within international organizations. These actors have access to a greater wealth of information, can provide early warning signs, and can again only serve to enhance the legitimacy and contextualisation of RtoP operations.

\footnotetext{
${ }^{18}$ NATO website. See: www.nato.int/docu/review/2005/issue3/english/history.html. (21st August 2010).

${ }^{19}$ For an in depth analysis of the role of both the UN and NATO in Bosnia. See: UN, Report of the Secretary General pursuant to General Assembly resolution 53/35, A/54/549 (15 th $^{\text {th }}$ November 1999).

${ }^{20}$ BBC Website. See: http://news.bbc.co.uk/1/hi/world/americas/892592.stm. (23rd August 2010).

${ }^{21} \mathrm{UN}$, Report of the Secretary General on the role of regional and sub-regional organizations in implementing the responsibility to protect, A/65/877-S/2011/393 (27 $7^{\text {th }}$ June 2011)

${ }^{22} \mathrm{Ibid}$.

${ }^{23}$ Interview with Simon Bagshaw, OCHA (28 ${ }^{\text {th }}$ August 2008), Interview with UN official (28 ${ }^{\text {th }}$ August 2008).

${ }^{24}$ Interview with Ambassador Colin Keating, Security Council Report, (28 ${ }^{\text {th }}$ August 2008).

${ }^{25}$ Interview with Former UN official (26 $6^{\text {th }}$ August 2008).
} 
All of these new roles and relationships will however have to be carefully managed with a focus on communication, inclusion and support. ${ }^{26}$ The reality is that the use of regional organizations instead of the UN 'may be politically expedient, but it does not represent a conceptual solution. ${ }^{27}$ It could also potentially lead to 'a brewing competition between the United Nations and regional organizations ${ }^{28}$ in which the primacy of the Security Council would not be guaranteed. The problem is that although the $\mathrm{UN}$ is strong in some aspects such as troop access, in the eyes of many member states it lacks other important tools. As one UK official outlined, 'the UN lacks organization and administrative skill and also military planning skills in comparison to the EU and NATO. There is also the problem of the small numbers in the UN in comparison to the EU and NATO particularly in relation to qualified military and administrative staff. ${ }^{29}$ In order to overcome these disparities, there needs to be a focused programme of capacity-building between the UN and regional organizations, along the lines of the UN-AU ten year capacity-building programme. This would go some way towards mitigating the problems of disparity between regions in their capabilities to undertake RtoP operations.

The use of regional organizations in the application of RtoP also serves to enhance the legitimacy of these operations. This is not to say however that the Security Council will become irrelevant. Instead its importance may even increase. Among the many considerations that could point in such a direction is that it can authorize the use of force and of peacekeeping operations in a wide range of circumstances, including the use of force by regional organizations. This need for Council oversight is clear, as 'the key danger is that those with the military capacity will take on such interventions outside the ambit of the United Nations, and will thereby forfeit the international legitimacy upon which such operations in the end depend. ${ }^{30}$ At the moment 'a UN Security Council resolution is the gold standard of legitimacy.'.31 However, should the influence of regional organizations continue to increase it is clear to see that the Security Council needs to be even more careful to ensure its own primacy continues. The UNSC also has an important role in guaranteeing a more consistent approach to the application of the norm. The credibility, authority and effectiveness of the operationalization of the third pillar of RtoP are entirely dependent on the consistency with which it is applied.

\section{The Dangers of Regionalization}

For many, regional organizations represent the future of peacekeeping operations, and the chance to create a more stable form of multilateralism to ensure international peace and security. NATO in particular has embraced this new role, and in many ways it has provided a new relevance in the post-Cold War world. These newer actors in peacekeeping are however not without their challenges. One of the key problems is, as Bellamy and Williams argue, the uneven occurrence of regionalization. Indeed, not all regions have developed capabilities to the same extent and more importantly not all regional organizations are confined to their own regions. ${ }^{32}$ As one United Kingdom mission official explains, different organizations have different capacities, for example:

'the EU can do things that the UN cannot. If the EU is looking at a peacekeeping mission or a peacekeeping scenario the EU looks at it from a much more pragmatic point of view than the UN does. The UN tends to look at it through a completely political prism and therefore you get missions set up which have no real clear military peacekeeping goal, or achievable clear

\footnotetext{
${ }^{26}$ E. C. Luck, The United Nations and the Responsibility to Protect, The Stanley Foundation, Policy Analysis Brief, (August 2008).

${ }^{27}$ J. Mayall, "Humanitarian Intervention and International Security" in J.M. Welsh, (ed.) Humanitarian Intervention and International Relations, (Oxford: Oxford University Press, 2004), p. 138.

${ }^{28}$ D. L. Bosco, Five to Rule Them All, (Oxford: Oxford University Press, 2009); p. 174.

${ }^{29}$ Interview with UK Ministry of Defence Official, (24 ${ }^{\text {th }}$ February 2009).

${ }^{30}$ O. Ramsbotham, T. Woodhouse \& H. Miall, Contemporary Conflict Resolution, (Polity Press, 2006), p. 147.

${ }^{31}$ Interview with UK MOD Official, (24 ${ }^{\text {th }}$ February 2009).

${ }^{32}$ A.J. Bellamy \& P.D. Williams, Understanding Peacekeeping, (Polity Press, 2010).
} 
peacekeeping goal. Whereas the EU on the other hand will look at it and say do we have the means to achieve this? If yes then we might go and do it, if no well we will not even consider it any further. It also has forces of course which are much more capable than the average forces that come forward as troop contributing countries in the UN. ${ }^{33}$

The lack of capacity of some organizations is directly connected to the involvement of other actors, however, there is still the issue of control and mandating of operations. The problem then becomes the fact that the UN cannot dictate to regional organizations and in many cases 'the leverage available to the UN to ensure accountability is limited to its moral authority and, at times, the resources that it can make available. ${ }^{34}$

Some practitioners such as one former UN Ambassador argue that all interventions 'should be retained under UN control,' and that 'the UN charter allows for regional organizations to follow their own initiatives so long as they follow the principles of the UN charter. ${ }^{35}$ However, the problem is that many regional organizations do not classify themselves as or associate themselves with the UN under Chapter VIII of the Charter, which subordinates regional organizations to the will of the UNSC. This is a clear demonstration that the hierarchy outlined in the Charter is not being put into practice. Whilst there is a need for an international division of labour based on who does what best or better, the ability of the international system to produce such a division is hampered by the lack of a straightforward hierarchy and the lack of accountability in regional security to the UN. It is clear that in many ways the UN is not viewed as the prime organization for keeping the peace, and in some places regional organizations are viewed as more powerful, particularly because of the practical operational capabilities of regional organizations. ${ }^{36}$

The reality is that greater coordination with other international organizations is unavoidable as the UN itself does not have the resources or capacity to deal with the increasing number of tasks it is being asked to undertake. The increased involvement of regional organizations could be beneficial to the UN and might also remove the question of selectivity in operations. As Daws argues, this has not necessarily been detrimental to all operations as:

'The various external reports have shown that UN nation building has been very cost effective, has greater legitimacy, and is more efficacious than similar US nation building exercises. It is just a political reality that we do not live in a perfect world. I think selectivity results from a combination of member states accepting that priority should be given to where the need is greater, but that there are limits on resources and that they need to be prioritized in part to reflect national interests. ${ }^{37}$

The increasing emphasis on the use of regional organizations can in part be attributed to this need for value for money and can also be connected with the argument that regional organizations might in some ways be a more effective force for peacekeeping than the UN. This is particularly relevant given the more complex situations into which troops are being deployed. This is one of the key arguments in support of increased reliance on regional organizations, that they will provide a more robust form of peacekeeping, something which the UN is not capable of producing.

The real problem is that 'the hierarchy envisioned in the Charter does not hold'38 and the Security Council has little influence over the actions of regional organizations other than its moral authority, which in some cases is limited. This has meant an increasing perception that major powers are utilizing the UNSC as a forum to authorize military action and garner international legitimacy for actions, which may not necessarily be aimed at preserving the international order, but rather at furthering their own

\footnotetext{
${ }^{33}$ Interview with UK Mission Official Two, (27th August 2008).

${ }^{34}$ M. Alagappa, "Regional Institutions, The UN and International Security", Third World Quarterly, Vol. 18, No.3, (1997), pp. 421-441.

${ }^{35}$ Interview with Sir Jeremy Greenstock, (8 ${ }^{\text {th }}$ December 2009).

${ }^{36}$ E. M. Smith \& T.G. Weiss, "UN Task-Sharing: Toward or Away from Global Governance" in T. G. Weiss, (ed.) Beyond UN Subcontracting, (New York: 1998).

${ }^{37}$ Interview with Sam Daws, UNA-UK, (9th December 2009).

${ }^{38}$ Op.Cit., "Regional Institutions, The UN and International Security", pp. 421-441.
} 
national interests. As Ambassador Colin Keating argues this situation occurs because: 'when you essentially have one group of civilians killing another group of civilians and there is a serious training and preparedness set of exercises that need to be undertaken and is there political will for that, who actually has the capacity to begin such a process, only four or five countries in the whole world and they all seem somewhat distracted at the moment. ${ }^{39}$

The reliance on a few countries to provide the key resources is also a huge challenge, one which the UN has failed to resolve. As one former peacekeeper argues 'you have difficulties straight away because you have some nations who will sign up to what you might call the cheap and cheerful missions, what the cynics talk about as "barefoot infantry". ${ }^{40}$ But states are much less willing to provide the more important resources, an issue that is unlikely to be resolved with increasing regionalization as the key resources are focused in a few countries.

The unequal division of resources between regional organizations is a huge obstacle to the regionalization of RtoP, an obstacle that is further exacerbated by the differing interpretations of the norm itself. In order for the norm to be successfully applied, both regionally and globally, more work needs to be done on establishing dialogue between the various actors to ensure consistency in approach and application. At the moment there is an inherent contradiction between ensuring regional organizations are allowed to develop the norm at their own pace and to suit their needs whilst also ensuring equality and consistency of application. This will become increasingly important if organizations such as NATO and the EU continue to undertake RtoP operations outside of their usual spheres of influence; particularly if there is a conflict of opinion between these organizations and those local to the region, as occurred with the situation in Libya and the AU. The Security Council will have an important role to play in ensuring consistency of application, and will have to work on limiting and controlling regional organization actions to reduce the potential backlash. This has already been seen following the suggested overreach of NATO in Libya, leading to the veto threat by China and Russia in relation to Syria, despite the clear support for intervention by the Arab League. The Security Council will have to focus on the provision of clear and unambiguous mandates in relation to RtoP operations, will have to learn from operations undertaken by different organizations, and focus on trust- and capacity-building between the Council and regional organizations, and between regional organizations themselves. In order for RtoP to be operationalized successfully, it will have to be implemented consistently.

\section{Implementation and Operationalization of RtoP}

The first challenge in operationalizing RtoP is the challenge it poses to the traditional normative basis of the international system. Sovereignty has been the cornerstone of the international system and it seems to provide 'order, stability and predictability in international relations since sovereign states are regarded as equal, regardless of comparative size or wealth. ${ }^{41}$ The development of RtoP challenges the inviolability of this sovereignty on the basis of the protection of human rights. Sovereignty is now evolving into a concept based on a state's responsibilities to its citizens and the international community. However, as the concept gains in popularity one of the key arguments against the development of RtoP is that it is 'eroding the existing normative basis of international society in order to provide major powers the facility to intervene selectively in the domestic affairs of weaker states ought not to form part of the humanitarian intervention argument. Otherwise the moral basis of the argument itself is diluted, detracting tremendously from the legitimacy of the humanitarian enterprise. ${ }^{42}$

This leads to another argument utilised by opponents of the concept, the question of who decides when and where to intervene? For many the gold standard of legitimacy remains a Security Council

\footnotetext{
${ }^{39}$ Interview with Ambassador Colin Keating, Security Council Report, (28th August 2008).

${ }^{40}$ Interview with Col. Ian MacFarlane former UN Peacekeeper, (8th July 2009).

${ }^{41}$ ICISS, The Responsibility to Protect, (Ottawa: 2001), p. 12.

42 M. Ayoob, "Humanitarian Intervention and International Society", Global Governance, Vol. 7, (Jul-Sept 2001), p. 225.
} 
Resolution, and the Council gains its legitimacy through its ability to reach out into virtually every society and to establish universally applicable norms. ${ }^{43}$ However the increasing disconnect between those states that mandate UN operations, advocate RtoP and support civilian protection and those that are contributing the troops for the operations is a demonstration for some that 'western support for RtoP derives more from its potential to be abused to legitimize unilateral intervention than from genuine concern about protecting people from grave harm. ${ }^{44}$ The danger is that those states deciding on when and where to intervene are not those in danger of being intervened in. The reality is that powerful states determine whose human rights justify departure from the principle of non-intervention and this leads to charges of neo-colonialism. ${ }^{45}$

Without a world body viewed as legitimate by all members of the international system there is little hope of a successful implementation of the concept. There is also a danger that if the UN Security Council is seen as a partial body that this will increase the utilization of the concept by regional organizations or individual states justifying their actions on the basis of RtoP not justifying interventions from 'a renewed commitment to human rights, but from a need for a new pretext for imperialist interventions. ${ }^{46}$ There is also another danger inherent in the potential failure of the Security Council, that if another organization was to take action, which did meet the criteria for an RtoP intervention 'this may have enduringly serious consequences for the stature and credibility of the UN itself. ${ }^{47}$ The supporters of RtoP need to 'ensure that RtoP is seen not as a Trojan horse for bad, old imperial, colonial and militarist habits but rather the best starting point the international community has and is maybe ever likely to have, in preventing and responding to genocide and other mass atrocity crimes. ${ }^{, 48}$ This will however prove easier said than done.

Along with the issue of legitimacy RtoP also faces more practical challenges in its development, the lack of political will and resources, and the problems of coordination and interoperability between the different organizations undertaking RtoP missions. Unfortunately 'the new term does not solve the fundamental problems of insufficient political will or provide a politically realistic blueprint for the changes in state practice that would be required to make the responsibility to protect meaningful in policy and operation terms. ${ }^{49}$ The UN is still operating with a "lack of coherent doctrine underpinning the growing number of mandates that fall between traditional peacekeeping missions and armed engagement with a specific adversary or adversaries. ${ }^{50}$ If RtoP is to become operational through the UN then the organization needs to ensure there are adequate resources available to do so.

More time will also need to be spent on the practicalities of planning and resourcing missions. In most interventions and 'in most of the countries where intervention takes place, a peace process coincides with a double political process of democratization and state-building. ${ }^{51}$ This increases the number of tasks that any UN mission needs to be capable of undertaking, and therefore increases the demand on resources. It is true that 'all conflicts have underlying causes and almost all have possible solutions. More often than not the greatest determinant of a successful outcome to any involvement will be whether key decision makers can take the time to understand the causes, and have the political will to vigorously pursue a

\footnotetext{
${ }^{43}$ T.G. Weiss \& L. Gordenker, "Introduction" in T.G. Weiss \& L. Gordenker (eds.) NGOs, The UN and Global Governance, (Lynne Rienner: London, 1996), p. 23.

${ }^{44}$ A.J. Bellamy, "Realizing the Responsibility to Protect", International Studies Perspectives, Vol. 10, (2009), pp. 111-128.

${ }^{45}$ S. N. Macfarlane, C. J. Thielking \& T.G. Weiss, "The Responsibility to Protect: Is Anyone Interested in Humanitarian Intervention?", Third World Quarterly, Vol. 25, No. 5, (2004), pp. 977-992.

${ }^{46}$ J. Conlon, "Sovereignty Versus Human Rights or Sovereignty and Human Rights?", Race and Class, Vol. 46, No. 1, (July, 2004).

${ }^{47}$ Op.Cit., The Responsibility to Protect, pp. 52-55.

${ }^{48}$ G. Evans, The Responsibility to Protect: An Idea Whose Time has Come and Gone?, Lecture to the David Davies Memorial Institute: University of Aberystwyth, (23rd April 2008).

${ }^{49}$ Op.Cit., "The Responsibility to Protect: Is Anyone Interested in Humanitarian Intervention?, pp. 977-992.

${ }^{50}$ Op.Cit., "The United Nations and the Responsibility to Protect" (August 2008).

${ }^{51}$ B. Pouligny, "Peacekeepers and Local Social Actors: the Need for Dynamic, Cross Cultural Analysis", Global Governance, Vol. 5, No. 4, (October/December 1999).
} 
solution. ${ }^{52}$ Getting the key states to sustain that political will is however another key challenge faced by those proponents of RtoP. The problem is that by the time a crisis is brought to the attention of the Security Council it is generally beyond the limited scope of any preventive measures. This then requires some form of intervention, be it military or diplomatic, which requires exponentially more resources than prevention as it requires a commitment to the intervention and rebuilding process. These situations tend to be more complex and dangerous and the Security Council is often unable, if not unwilling, to commit the resources.

The main argument in support of regionalization is that these organizations represent an alternative to the UN structure, that these organizations will offer increased accountability and representation through greater local input, and will also reduce the increasing strain on the UN. ${ }^{53}$ The problem is that in many cases they have also complicated the UN's peacekeeping role. There are also unanswered questions as to the legal authority of regional organizations to mandate interventions and the potential for what Marrack Goulding termed a peacekeeping apartheid to develop. ${ }^{54}$ An increased reliance on regional organizations also represents a challenge to the authority of the UN and has increased the complexity of the operating situation in the field where the lack of coordination and the risk of organizations being played off each other is a real danger. As Ambassador Keating highlighted:

'the interaction between the Security Council and regional organizations has got both significant potential opportunities, but also, if its not handled well by one or both sides of the equation, then it could actually be misused to the detriment of international peace and security. The international organizations that operate at the regional level are somewhat ephemeral by comparison to the UN at the present point in time and as a result the relationships often tend to be somewhat one sided. ${ }^{55}$

Although these risks are somewhat ameliorated by the benefits the organizations can provide, including a faster response time and improved troop provision, 'they', as Simon Bagshaw states, 'fill a gap in the sense that we do not have the capacity to deploy as quickly as we would like, so they can get there much quicker and they are often seen as much more acceptable to other African states. ${ }^{56}$ These benefits do not however prevent the organizations facing similar charges to the Security Council in relation to accountability and legitimacy especially when there is a dominant regional hegemon.

\section{Conclusion}

As explored above, in order for RtoP to be successfully implemented at regional and global levels there are several issues that need to be addressed. These issues can be divided into four key areas: legitimacy, accountability, resources and finally capabilities. In order to establish legitimacy in the application of RtoP there needs to be a concerted effort by the Security Council to ensure consistency. This will involve building on the already strong normative consensus surrounding RtoP to establish a clear doctrine in the application to specific cases.

The Security Council needs to focus on creating clear and unambiguous mandates through their Resolutions, establishing dialogue with regional partners, and clearly defining the roles of these partners in relation to the implementation of mandates. In many cases regional organizations should be enabled to undertake RtoP actions using the diplomatic tools of the Third Pillar without requiring Security Council authorization. A Council mandate should be reserved for the most serious cases, where force is required,

\footnotetext{
${ }^{52}$ Commodore T. Laurence, "Humanitarian Assistance and Peacekeeping: An Uneasy Alliance?", Whitehall Papers Series, No. 48, RUSI, (1999), p. 3.

${ }^{53}$ UN, Report of the Secretary General on implementing the responsibility to protect, A/63/677 (12 ${ }^{\text {th }}$ January 2009)

${ }^{54}$ M. Goulding, Peacemonger, (Johns Hopkins University Press, 2003).

${ }^{55}$ Interview with Ambassador Colin Keating Security Council Report, (28 ${ }^{\text {th }}$ August 2008).

${ }^{56}$ Interview with Simon Bagshaw OCHA, (28 $8^{\text {th }}$ August 2008).
} 
and when it is required the Council should act to ensure there is a credible, consistent, and authoritative response.

In order to ensure accountability for these actions there needs to be a formalization of the relationships between the different actors. This formalization should include a clear division of labour between the UN and other regional actors based on the capacities of each actor to respond to different RtoP situations. The accountability of each organization to the wider international community will also be key to ensuring the continued legitimacy of the norm, particularly in preventing the misuse or misinterpretation of the situations to which it is applicable.

Alongside the division of labour, the UN also needs to focus on capacity-building within regional organizations, along the lines of the ten-year UN-AU capacity-building programme. The amount of resources available is limited and there is a need to focus on capacity sharing alongside capacity-building. The need for global and regional collaboration is clear, and in order for this to be successful it will need to be carefully managed. Part of the responsibility for the management of this collaboration also falls on the regional organizations. Alongside the UN actors including the AU, EU, NATO, ECOWAS, and the Arab League have a key role to play in developing the implementation and operationalization of RtoP. Perhaps the most important of these roles will be in establishing the legitimacy of the norm in a regional setting. This role will be particularly important for organizations operating outside their usual sphere of influence. The importance of regional organizations in establishing the legitimacy of RtoP operations is clearly demonstrated by the ongoing situation in Syria. The perceived overreach of NATO in Libya led directly to the backlash against authorising any intervention into Syria. This underlines the impact regional organizations can have on the successful operationalization of the norm, and the need for the Security Council to maintain control over operations, to ensure the mandate they provide is not exceeded. Alongside this, regional organizations also have a responsibility to live up to expectations in their response to RtoP situations. The AU in particular has established itself as an organization determined to intervene when member states fail to live up to their responsibilities. What regional organizations need to do now is clarify the situations in which RtoP does override the norm of non-interference, and the ways in which they are willing to intervene, and assist their member states.

There is a clear need for doctrine creation in relation to the use of third pillar tools, not only at the global level, but also at the regional level. The various actors involved should work to formalize and define their different roles through further research. Communication between the different organizations will be key to the successful implementation of RtoP, as will the process of learning from each other, particularly in relation to the contextualisation of operations. Hopefully lessons can be learned for future operations in order to ensure the continued legitimacy of RtoP. Unfortunately, the reality of international intervention is that it occurs only when the situation has developed to such a stage as to shock the world into action. The goal of operationalizing RtoP should be to minimize the need for this shock by preventing the escalation of crises. In order for RtoP to be successfully implemented there is a clear need for much more frank and inclusive discussion between all the actors involved to ensure the consistency in application required to gain legitimacy for the norm. 


\title{
A Reluctant Actor: China's Dilemmas in the Responsibility to Protect
}

\author{
PEIRAN WANG
}

\author{
Introduction
}

As a rising power, China has undertaken the international responsibilities towards the regional stability and peace through a step-by-step approach, such as dispatching blue helmet personnel and engineer troops to assume mine-clearing and infrastructure construction in the post-conflict regions under the framework of the UN. Moreover, China accepted the principle of the RtoP, which endorsed RtoP at the UN, first at the World Summit in 2005 and later in SCR 1674. However, China remains persistently caution to non-consensual force and is reticent to apply sanctions, particularly when these measures are not fully backed by relevant regional organizations. The ambivalent attitude and behaviour can be tracked from the domestic realpolitik in China and the country's strategic culture. Firstly, the lack of strategic projection capabilities limit China's policy options; secondly, the non-intervention principle derived from the traditional understanding of sovereignty still holds an important position in China's diplomacy discourse, which profoundly influences the thinking of policy-makers; thirdly, China is concerned that domestic separatist movements will be spurred on by RtoP; fourthly, China's ambivalence of keeping the balance of economic interests and international norm values; and, finally, the use of force is usually regarded as the last resort to recovering social order in China's traditional strategic culture. This chapter will look at such themes and make some recommendations based on the analysis.

\section{China's Engagement in UN Peacekeeping Operations: the 1990s to Present}

In the year 1990 China sent its first military personnel to participate in a UN military observer mission. From the perspective of the western world, China's engagements are derived from the need to break out of its diplomatic isolation and improve its international image by adopting a relatively constructive approach. ${ }^{1}$ The People's Liberation Army (PLA) has dispatched military blue helmet personnel and sapper troops to assume mine clearing and infrastructure construction in the post-conflict areas under the framework of UN. Since the beginning of $21^{\text {st }}$ century, China has become much more involved in international peacekeeping operations under the framework of the UN. After 2003, whether it is by rank or personnel contribution, the role of China has obviously increased. Moreover, the stable rank shows China's consistent support for the UN's peacekeeping operations (PKO). In 2004, Hu Jintao, China's president, said, that the PLA should be able to undertake 'new historical missions', some of which involve UN peacekeeping. Among the P5 of the UN Security Council, China has been the biggest contributor of peacekeeping troops. ${ }^{2}$

By participating in UN peacekeeping missions, China has gained practical and potential benefits for its diplomacy and the PLA. Since the late 1990s, Chinese peacekeeping contributions have raised its profile in the international community as a constructive and responsible power. Beijing policymakers see engagement in peacekeeping, and in conflict resolution, as a way for China to project a more benign and "harmonious" image beyond its borders, to reassure neighbours about its peaceful intentions, and to softly balance US and other Western influence while gradually but more firmly establishing China's status as a

\footnotetext{
${ }^{1}$ O. Bräuner, China's Changing Approach to International Intervention: in the Post-Cold War Era, (Munich: GRIN Verlag, March 2010), p. 65.

2 “The Dragon's New Teeth", The Economist, (April $\left.7^{\text {th }}, 2012\right)$.
} 
great power. ${ }^{3}$ China's peacekeeping deployments, and the associated opportunities to train and operate alongside other countries' forces, have provided practical experiences for the PLA.

Finally, China's arms exportation has evolved into the field of peacekeeping equipment. Ghana signed a RMB 160 million agreement with China in September 2008, which included help with re-equipping the Ghanaian Armed Forces and enhancing Ghanaian preparations for multilateral peacekeeping operations. Zambian troops have been using Chinese-manufactured WZ-551 armoured personnel carriers in their peace support operations in Sudan. In 2008, Argentina ordered WZ-551s from China for its troops in the UN Stabilization Mission in Haiti (MINUSTAH). ${ }^{4}$ More recently, landmine detection equipment was provided to Egypt as was mine-clearance training courses for engineers from African and Asian countries, such as Angola, Chad, and Thailand. Moreover, the mine detectors manufactured by the Chinese have been used extensively by UNIFIL (the UN Interim Force in Lebanon) along the southern border of Lebanon. ${ }^{5}$

China's Contributions to UN Peacekeeping Operation: 2003-2011

\begin{tabular}{|l|l|l|}
\hline Year & Personnel Contribution & Rank \\
\hline 2003 & 307 & 28 \\
\hline 2004 & 942 & 17 \\
\hline 2005 & 871 & 18 \\
\hline 2006 & 1,648 & 13 \\
\hline 2007 & 1,811 & 13 \\
\hline 2008 & 2,164 & 13 \\
\hline 2009 & 2,155 & 14 \\
\hline 2010 & 1,995 & 15 \\
\hline 2011 & 1,943 & 15 \\
\hline
\end{tabular}

\section{Chinese Perceptions of RtoP and its Concerns}

In 2001 the International Commission on Intervention and State Sovereignty (ICISS) made an effort to solve the conflict between the principle of national sovereignty and the right of the international community to intervene in cases of mass atrocity crimes. The Commission developed the RtoP concept. Specifically speaking:

'the responsibility to prevent [is] to address both the root causes and direct causes of internal conflict and other man-made crises. The responsibility to react [is] to respond to situations of compelling human need with appropriate measures, which may include coercive measures like sanctions and international prosecution, and in extreme cases military intervention. The responsibility to rebuild [is] to provide, particularly after a military intervention, full assistance with recovery, reconstruction and reconciliation, addressing the causes of the harm... ${ }^{7}$.

\footnotetext{
${ }^{3}$ B. Gill, Rising Star: China's New Security Diplomacy, (Washington DC: Brookings Institution Press, 2007), pp. $200-202$.

${ }^{4}$ B. Gill \& Chin-Hao Huang, "China's Expanding Role in Peacekeeping: Prospects and Policy Implications", SIPRI Policy Report, No. 25, Nov. 2009, p. 29. See: http://books.sipri.org/files/PP/SIPRIPP25.pdf.

${ }^{5}$ China-Made Mine Sweeping Tools used in UN Peacekeeping Mission. See:http://english.chinamil.com.cn/site2/newschannels/2009-03/05/content_1676051.htm.

${ }^{6}$ UN Department of Peacekeeping Operations: Peacekeeping Fact Sheeting. See: www.un.org/en/peacekeeping/resources/statistics/factsheet.shtml.

${ }^{7}$ ICISS Report 2001: XI.
} 
In all the above-mentioned responsibilities, the most sensitive point is when and how the international community is eligible to launch military intervention against a sovereign state. While the UNSC has the primary role in international peace and security fields, especially the right to the launch military interventions and sanctions under the UN Charter, it also "bravely" permits the possible use of force outside of the authority of the UNSC, more specifically, by the UNGA and regional organizations.

China has twice endorsed RtoP at the UN, first at the World Summit in 2005 and later in SCR 1674. Since then, China has clearly and consistently affirmed the RtoP principle and issued corresponding statements in favour of bolstering the UN's capacity to avert mass atrocities. It is important to note, however, that China remains persistently averse to non-consensual use of force and is reticent to apply sanctions, particularly when these measures are not fully backed by relevant regional organizations. ${ }^{8}$ However, China still holds some differences over RtoP. It is well known that the traditional view of state sovereignty and non-interference will continue to be the most important concern for Chinese policymakers. ${ }^{9}$ As a general rule, the effectiveness of action depends on two variables: one is capability, the other is intention. If any variable is zero, the effectiveness will be destined to fail. In the following sections, the chapter explores the issues which limit China's policy adoption of RtoP concerning the dimension of capabilities and intention.

According to the UNSG, Ban Ki-moon, the third pillar of RtoP was defined as 'the responsibility of UN Member States to respond in a timely and decisive manner, using Chapters VI (Pacific Settlement of Disputes), VII (Action with Respect to Threat and Peace), and VIII (Regional Arrangements) of the UN Charter as appropriate, when a state manifestly fails to provide such protection'. ${ }^{10}$ The international community has a range of options under the third pillar, including preventive diplomacy, fact-finding missions, economic sanctions and embargoes, and military operations such as no-fly zones, monitoring and civilian defense missions. ${ }^{11}$ Facing such a wide range of options, China has showed its aversion to coercive measures, although it is increasingly open to participating in political dialogue and mediation efforts to coax state leaders to consent to international involvement.

\section{China's Limited Power Projection Capabilities as an Obstacle to Supporting RtoP}

The current ability to project strategic power fundamentally limits China's aspirations for the adoption of preventive military measures. China's ability to project air and sea power is gradually increasing but limited. The PLA Air Force (PLAAF) has about 10 IL-76 transporters that can provide strategic airlift. ${ }^{12}$ As far as the performance of the PLAAF's extraction of citizens from Libya is concerned, according to an interview with Xiang Xiaoling, Deputy Director at the Institute for Military Strategy, National Defense University, PLA, the largest transport aircraft equipped in the PLAAF usually loads a maximum of 50 tonnes. ${ }^{13}$ With the disputes over military transfers among China and Russia, Chinese endeavours to import IL-76 transport aircraft and IL-78 refuelling aircraft have yet to gain substantive fruits. Although there are military modernization programmes underway in the region, the power projection capabilities of

\footnotetext{
${ }^{8}$ S. Teitt, China and the Responsibility to Protect, Asia-Pacific Centre for the Responsibility to Protect, December 2008. See: www.r2pasiapacific.org/images/stories/food/china_and_r2p.pdf.

${ }^{9}$ R. Kamphausen, D. Lai \& A. Scobell, Beyond the Strait: PLA Missions Other Than Taiwan, (Strategic Studies Institute, April 2009), p. 115.

${ }^{10}$ Ban Ki-moon, 2005 World Summit Outcome, 24 October 2005.

${ }^{11}$ International Coalition for the Responsibility to Protect, "Clarifying the Third Pillar of the Responsibility to Protect:

Timely and Decisive Response", 20 September 2011. See: http://responsibilitytoprotect.org/Clarifying\%20the\%20Third\%20Pillar\%20of\%20the\%20Responsibility \%20to\%20Prote ct_Timely\%20and\%20Decisive\%20Response(1).pdf.

${ }^{12}$ P.C. Saunders, Chinese Views of Its Military Modernization, Monterey Institute of International Studies. See: http://cns.miis.edu/archive/cns/programs/dc/track2/1st/saunders.pdf.

${ }^{13}$ China Net. See: www.china.com.cn/military/txt/2009-11/04/content_18826387.htm.
} 
China, Japan, and India will remain limited and their policies restrained. ${ }^{14}$ In a word, China's capability to project power will still be limited to the regional level in the foreseeable future.

If China agrees to preventive military measures at the UN Security Council, it is obvious that China lacks the "global reach" capabilities to carry out such operations along with other actors, such as NATO or the US. China's power projection capabilities are currently limited to voting on the relevant resolution at the UNSC. For its high profile as a rising power, China's role as an onlooker cannot be accepted. In the domestic media, China's diplomacy has been described as "positive", "rising" and "influential". As an onlooker the government has to explain why a more practical role for China is incompatible with its discourse to citizens. At the same time, without aircraft carriers and long-range transport aircrafts, China's military power projection has to depend on third-parties rather than their own platform, when, for example, imaging how to address the potential scenarios of an RtoP mission in Sub-Saharan Africa. Who will offer the equipment to China? Besides the Shanghai Cooperation Organization, China is not a member state of any security organization. Under the framework of NATO or the EU's CSDP, Europeans and Americans share their defence and operation capabilities and assets. Hence, RtoP missions will be completed in a cooperative and coordinated way. However, there are not any official mechanisms among China, the EU and NATO on security affairs. China has two options: one is carrying out the related operations through long-term independent capability construction; and the other is acting as onlookers with only a vote in the UNSC. The former will cast more doubt on the future of China's military buildup. Chinese nationalists and conservatives will understand the latter to mean that China will be secondary player, which will result in pressure on China's foreign policy. Perhaps NATO should seek to construct relations of cooperation and mutual trust with China rather than rest on concerns and mistrust. The related technology and equipment exchange and exercise can be regarded as a starting point. Complicated decision-making procedures hinder the lifting of the Arms Embargo against China, which has been regarded as an obstacle in EU - China relations. ${ }^{15}$ The related equipment and technology transfer under the framework of NATO, which is not designed to get around the EU's embargo of China, but also NATO will benefit from China's engagement in RtoP and the other security affairs.

\section{China's Traditional Perceptions on the Obstacle of Sovereignty to RtoP}

Compared with humanitarian intervention, military measures are authorized solely by the Security Council and are to be employed when peaceful measures have proved inadequate. Humanitarian intervention - characterized as unauthorized coercive action (unilateral or multilateral) - has not been endorsed as a norm by Member States, and is not permitted under the third pillar of RtoP. ${ }^{16}$ Be that as it may, sovereignty is still a sensitive subject to Beijing. Ethnic separatism in the Xinjiang and Xizang regions is the most practical and ultimate concern. Human rights protection and freedom have been central to political discourse over ethnic separatism. Moreover, different understandings about sovereignty influence China's perceptions and practice towards RtoP.

Sovereignty is the inter-subjective term from the perspective of the social contract. Significantly, a central component in the transformation from the medieval to the modern system was the formation of the sovereign territorial state, where the interlocking levels of local, regional and imperial authorities gave way to one sovereign centre and the territorial boundary became the significant dividing line. This transformation was one where political authorities gained ground compared to religious ones. It meant that the state became more secular and that this secularity was played out in interstate relations as well as domestically. Through Hobbes' famous understanding of the sovereign state as the Leviathan, which provided the solution to the problem of individual security, the 'contract' between the individual and the

\footnotetext{
${ }^{14}$ D.C. Blair, Military Power Projection in Asia, The National Bureau of Asian Research, September 2008. See: www.nbr.org/publications/strategic asia/pdf/sa08xs MilPower.pdf.

${ }^{15}$ Wang Peiran, 'A Tough Sell: Overcoming the EU Arms Embargo', China Security, Vol. 6, No. 2, (2010), pp. 51-58.

${ }^{16}$ Op.Cit., "Clarifying The Third Pillar of the Responsibility to Protect".
} 
state is one where the individual grants the state the right to protect - and define - individual security in exchange for an acknowledgement of its sovereign authority. ${ }^{17}$

In the mid- $19^{\text {th }}$ century, sovereignty was introduced into China's intellectual community through William A. P. Martin who translated Elements of International Law by Henry Wheaton into Chinese. Through Elements of International Law, the Chinese got to know that the concept of sovereignty has two dimensions, external and internal. Externally, this centres around the recognition of a state by other actors in the international system. ${ }^{18}$ Sovereignty can be defined as 'the recognition by both internal and external actors that the state has the exclusive authority to intervene coercively in activities within its territory'. ${ }^{19}$ States are recognized as sovereign when they present a fact of sovereignty; that is, states recognize another's sovereignty when the latter has achieved the capability to defend its authority against domestic and international challengers. ${ }^{20}$ Internally, as Pan points-out, 'sovereignty means supreme authority over jurisdiction: in any single territorial entity there is only one final and unlimited decisionmaking centre that is unquestioned within state borders. Internal sovereignty signifies the right of a nation state to determine its own political system and authority structure'. Under the historical background of the weakened Qing Empire, as the loser of international competition, China easily accepted the non-interference principle derived from the concept of sovereignty. At the same time, the Chinese saw sovereignty as the right to autonomously handle domestic issues free from external interference. ${ }^{21}$ On the internal dimension of sovereignty, as far as the juridical independent territorial entity is concerned, China has experienced an absolutist history of more than 2,000 years, and not the heritage of social contract between government and citizens, which means the imbalance in relations between state/government and individuals. Hence, the protection of the individual from the state has been secondary to the survival and power of the state. At the same time, in China's academic community there are seldom critical-studies on sovereignty from the perspective of post-modernism since the postCold War. In light of the constructivist school of International Relations, agents act within their social reality based on rules and their knowledge of it. Thus, when official dialogues on sovereignty occur between Chinese and Western counterparts, which are certain to be influenced by the thinking and research gap, Chinese diplomatic practitioners cannot get intellectual support from the Chinese academic community.

Since the foundation of People's Republic of China (PRC), the principle of respecting sovereignty and non-interference has been centralized in the PRC's diplomacy discourse. The discourse and behaviour of an actor constitutes a constructive relationship. When an actor puts forward discourse, its behaviour will be restricted by this discourse. In the post-Cold War period, although the principle of non-interference restricts China's diplomacy, Chinese diplomacy has been in a dilemma that insists on its discourse while also trying to act as a responsible, rising great power.

\section{Some Elements in Chinese Strategic Culture are Compatible with RtoP}

As for the use of force, this chapter explores the preferences in China's behaviour from the perspective of its strategic culture. The chapter adopts Alastair Iain Johnston's definition of strategic culture as an

\footnotetext{
${ }^{17}$ B. Buzan \& L. Hansen, The Evolution of International Security Studies, (Cambridge: Cambridge University Press, 2009), p. 25.

${ }^{18}$ T. Lansford, "Post-Westphalian Europe? Sovereignty and the Modern Nation-State", International Studies, Vol. 37, No. 1, (2000), pp. 1-15.

${ }^{19}$ J.E. Thomson "State Sovereignty in International Relations: Bridging the Gap Between Theory and Empirical Research", International Studies Quarterly, Vol. 39, No. 2, (1995), pp. 213-233.

${ }^{20}$ Ibid.

${ }^{21}$ Pan Zhongqi, "Managing the Conceptual Gap on Sovereignty in China-EU Relations", Asian Europe Journal, Vol. 8, (2010), pp. 227-243. See: www.cewp.fudan.edu.cn/attachments/article/68/Pan\%20Zhongqi,\%20Managing\%20the\%20Conceptual\%20Gap\%20on \%20Sovereignty\%20in\%20China\%20EU\%20Relations.pdf.
} 
integrated 'system of symbols (e.g., argumentation structures, analogies, metaphors) which acts to establish pervasive and long-lasting strategic preferences by formulating concepts of the role and efficacy of military force in interstate political affairs, and by clothing these conceptions with such an aura of factuality that the strategic preferences seem uniquely realistic and efficacious. ${ }^{22}$ In the other words, strategic culture refers to the means deemed appropriate to ensure security. ${ }^{23}$

Some elements of China's strategic culture are clearly rooted in the historic record. Retired Lieutenant General Li Jijun, former Deputy Director of the Academy of Military Sciences, has said that 'China's ancient strategic culture is rooted in the philosophical idea of unity between man and nature (tian ren he yi, 天人合一), which pursues overall harmony between man and nature and harmony among men'. ${ }^{24}$ In this regard, 'the political-military pattern of PLA deployment from 1950 to 1996 showed certain consistent characteristics, such as early warning for deterrence, seizure of the initiative, risk acceptance, and risk management'. ${ }^{25}$ Such patterns can be traced from The Art of War by Sun Tzu. Sun Tzu stated that 'The art of war, then, is governed by five constant factors, to be taken into account in one's deliberations when seeking to determine the conditions obtaining in the field. These are: i) Moral Law; ii) Heaven; iii) Earth; iv) the Commander; and, v) Method and discipline'. "Heaven" refers to the night and day, cold and heat, times and seasons.

Most Chinese researchers believe that ancient principles, such as 'trying peaceful means before resorting to force' (xian li hou bing, 先礼后兵), has been a major influence on post-1949 China. Professor Alastair Iain Johnston has pointed out that there are three preferences - 'territory-oriented', 'policy-oriented' and 'regime-oriented' - when analyzing China's basic political approach to the use of force. These preferences aim at alternating or defending the territory status quo, alternating the policies of the given related states, and alternating the regime of other states or maintaining the legitimacy or stability of its own state. Professor Johnston's conclusion is that from 1949-1992, in Chinese foreign policy the first category accounts for $49 \%$, the second $42.3 \%$ and the third is only about $7 \%{ }^{26}$ That is to say, regime change has been less of a preference in China's foreign policy agenda.

As Sun Tzu famously wrote, 'the best thing of all is to take the enemy's country whole and intact' (不战而屈人之兵), however, this arises not out of any humanitarian impulse but a general correct assessment of the full range of variables, and such victory will be determined before engaging in battle and may even make battle superfluous. Most Chinese strategic thinkers believe that Chinese strategic culture is pacifistic, defensive-minded, and non-expansionist. ${ }^{27}$ However, as the coin has two sides, there are some contradicting viewpoints and arguments on the surface. Indeed, Sima Rangju, a professional militarist in the latter part of the "Spring and Autumn period" (BC. 770 - BC. 476), states that "warfare is necessary to the existence of the state, that it provides the principle means for punishing evil and rescuing the oppressed, and that its conscientious exploitation is the foundation for political power'（攻其国，爱其民，攻之可也；以战止战，虽战可也）. To pursue justice and legitimate goals, he opined, necessary military means can be considered and accepted, even aggressive approaches. However, it is a difficult to demonstrate how war can be just or not. It is well known that the judgments on "just war" depend on different values and philosophy. Hence, how to make Beijing accept that RtoP is both just and legitimate is the challenging task for the related stakeholder.

\footnotetext{
${ }^{22}$ A.I. Johnston, 'Thinking about Strategic Culture', International Security, Vol. 19, No. 4, (1995), p. 46.

${ }^{23}$ M. Gariup, European Security Culture: Language, Theory, Policy, (Farnham: Ashgate, 2009), p. 41.

${ }^{24}$ Li Jijun, “On Strategic Culture” (Lun Zhanlue Wenhua, 论战略文化), Chinese Military Science (Zhongguo Junshi Kexue, 中国军事科学), No. 1, (1997), p. 9.

${ }^{25}$ A.S. Whiting, "China's Use of Force, 1950-96, and Taiwan," International Security, Vol. 26, No.2, (2001), p. 124.

${ }^{26}$ A.I. Johnston, “China's Militarized Interstate dispute Behaviour, 1949-1992: A First Cut as the Date” in Liu Guoli (ed.) Chinese Foreign Policy in Transition, (New York: Aldine de Gruyter, 2004), p. 260.

${ }^{27}$ A. Scobell, China and Strategic Culture, (2002, Carlisle Barracks: US Army War College), p. 4. See: www.strategicstudiesinstitute.army.mil/pdffiles/pub60.pdf.
} 


\section{Recommendations and Conclusion}

As an ever more important player in UN peacekeeping, China's attitudes and behaviour are certainly essential to RtoP decision-making and implementation through the UN. Criticism is not the appropriate way to promote China's engagement in RtoP. The PLA's researcher at the Academy of Military Science, Yao Yunzhu says, 'we are criticized if we do more and criticized if we do less. The West should decide what it wants. The international military order is either US-led through NATO or through bilateral deals - there is nothing like the World Trade Organization (WTO) for China to get into'. ${ }^{28}$ Once China is accepted by international regimes, it will accept the related rules and norms. China's access to the WTO is an excellent example. Without the WTO as a platform, the EU's and US' debates over intellectual property and other issues with China would be more difficult than present. If only criticism against China pervades, China will be more reluctant to play a role. More reluctance results in more criticism and so the spiral continues. Then, mistrust similar to the security dilemma witnessed during the Cold War will promote rising conservative nationalism in China, which will be a further obstacle to cooperation. The importance of consensus between Chinese and Western values should be attached. Consensus is the social and intellectual basis of international cooperation between China and the Western stakeholders. To promote China's engagement in RtoP, a multi-track dialogue mechanism should be established, including official, academic and civilian. Through academic exchange, Chinese intelligentsia acquaints and accepts Western perceptions and values, which will exert its influence on political policy-makers. In China, international studies, especially applied policy analysis, will get funding support from the Ministry of Education and related institutions, which means there are dialogue mechanisms and tracks between government and academic researchers. Last but not least, as was mentioned above, the dilemmas faced by China, such as regime-change oriented preferences, diplomacy taboos and its limited power projection capabilities, should be considered by the international community.

\footnotetext{
${ }^{28}$ Op.Cit., "China’s Military Rising Up".
} 


\title{
An Examination of the Level of Standby Effectiveness in the EU for RtoP Style Deployments
}

\author{
DAVID CURRAN
}

\author{
Introduction
}

The EU (and its Member States) has been a key advocate of developing RtoP capabilities on a regional and international level. In 2008, Oxfam International reported that EU Member States were 'at the forefront of the successful diplomacy' that resulted in the historic 2005 World Summit Outcome Document ${ }^{1}$. In the 2011 General Assembly dialogue on the role of regional and sub-regional arrangements in implementing RtoP, the EU 'voiced support' ${ }^{\prime 2}$ for the suggestion of the UN Secretary General to hold next year's dialogue on the third pillar of RtoP $\mathrm{P}^{3}$. However, questions remain over the extent to which EU standby arrangements are prepared to develop capacities to meet demands that a human security orientated foreign policy would demand.

It is thus worth analyzing current EU preparedness for operations that would be akin to suggested RtoP deployments: namely deployments centred around the 'Protection of Civilians' (PoC) as defined by the UN's 'cross-cutting mandates'. This chapter demonstrates that although the EU has declared approaches to human security and PoC operations, the preparedness of military Battlegroups and civilianled peacekeeping operations is less clear. Therefore in examining 'timely and decisive' approaches to third pillar activity from a regional organization, this chapter makes an important contribution to ongoing debates.

At this stage it is important to make the qualification between PoC and RtoP, and also explain why there exist sufficient relations between the two concepts so that analysis of the EU's approach to PoC may indicate its approach to RtoP. Although the protection of civilians has a differing legal precedent ${ }^{5}$ (through international humanitarian law as well as international human rights and refugee law ${ }^{6}$ ), narrower conceptions ${ }^{7}$ of $\mathrm{PoC}$, as undertaken by $\mathrm{UN}$ mandated peacekeeping operations is a relatively recent phenomenon. The development in the UN has been predominantly through UN Security Council Resolutions 1265 (1999) and 1296 (2000). Resolution 1296 provides a definition of the narrow approaches to PoC advocated in the UN: 'the deliberate targeting of civilian populations or other protected persons and the committing of systematic, flagrant and widespread violations of international humanitarian and human rights law in situations of armed conflict may constitute a threat to international peace and security. ${ }^{8}$

\footnotetext{
${ }^{1}$ Oxfam International, The Responsibility to Protect and the European Union, (Brussels: March 2008), p. 1.

${ }^{2}$ International Coalition for the Responsibility to Protect, Interactive Dialogue of the UN General Assembly on the Role of Regional and Sub-Regional Arrangements in Implementing the Responsibility to Protect, ICRtoP Report, New York, (Aug, 2011$)$, p. 5.

3 "Pillar Three" focuses on the responsibility of international community to take timely and decisive action to prevent and halt genocide, ethnic cleansing, war crimes and crimes against humanity when a State is manifestly failing to protect its populations.

${ }^{4}$ Outlined in UN Security Council Resolutions 1265 (1999), 1296 (2000), 1674 (2006), 1738 (2006), 1894 (2009).

${ }^{5}$ Popovski provides an overview of the differing legal documentation which forms PoC and RtoP - V. Popovski, Siblings, but not twins: POC and R2P, United Nations University, $11^{\text {th }}$ January 2011 (at: http://unu.edu/articles/peace-security-humanrights/siblings-but-not-twins-poc-and-r2p. (Accessed 23rd April 2012).

${ }^{6}$ Asia Pacific Centre for the Responsibility to Protect, Protection of Civilians, University of Queensland (at: www.r2pasiapacific.org/protection-of-civilians. (Accessed 23 ${ }^{\text {rd }}$ April 2012).

${ }^{7}$ For a comprehensive overview of PoC, see Hugh Breakey, The Responsibility to Protect and the Protection of Civilians in Armed Conflicts: Review and Analysis, Institute for Ethics, Governance and Law, Griffith University, May, 2011.

${ }^{8}$ UN, “United Nations Security Council Resolution 1296 (S/Res 1296, 2000)”, New York, United Nations, 2000.
} 
Whereas PoC examines how peacekeeping deployments can operationally protect civilians in the deployment zone, the R2P principle provides a 'political framework for preventing mass atrocities'. Moreover, narrow PoC is generally seen as a norm that mainly occurs during a conflict, whereas RtoP is seen as an organizing norm which predominantly occurs outside of armed conflict (although there are grey areas in this). However, there is crossover between the two concepts, seen most clearly in the UN's approaches to peacekeeping operations. The Global Centre for the Responsibility to Protect notes that open debates in the Security Council on PoC have provided the 'only occasions within the formal Council agenda to reflect on the development of the R2P norm and its practice. ${ }^{10}$ Moreover, Popovski finds that there are links between the narrow approaches to PoC and the RtoP. He argues that in many situations, the two circles of R2P and PoC can overlap - for example, when war crimes against civilians or crimes against humanity (including ethnic cleansing and genocide) are committed during armed conflict., ${ }^{11}$

This has led practitioners and observers to attempt to define the exact relationship between the two concepts. Ed Luck, Special Representative of the UN Secretary-General on R2P has characterized it as 'cousins but not sisters', Popovski argues it is more akin to 'sisters, but not twins ${ }^{12}$. Nevertheless there is a relationship between $\mathrm{PoC}$ and RtoP, particularly with regards to the possibility that RtoP style interventions may have a high civilian protection component. This in turn will have considerable effects on the mandates, and the roles and responsibilities of peacekeeping personnel. It is thus appropriate to examine the EU's existing approaches to PoC cases as an indicator to how the organization would approach RtoP style deployments.

\section{The EU and the UN}

Regional organizations play a 'significant' role in the conduct of international conflict resolution ${ }^{13}$, and it was the contribution of regional organizations to RtoP which formed the basis of an informal interactive dialogue in the General Assembly in 2011. In his 2011 report to the General Assembly (which formed a guide to the dialogue), UN Secretary General Ban Ki Moon stated: 'as the principle moves from words to deeds on both the global and regional levels, what is needed is an early and flexible response tailored to the circumstances of each case rather than any generalized or prescriptive set of policy options' ${ }^{14}$

The relationship between the EU and UN in peace operations is a familiar one. Of the 23 Common Security and Defence Policy (CSDP) ${ }^{15}$ missions launched between 2003 and 2009, 15 have been deployed in countries where the UN has a peacekeeping or peacebuilding mission. Moreover, all EU missions in Africa 'have involved direct or indirect cooperation with the $\mathrm{UN}^{\prime 16}$. Joint EU/UN policy reflects this growing trend ${ }^{17}$, in particular the EU Council's paper, EU.UN Co-operation in Military Crisis Management Operations $^{18}$. This identified that the EU could deploy forces to assist UN operations, introducing the concept of the 'bridging model', which would be able to provide the UN with 'time to mount a new

\footnotetext{
${ }^{9}$ Asia Pacific Centre for the Responsibility to Protect, (Note 6).

${ }^{10}$ Global Centre for the Responsibility to Protect, The Relationship between the Responsibility to Protect and the Protection of Civilians in Armed Conflict: Policy Brief, January 2009, New York, CUNY, p. 1.

${ }^{11}$ Op.Cit., Siblings, but not twins: POC and R2P.

${ }^{12}$ Ibid.

${ }^{13}$ A. Bellamy \& P. Williams, Understanding Peacekeeping, (Cambridge: Polity, 2010) (Second Edition), p. 305.

${ }^{14}$ UN, "The Role of Regional and Sub-Regional Arrangements in Implementing the Responsibility to Protect, Report of the Secretary-General”, A/65/877-S/2011/393, New York, (27 June 2011), p. 11.

${ }^{15}$ Formerly known as the European Security and Defence Policy (ESDP).

${ }^{16}$ R. Gowan, "ESDP and the United Nations" in G. Grevi \& D. Keohane, European Security and Defence Policy: The First Ten Years (1999-2009), (Paris: Institute for Security Studies, 2009), p. 117.

${ }^{17}$ UN/EU, Joint Declaration on UN-EU Cooperation in Crisis Management: Signed September 24 2003, New York, p. 4.

${ }^{18}$ Council of the European Union, "ESDP Presidency Report, Annex II, 'EU-UN Co-operation in Military Crisis Management Operations: Elements of Implementation of the EU-UN Joint Declaration”, Brussels, 17-18 June 2004.
} 
operation or to reorganize an existing one'. Taking this synergy a stage further, the paper discussed a model for an 'over the horizon reserve' of EU forces to be able to react rapidly to crises. This demonstrated the desire for EU crisis management and UN peacekeeping to have synergy in motivations, desired end states, and means to achieve those goals. The 2008 implementation report on the European Security Strategy reaffirmed this close relationship by stating that 'everything the EU has done in the field of security has been linked to UN objectives ${ }^{19}$.

\section{EU Crisis Management and Human Security}

Since 1992, the EU (and the former Western European Union) has developed capabilities for deploying military and civilian personnel into what is termed crisis management operations, and creating a 'European identity' to 'promote peace, security and progress in Europe and in the world' ${ }^{20}$. The "Petersberg Tasks" ${ }^{21}$ have undergone a process of realignment and expansion through the Helsinki Council Conclusions (1999) ${ }^{22}$, and the Headline Goals 201023. The Headline Goals encompass both military and civilian actors, and are complemented by the Civilian Headline Goals (outlined further below in this article):

\section{Box 1-1}

\section{Military Headline Goals}

- Humanitarian and Rescue Tasks;

- Peacekeeping Tasks;

- Tasks of Combat Forces in Crisis Management, Including Peacemaking;

- Support for Third Countries in Combatting Terrorism;

- Security Sector Reform.

The desire to develop crisis management operations is reflected in the European Security Strategy (ESS), as two of the five key threats it outlines - regional conflicts, state collapse - relate to crisis managementstyle responses outlined in the Headline Goals $2010^{24}$. Such responses are suited to the EU, through its ability to combine economic, civilian and military capabilities. This view is reinforced in the 2008 Report on the Implementation of the ESS, which gave working examples of the EU's multitude of crisis management responses.

The development of capacities to meet the ESS demands and the Headline Goal has also required the EU to develop a wider normative value to its conflict management activities. This can be seen in the 2008 ESS implementation report, which outlined the EU's success and remaining challenges in relation to

\footnotetext{
${ }^{19}$ EU, "Report on the Implementation of the European Security Strategy - Providing Security in a Changing World”, Doc. S407/08, Brussels, 11 December 2008, p. 11.

${ }^{20}$ European Union, "The Treaty of Amsterdam”, October 1997.

${ }^{21}$ Western European Union Council of Ministers, "Petersburg Declaration”, Bonn, 19 June 1992, p. 6.

${ }^{22}$ EU Council, "Presidency Conclusions, Helsinki European Council”, 10-11 December 1999.

${ }^{23}$ EU Council, "Headline Goal 2010”, 2004.

${ }^{24}$ The full list: terrorism; proliferation of WMD; regional conflicts; state collapse; organised crime.
} 
concepts of 'human security' ${ }^{25}$, stating that 'we need to continue mainstreaming human rights issues in all activities in this field, including ESDP missions, through a people-based approach coherent with the concept of human security'. ${ }^{26}$

A "people-based approach" outlook on foreign and defence policy is related strongly to RtoP approaches to peace and security, with the report stating that "sovereignty entails responsibility", and that the EU holds 'a shared responsibility to protect populations from genocide, war crimes, ethnic cleansing and crimes against humanity'. ${ }^{27}$

The development of RtoP principles in the EU has developed in conjunction with an 'EU approach' to Human Security. In 2003, High Representative Javier Solana initiated a process to study the applicability of "human security" to EU policy. The Barcelona Report ${ }^{28}$ represents the "first coherent attempt to develop a security policy based on the human security concept ${ }^{29}$. The report defined human security as being: 'individual freedom from basic insecurities. Genocide, wide-spread or systematic torture, inhuman and degrading treatment, disappearances, slavery, and crimes against humanity and grave violations of the laws of war as defined in the Statute of the International Criminal Court (ICC) are forms of intolerable insecurity that breach human security'. ${ }^{30}$

In this light the Barcelona Report argued that the EU should 'contribute to the protection of every individual human being', as opposed to focussing on the defence of borders. Militaries should therefore be 'configured in quite new ways', reflecting the 'real security needs of people', "New European Security Doctrine", which would cover the whole spectrum of crisis response mechanisms - from prevention to resolution. Thus, interventions would look different to what has been seen before, sitting between 'classical peacekeeping and classic military intervention', offering a comprehensive approach, and involving 'different types of political institutions and different phases of conflict or state failure $^{32}$.

In order to put this into practice, the Barcelona Report makes a case for a 15,000 strong "Human Security Response Force", with a military component being combined with civilian capabilities. Significant training developments would be required to assist military personnel in carrying out future human security interventions, identifying a "considerable culture shift' for the military, with a new type of 'human security officer' being highly skilled and flexible, in order to meet the tasks bestowed upon him/her. ${ }^{33}$

In 2006, the same panel of experts was commissioned by the Finnish Presidency of the EU to write an update report reflecting the progress of human security in the EU. The outcomes were outlined in the 2007 Madrid Report ${ }^{34}$. Like the Barcelona Report, the Madrid Report strongly advocated for an approach that involved the use of robust military force ${ }^{35}$, combined with nuanced forms of integration between civilian and military actors. The report makes the point that instead of using civilian and military assets as 'part of a standard toolkit', human security interventions should foster a deeper understanding about 'how and why civil and military capabilities are combined' ${ }^{36}$. Importantly, the Madrid Report reflected the growing

\footnotetext{
${ }^{25}$ M. Martin \& T. Owen, "The Second Generation of Human Security: Lessons from the UN and EU Experience", International Affairs, Vol. 86, No. 1, (2010), p. 216.

${ }^{26}$ Op.Cit., "Report on the Implementation of the European Security Strategy", p. 10.

${ }^{27}$ Ibid., p. 12.

${ }^{28}$ Study Group on Europe's Security Capabilities, A Human Security Doctrine for Europe: The Barcelona Report of the Study Group on Europe's Security Capabilities, 2004.

${ }^{29}$ Two papers provide a good background to the development of Human Security: J.H. Matlary, "When Soft Power Turns Hard: Is an EU Strategic Culture Possible?", Security Dialogue, Vol. 37, No. 1, (2006); Ibid., "The Second Generation of Human Security".

${ }^{30}$ Op.Cit., A Human Security Doctrine for Europe, p. 5.

${ }^{31}$ Ibid., p. 2.

${ }^{32}$ Ibid., p. 6.

${ }^{33}$ Ibid., p. 19.

${ }^{34}$ Study Group on Europe's Security Capabilities, A European Way of Security: The Madrid Report of the Human Security Study Group comprising a Proposal and Background Report, 2007.

${ }^{35}$ Ibid., p. 10.

${ }^{36}$ Ibid., p. 11.
} 
importance of the RtoP principle, and argues that a human security approach would draw on debates 'in current global discourse such as 'responsibility to protect', 'effective multilateralism' and 'human development" 37 .

Both the Barcelona and Madrid reports advocate the institutionalization of human security in European security principle and practice, outlining ambitious plans for the EU to incorporate not only the language, but also the ethos of Human Security. With the Madrid Report, the EU is seen as a vehicle which can strengthen the goals of RtoP through a human security approach to operations, arguing that a human security approach 'would allow the EU to refine and coordinate what it already does under multiple labels'. In order to understand where the EU can contribute to third pillar activities, it is worth seeing exactly where it has contributed in RtoP style activities, namely preparation for operations with a high PoC component.

\section{Protection of Civilians in EU policy}

In 2003, the EU Council concluded that EU crisis management operations would fully address the 'special protection, rights and assistance needs of civilians' ${ }^{38}$. The subsequent policy process led to the 2010 Draft Revised Guidelines on the Protection of Civilians in CSDP Missions and Operations. The 2010 guidelines were created at the suggestion of the EU Council firstly to explore the extent to which PoC issues are considered during the formulation of CSDP missions, and secondly to capture experience of other organizations in operationalizing $\mathrm{PoC}^{39}$. Importantly, the guidelines attempt to differentiate between the development of existing $\mathrm{UN}$ approaches to incorporating $\mathrm{PoC}$, and the requirement for the EU to develop its own specific operational guidance. In doing this, it suggests that the EU should develop its own PoC contribution on both external and internal levels. Externally, the EU would cooperate with the UN through the New Horizons process and other formal channels ${ }^{40}$. Internally, the Revised Guidelines propose that EU deployments take into account $\mathrm{PoC}$ at all stages, from advance planning, operational planning, conduct of operations, and lessons learned ${ }^{41}$.

Nevertheless, the Revised Guidelines contain no EU-specific definition of PoC. This is recognised in the guidelines, which note that although PoC provisions have been included in 'several mandates', there has not been an explicit mention of the 'concept of PoC' in mandates of CSDP missions. UN concepts are seen as providing input only to the EU processes, and the guidelines only suggests that the EU is well placed for developing a coordinated approach to PoC 'in its broadest sense ${ }^{\text {'2 }}$. The closest attempt of a definition is provided by the 'operational aspects' of proposed deployments, and the training requirements for EU personnel preparing for deployment (Box 1-2). Operational and training aspects show a full spectrum of peacekeeping activity, carried out by personnel with a wide knowledge of relevant human rights law, and how that law applies in the deployment zone.

\footnotetext{
${ }^{37}$ Op.Cit., A European Way of Security, p. 10.

${ }^{38}$ EU Council, "Council Conclusions on Cooperation between the EU and the United Nations on Crisis Management: The Protection of Civilians in the EU-led Crisis Management Operations - Council conclusions", (doc. 11439/03), Brussels, 21 July 2003; EU Political and Security Committee, "Guidelines on Protection of Civilians in EU-led Crisis Management Operations” (Doc. 14805/03), Brussels, 14 November 2003.

${ }^{39}$ EU Council, "Protection of Civilians in EU-led Crisis Management Operations - Recommendations on the Way Forward”, (Doc. 8830/10), April 2010.

${ }^{40}$ EU Council, "Draft Revised Guidelines on the Protection of Civilians in CSDP Missions and Operations", (Doc. 15091/10), 15 October 2010, p. 8.

${ }^{41}$ Ibid., p. 13.

${ }^{42}$ Ibid., pp. 4-5.
} 


\section{$\underline{\text { Box } 1-2}$}

\section{Operational aspects of operations involving PoC}

- Monitoring the implementation of a peace agreement and ceasefires;

- Creating conditions conducive to safe, timely and unimpeded delivery of humanitarian assistance;

- Ensuring freedom of movement and route security (including for refugees/IDPs);

- Public order management;

- Monitoring (including of the human rights situation) and reporting;

- Police and military patrols;

- Mentoring and training of local military or police structures to ensure the PoC;

- Stabilization of a post-crisis situation through Disarmament, Demobilization and Reintegration (DDR) and Security Sector Reform (SSR);

Specific training requirements for personnel deploying on operations including PoC

- Human rights, gender, international humanitarian, refugee, international and national criminal law;

- Issues regarding discrimination;

- The rights and protection of children and other vulnerable groups, including the special needs of women and girls to be protected from sexual and gender-based violence, forced labour, trafficking and all other forms of violence in situations of armed conflict and postconflict environments;

- The human rights situation and the international human rights obligations of the Host State or States of a CSDP mission/operation. ${ }^{43}$

This lack of definition can be interpreted as a positive factor, enabling the EU to draw on a wide range of policies, initiatives, and tools all in the name of PoC. It can also be interpreted as a negative factor. Not defining PoC runs the risk of the EU lacking strategic direction to guide its activities and operations. Furthermore, a lack of definition creates difficulties in quantifying the success of PoC strategies. Both of these factors have influenced the success of military and civilian preparedness.

\section{Military Crisis Management - the Battlegroups}

Although the EU has deployed military capabilities in the past (EUFOR Tchad/RCA, as well as deployments in the DRC), this chapter will focus on EU Battlegroups. EU military capacity is largely represented by the 'Battlegroup concept', which were operationalized in 2007. In the Battlegroup model two separate multinational formations of 1,500 soldiers inclusive of all 'combat and service support as well as deployability and sustainability assets ${ }^{44}$ are placed on rotation for six months (two Battlegroups from December to June, then two Battlegroups from July-December). Battlegroups are composed in

\footnotetext{
${ }^{43}$ Op.Cit., "Draft Revised Guidelines on the Protection of Civilians in CSDP Missions and Operations", p. 13.

${ }^{44}$ G. Quille, Quo Vadis, The EU Battlegroups?: Directorate General for External Policies of the Union Policy Department Policy Briefing, Brussels, European Parliament, 2010; N. Granholm \& P. Jonson, EU-Battlegroups in Context. Underlying Dynamics, Military and Political Challenges, FOI Base Data Report, Stockholm, FOI, March 2006, p. 9.
} 
different ways. Fundamentally, personnel are provided by EU Member States. In some cases, a Battlegroup can be comprised of two states (usually if one of the states is a larger military power), in some cases there are a large number of smaller states (the strength of many different parts making the whole), and in other cases, there is a mixture of the two.

Battlegroups are intended to provide a rapid reaction capability to the EU's crisis management structures, by being ready to deploy between 5 and 30 days from a EU Council Action setting up an operation ${ }^{45}$. Moreover, they are intended to 'prepare the ground for larger, more traditional peacekeeping forces, ideally provided by the UN or the Member States', and thus be prepared to operate in hostile deployment zones where a peace process (if there is one) is its earliest stages and at its most fragile ${ }^{46}$. Granholm's study of Battlegroups finds that they provide the EU with an autonomous rapid response option, which can be utilized as a 'spearhead force', with the capabilities to enter a conflict zone with the goal of stabilizing it under a UN Chapter VII mandate, before a multinational force is able enter ${ }^{47}$. This also links with conceptions of 'bridging forces' outlined above. A list of the Battlegroup rotation is below in Table 1-1.

Battlegroups are primarily designed to undertake small deployment, and cover the tasks outlined in the Helsinki Headline Goals 2010. As the Battlegroups are comprised primarily of military personnel, they would be at the 'demanding end' of the spectrum of activities. Within this demanding end, the Battlegroups have five planning scenarios, or 'activities'. The five military planning scenarios that the EU uses for the Battlegroups are outlined in Table 1-2.

Table 1-1: The Battlegroups ${ }^{48}$

\begin{tabular}{|l|c|c|c|c|c|c|c|c|}
\hline Year & Period & Battlegroup & BG Name & Lead Nation & Nation 2 & Nation 3 & Nation 4 & Nation 5 \\
\hline $\mathbf{2 0 1 0}$ & Jul-Dec & 1 & & Italy & Romania & Turkey & & \\
\hline & & 2 & & Spain & France & Portugal & & \\
\hline $\mathbf{2 0 1 1}$ & Jan-Jul & 1 & Battlegroup 107 & Netherlands & Austria & Finland & Germany & Lithuania \\
\hline & & 2 & Nordic & Sweden & Estonia & Finland & Ireland & Norway \\
\hline & Jul-Dec & 1 & Balkan/Helenic & Greece & Bulgaria & Cyprus & Romania & \\
\hline & & 2 & Eurofor BG & Portugal & France & Italy & Spain & \\
\hline $\mathbf{2 0 1 2}$ & Jan-Jul & 1 & & France & Belgium & Luxembourg & & \\
\hline & & 2 & Italian-Slovenian- & Vacant & & & & \\
\hline & Jul-Dec & 1 & Italy & Hungary & Slovenia & & \\
\hline & & 2 & Austo-German BG & Germany & Austria & Czech Rep & Croatia & FYR Macedonia \\
\hline $\mathbf{2 0 1 3}$ & Jan-Jul & 1 & Weimar & Poland & France & Germany & & \\
\hline & & 2 & & Vacant & & & & \\
\hline & Jul-Dec & 1 & UK-Swedish Battlegroup & Uk & Sweden & & & \\
\hline & & 2 & & Vacant & & & & \\
\hline $\mathbf{2 0 1 4}$ & Jan-Jul & 1 & Balkan/Helenic/HELBROC & Greece & Bulgaria & Cyprus & Romania & \\
\hline & & 2 & & Vacant & & & & \\
\hline
\end{tabular}

\footnotetext{
${ }^{45}$ European External Action Service, "Common Security and Defence Policy: Development of European Military Capabilities", January 2011, p. 5.

${ }^{46}$ Op.Cit., Quo Vadis, The EU Battlegroups?, p. 5.

${ }^{47}$ Op.Cit., EU-Battlegroups in Context. Underlying Dynamics, Military and Political Challenges, p. 8.

${ }^{48}$ International Institute for Strategic Studies, Military Balance 2010, (London: IISS, 2010).
} 
Table 1-2: List of Planning Scenarios ${ }^{49}$

\begin{tabular}{|l|l|}
\hline Task & Description \\
\hline Separation of Parties by force & $\begin{array}{l}\text { Peacekeeping, peacemaking and peace } \\
\text { enforcement. }\end{array}$ \\
\hline $\begin{array}{l}\text { Stabilization, Reconstruction and Military } \\
\text { Assistance to Third Countries }\end{array}$ & $\begin{array}{l}\text { Peacekeeping, election monitoring, } \\
\text { institution building, security-sector reform } \\
\text { and support to third countries combating } \\
\text { terrorism. }\end{array}$ \\
\hline Conflict Prevention & $\begin{array}{l}\text { Preventive engagement, preventive } \\
\text { deployment and embargo, counter- } \\
\text { proliferation and joint disarmament } \\
\text { operations. }\end{array}$ \\
\hline $\begin{array}{l}\text { Evacuation Operation in a Non-Permissive } \\
\text { Environment }\end{array}$ & Evacuation of non-combatants. \\
\hline Assistance to Humanitarian Operations & $\begin{array}{l}\text { Management of the consequences of disasters } \\
\text { and atrocity prevention. }\end{array}$ \\
\hline
\end{tabular}

Conceptually, these activities fit in with concepts of human security and third pillar approaches. Their tasks can be aligned within the spectrum of operations under the term 'peace support operations', the concept calls for rapid deployment, of considerable importance when reacting to ongoing abuses of civilians by armed group ${ }^{50}$. Battlegroups are also intended to deploy alongside the EU's police and civilian capabilities in post-conflict environments. Although this is not specified in policy, observers note that many of the tasks undertaken by EU civilian personnel (outlined below) will lead to encounters with their military counterparts ${ }^{51}$. This is also in line with wider Peace Support Operations (PSO) doctrine, which outlines a combination of both military and civilian interaction in post conflict environments ${ }^{52}$

Implementing a culture of PoC into EU peacekeepers is however a difficult task. 'Specialist skills' have been highlighted by Granholm and Jonson, who find, in their FOI ${ }^{53}$ study of Battlegroups, that the operating environment for EU Battlegroups will demand an increased ability to incorporate a wider series of skills, including 'operational adaptability, use of force, technical and cultural know-how, and, not least, ability to cooperate with various civilian agencies ${ }^{54}$. Moreover, the unique aspect of 'interoperability' amongst EU military and civilian mechanism has placed demands on both military and civilian peacekeepers, with the Political and Security Committee outlining the desire to promote synergies

\footnotetext{
${ }^{49}$ This list is drawn from two sources: B. Giegerich, EU Crisis Management: Ambitions and Achievements, The Adelphi Papers, Vol. 48, Issue 397, 2008, pp. 19-20; FINABEL Coordinating Committee, European Union Battle Group Manual, April 2008, Brussels, FINABEL.

${ }^{50}$ For a discussion on the PSO concept, see: P. Wilkinson, "Sharpening the Weapons of Peace" in T. Woodhouse \& O. Ramsbotham, Peacekeeping and Conflict Resolution, (London: Frank Cass, 2000).

${ }^{51}$ G. Lindstrom, "Enter the EU Battlegroups", Chaillot Paper N97, EU Institute for Security Studies, Paris, February 2007, p. 68 .

${ }^{52}$ UK Joint Doctrine and Concepts Centre, Joint Warfare Publication 3-50: Peace Support Operations. London: Permanent Joint Headquarters, 2008.

${ }^{53}$ Swedish Defence Research Agency.

${ }^{54}$ Op.Cit., EU-Battlegroups in Context. Underlying Dynamics, Military and Political Challenges, p. 26.
} 
between civilian and military actors ${ }^{55}$. Moreover, as seen above, the demands of institutionalizing PoC should provide a normative underpinning to how the Battlegroups are developed, trained and deployed. Without a strategic definition of PoC, this may prove problematic. Added to this, the Battlegroup concept suffers two further difficulties in operationalizing PoC: that of training, and that of force size.

Training PoC is difficult to assess. As Martin outlined in her study of EU training in the field of human security, training of EU military and civilian personal is 'highly diverse and fragmented', thus making it 'particularly hard to arrive at a generalized assessment ${ }^{56}$. Military training for Battlegroups is decentralized in the EU, firstly to the Framework nations, who are then responsible for the individual troop contributing countries (thus, in effect offering two levels of decentralization) $)^{57}$. This decentralized system carries positive aspects. For example, it encourages increased flexibility for framework nations to taper training cycles to more contemporary conflict situations, as opposed to following a 'one rule fits all' approach to training. It also allows for good practice to spread amongst Member States, encouraging a bottom-up process of training for EU deployment ${ }^{58}$. There is also evidence to suggest that Battlegroup training is a well organized activity. The Nordic Battlegroup (NBG) offers a solid example of training processes to prepare a multinational group of personnel for joint deployment. The NBG Lessons Learned report highlights the high level of joint training for personnel, including design and implementation of four major exercises, individual and collective staff training, testing of self-developed concepts, as well as involvement in wider European training exercises (e.g. VIKING 11). According to the NBG Lessons Learned report, the outcome of training, exercise and evaluation was assessed as 'very good'59.

However, little information exists on the level of training across other Battlegroups. This leads to more subjective approaches to how well adapted military personnel are to operate in a PoC environment. The Institute of Security Studies' assessment is particularly strong: 'Europeans do not have nearly enough soldiers with the necessary skills for international peacekeeping. Some EU Member States have not yet fully reformed their armed forces from a Cold War posture of defending national territory to participating in international peacekeeping operations. ${ }^{60}$

Lindstrom outlines that 'credibility gaps' may surface amongst nations in a Battlegroup, particularly if nations choose not to share exactly how prepared they are with other Member States ${ }^{61}$. This is partly a result of a lack of overarching strategy on PoC, and there being, apart from the European Defence Agency and European Security Strategy, 'no evidence of top down approaches' ${ }^{162}$. This is reflected to an extent in the EU's own reports. It was reported in 2010 that although the Headline Goal 2010 adds that Member States are committed to develop 'quantitative benchmarks and criteria' in the field of multinational training, Member States were still unable to agree an EU level Standard of Training for Multinational Battlegroups $^{63}$. Additionally, the Committee of Civilian Aspects of Crisis Management (CIVCOM) recommended that pre-deployment training be 'standardized to a greater extent ${ }^{64}$. This not only impacts levels of military preparedness. Lack of standardization in joint training programmes with civilian counterparts has been cited as a missing element of Battlegroup training. This may contribute to wider

\footnotetext{
${ }^{55}$ EU Council, "Promoting Synergies between the EU Civil and Military Capability Development as agreed by PSC on 6 November, (with a view to Council agreement on 16-17 November)”, Brussels, November 2009.

${ }^{56}$ M. Martin, Secure Learning: The Role of Training in Embedding a Human Security Doctrine for Europe - Case Study for the Madrid Report of the Human Security Study Group, London, London School of Economics, 2007, p. 4.

${ }^{57}$ EU Council, "Cover Note from Mr Javier Solana, Secretary-General/High Representative to: The Rt. Hon. Tony Blair MP, President of the European Council, Subject: Follow-up to Hampton Court: CFSP and ESDP - Initial orientations by SG/HR", (Doc. 15780/05), Brussels, 14 December 2005, p. 7.

${ }^{58}$ Op.Cit., "Enter the EU Battlegroups", p. 27.

${ }^{59}$ Swedish Armed Forces, NBG 11 (F)HQ Final Lessons Identified/Lessons Learned Report, Stockholm, 2011, p. 29.

${ }^{60}$ G. Grevi \& D. Keohane, "ESDP Resources" in G. Grevi \& D. Keohane, European Security and Defence Policy: The First Ten Years (1999-2009), (Paris: Institute for Security Studies, 2009), p. 69.

${ }^{61}$ Op.Cit., "Enter the EU Battlegroups", pp. 27-28.

${ }^{62}$ Op.Cit., "When Soft Power Turns Hard: Is an EU Strategic Culture Possible?", pp. 110-111.

${ }^{63}$ Op.Cit., Quo Vadis, The EU Battlegroups?, p. 6.

${ }^{64}$ EU Council, "Lessons and Best Practices of Mainstreaming Human Rights and Gender into CSDP Military Operations and Civilian Missions”, Brussels, 30 November 2010, p. 23.
} 
difficulties of establishing effective civil-military coordination mechanisms in deployment zones, thus impacting on the EU's ability to provide comprehensive approaches to crisis management ${ }^{65}$.

As well as training, it is debatable to the extent that EU Battlegroups can offer the full range of protection to civilian populations. The Battlegroup is a restricted tool for the EU - offering a relatively small number of soldiers to enter a conflict environment for a relatively short space of time. The Nordic Battlegroup offers a solid example of this. The lessons learned report identifies that when choosing the possible deployment scenarios for the Battlegroup, it was recommended by the EU Military Staff to leave out the scenario 'Stabilisation, Reconstruction and Military Assistance to Third Countries' ${ }^{16}$. Although this is a rational approach to what can and cannot be achieved, it demonstrates that the EU's Battlegroup capability is unable to meet the wide and demanding range of policy objectives outlined in EU PoC and human security plans. A Battlegroup of 1,500 personnel can only achieve so much when deployed. The level of demand placed on the Battlegroup by a potentially wide range of planning scenarios, could be dangerous for the $\mathrm{EU}$ if the Battlegroup is unable to meet the demands.

Overarching this is the fact that EU battlegroups are yet to be deployed. The Battlegroups are conspicuous by their absence in international crisis management operations, and such inactivity has led to critical assessments of EU Member States' willingness to deploy Battlegroups. Most recently, this has been in the form of analysis of the EU's lack of engagement in the Goma region of the DRC in late $2008^{67}$. Although the EU were formally asked by UN Secretary General Ban Ki Moon (through a letter to Javier Solana) to provide forces to support the UN's MONUSCO deployment, and certain EU Member States were enthusiastic about deployment under the Battlegroup concept, the British and German governments - framework nations for the two Battlegroups on rotation - refused to deploy ${ }^{68}$. Gowan notes that this refusal to send Battlegroups into Goma highlighted wider political difficulties at the heart of the concept, namely that structural flaws in the Battlegroup structures meant that the two framework nations were effectively able to avoid a commitment to deploying their Battlegroups.

Gowan also relates this to debates over RtoP, citing an article which appeared in the Irish Times which argued 'If successful, an EU battlegroup can help transform the responsibility to protect from word to deed" ${ }^{169}$. The fact that this did not happen left advocates of intervention disappointed. As demonstrated in the case of the DRC, deploying Battlegroups for PoC and human security objectives is a complex undertaking. Immediate post-conflict environments are fraught with hazard, and have a higher potential for violence. To deploy an EU Battlegroup, the EU will require the consensus from the 27 Member States and a firm commitment from the framework nation ${ }^{70}$. If a request is made to use a Battlegroup in a potentially violent environment, with little relation to the national security objectives of the framework nation, then tough decisions will have to be made.

\section{Civilian Crisis Management}

In comparison with developments in the military arena, the EU's civilian approach to crisis management has a longer history. The 2000 Feira Council conclusions reinforced the 'priority areas' for civilian capabilities - police, rule of law, civil administration and civil protection - and declared that by 2003, the EU will be able to provide up to 5,000 police officers for international missions covering crisis response

\footnotetext{
${ }^{65}$ Op.Cit., "Enter the EU Battlegroups", p. 68

${ }^{66}$ Op.Cit., NBG 11 (F)HQ Final Lessons Identified/Lessons Learned Report, p. 15.

${ }^{67}$ L.M. Balossi-Restelly, "Fit for What? Towards Explaining Battlegroup Inaction", European Security, Vol. 20, No. 2, (June 2011); R. Gowan, "From Rapid Reaction to Delayed Inaction? Congo, the UN and the EU”, International Peacekeeping, Vol. 18, No. 5, (2010), pp. 593-611.

${ }^{68}$ The Belgian and Swedish Governments were particularly enthusiastic about intervention. The latter having just been a framework nation for the Nordic Battlegroup in the first half of 2008, and willing to re-mobilize forces.

${ }^{69}$ R. Keane, EU Battle group Must Be Deployed to Conflict in Congo, Dublin, The Irish Times, 1 November 2008, (at: www.responsibilitytoprotect.org/index.php/component/content/article/129-africa/1932-dr-rory-keaneeu-battle-groupmust-be-deployed-to-conflict-in-congo. (Accessed 23rd April 2012).

${ }^{70}$ Op.Cit., "Fit for What? Towards Explaining Battlegroup Inaction", p. 170.
} 
and prevention activities ${ }^{71}$. In 2004, this was developed in the Civilian Headline Goals 2008, which outlined the EU's vision for enhancing civilian capacity: '[The EU] will, inter alia, contribute to activities such as security sector reform and support disarmament, demobilization/reintegration processes. Civilian missions can achieve this by strengthening local institutions through advice, training and monitoring, and/or performing executive functions (substitution missions) ${ }^{772}$.

This was further developed in 2008, with the establishment of the Civilian Headline Goal 2010. The 2010 goal sought to further strengthen areas of civilian participation in crisis management operations and explicitly outlined developments in 'rapidly deployable police elements' and the desire to make 'civilian response teams' increasingly operational. This certainly contributes in areas where the Battlegroups are unable to reach.

Like the military aspect, training is an important indicator of to what extent $\mathrm{PoC}$ is infused through the crisis management architecture. The process of working out whether police and civilian training for crisis management contributes to protection of civilians strategies is difficult to understand due to the diverse nature of training, and the number of civilian and police training academies that there are. Hadden observes that each Member State is responsible 'for the design of its own pre-deployment training curriculum and its delivery, with only limited guidance supplied by the mission', leading to variations in the level and content of training ${ }^{73}$.

Despite this, coordination in training programmes has emerged over the past ten years, firstly with the development of the European Group on Training (EGT) ${ }^{74}$, and its subsequent replacement 'Europe's New Training Initiative for Civilian Crisis Management' (ENTRi). ENTRi is the result of collaboration between a number of training organizations and government institutes ${ }^{75}$, and offers a coordinated approach to training civilian personnel, offering 34 'pre-deployment and specialization courses' between May 2011 and December 2012, with a possible audience of up to 8,000 ${ }^{76}$. Alongside pre-deployment courses for particular operations, ENTRi runs subject specific courses, including conflict analysis, human rights, mediation and negotiation, and child protection ${ }^{77}$. As well as covering many of the 'softer end' tasks of deployment, these training programmes offer a considered response to wider issues of civilian protection in conflict and post-conflict societies.

This is shown most explicitly through the introduction of the Folke Bernadotte Academy - a Swedish government agency - run course entitled Field Strategies for Protection of Civilians. This course is based on Proactive Presence, a concept developed at the Centre for Humanitarian Dialogue, which offers a guide to the 'actions and strategies that deter or dissuade against abuses, persuade abusers to behave differently, strengthen or expand civilian capacity for self-protection, and foster institutional reform'. ${ }^{78}$

The course is designed to develop participants' awareness as to how they can 'promote the protection of civilians through effective field presence' through examining different models and strategies of

\footnotetext{
${ }^{71}$ EU Council, "Conclusions of the Presidency: Santa Maria Da Feira European Council”, 19-20 June 2000.

${ }^{72}$ EU Council, "Civilian Headline Goal 2008 approved by the Brussels European Council on 17 December 2004”, (Doc. 15863/04), Brussels, 2004, p. 3.

${ }^{73}$ T. Hadden (ed.), A Responsibility to Assist: Human Rights Policy and Practice in European Union Crisis Management Operations, (Hart: Oxford/Oregon, 2009), p. 92.

${ }^{74}$ Directorate-General for External Policies of the Union Policy Department, "Consolidating Civilian and Military Training for Crisis Management: Taking Stock of EU Initiatives”, Brussels, 2010, pp. 2-3.

${ }^{75}$ Austrian Study Center for Peace and Conflict Resolution, Austria; Royal Institute for International Relations, Belgium;

Danish Emergency Management Agency, Denmark; Crisis Management Centre, Finland; Ecole Nationale

d'Administration, France; Centre For International Peace Operations, Germany; International Training and Civilian Crisis Management Center, Hungary; Scuola Superiore Sant'Anna, Italy; Netherlands Institute of International Relations Clingendael, Netherlands; Ministry of Exterior, Romania; Centre for European Perspective, Slovenia; Folke Bernadotte Academy, Sweden; International Alert, UK.

${ }^{76}$ ENTRi Website www.entriforccm.eu/activities/. (Accessed 15 April 2012).

${ }^{77}$ Child Protection; Civilian Response Team Training Course; Conflict Analysis \& Conflict Sensitivity; Hostile Environment Awareness Training; Human Rights; Leadership \& Gender: Principles and Particularities; Mediation \& Negotiation; Mentoring and Advising; Mission Administration and Support; New Dimensions of EU External Policies; Press \& Public Information; Rule of Law; Security Sector Reform.

${ }^{78}$ L. Mahony, Proactive Presence: Field Strategies for Civilian Protection, Centre for Humanitarian Dialogue, Geneva, 2006, p. 13.
} 
protection. The course represents a step forward in the development of training concepts for PoC, and thus a positive step in designing models for PoC within the EU.

Both ENTRi and the EGT also develop training programmes to prepare Civilian Response Teams (CRTs), defined by the EU as a 'rapid reaction capability of flexible size and composition, consisting of Member State experts with, in principle, Council Secretariat participation ${ }^{79}$ Over 100 staff remain in this pool of civilian expertise, working in four main areas: carrying out assessment and fact-finding missions in crisis situations; helping to prepare operation plans; ensuring a rapid operational presence on the ground; and supporting the initial phase of civilian missions. Both the EGT and ENRI have assisted training, and CRTs have deployed in the Democratic Republic of Congo and Afghanistan ${ }^{80}$. This again outlines a wider approach to PoC, where civilian expertise can be fostered to create larger multidimensional operations with a strong civilian component.

The level of civilian expertise gives the EU 'its comparative appeal as a global crisis-management actor ${ }^{81}$. Some go further and argue that such tools take the organization closer than ever to concepts of human security. Matlary's assessment of the evolution of the EU's civilian and military capacities marks the 'political conclusion' of the development of human security as a concept, and therefore makes the EU a 'potentially more relevant' security actor as the nature of security is less aligned with the nation state and more aligned with concepts of human security. Matlary goes on to argue that the EU Security Strategy 'weds' human rights to security, including military security' ${ }^{82}$. Although one may argue against Giegerich's claim that the EU has the potential to 'dominate' future forms of integrated crisis management ${ }^{83}$, it is certainly true that the more optimistic EU policy makers understand that the EU has an advanced role in international crisis management. This optimism is borne out of the view that the civilian assets at the EU's disposal make the organization a leader in PoC activities.

On the other hand, this must be tempered with a more skeptical analysis of the difficulties that the EU faces in the physical constraints that is placed on it. In 2009, ISIS Europe offered a sobering account of the challenges faced by EU civilian peacekeeping, stating that developments of civilian capabilities have not improved since the Headline Goal 2008. It went on to argue:

'The first CHG [Civilian Headline Goal] being theoretical in what would be needed for CCM, it is only now that the gaps for civilian capabilities have been ascertained. Furthermore, the EU is also suffering overload with ESDP missions and EU Member States now face problems of personnel rotation and doing more with less. Quality across-the-board EU training and the support structures for planning and deployment are still nascent ${ }^{9}{ }^{4}$

The ISIS report also touches on how such training developments have dealt with PoC. Questioning issues of concepts, resources and procurement dedicated to operationalizing PoC and human security, the paper makes a strong warning. That such a warning is still valuable tells of the divide between principles and action: 'tacking on as an afterthought frameworks such as: international humanitarian law; civilian participation in security sector reform; and gender perspectives - only if there is sufficient budget or "relevance" - is a poor strategy for concretizing the basis for missions to protect the population". ${ }^{85}$

Instead of this 'afterthought approach', the paper advocates that such issues must be involved from the pre-planning stage, and include local actors in order to engage the local population. Human Security, the paper argues, can be used as an 'organizing concept', 'binding and explaining the core aim of a holistic EU approach ${ }^{86}$. This is reflected in an article authored by Mary Kaldor, who strongly advocates that

\footnotetext{
${ }^{79}$ EU Council, "Civilian Headline Goal 2008 General Secretariat Document: Multifunctional Civilian Crisis Management Resources in an Integrated Format - Civilian Response Teams”, (Doc. 10462/05), Brussels, 2005.

${ }^{80}$ ZIF, Glossary Peace Operations: Your Gateway to Peace Operations, Berlin, Zentrum für Internationale Friedenseinsätze (ZIF), 2010.

${ }^{81}$ Op.Cit., EU Crisis Management: Ambitions and Achievements, p. 18.

${ }^{82}$ Op.Cit., "When Soft Power Turns Hard: Is an EU Strategic Culture Possible?", p. 119.

${ }^{83}$ Op.Cit., EU Crisis Management: Ambitions and Achievements, p. 24.

${ }^{84}$ G. Gya, ISIS Briefing Note 2009:1, "Tapping the Human Dimension: civilian capabilities in the ESDP”, European Security Review, No. 43, ISIS Europe, Brussels, March 2009, pp. 1-2.

${ }^{85}$ Ibid., p. 2.

${ }^{86}$ Ibid., p. 2.
} 
Human Security requires a 'change in the way of thinking' towards 'an entirely new way of functioning in crises $^{187}$.

\section{Conclusions}

This chapter has looked at how, through operationalizing PoC, the EU is developing capacities for timely and effective responses to RtoP style responses. As the chapter shows, there is at the declaratory level, a commitment to human security, protection of civilians and RtoP. This is outlined in policy statements. At the operational level there is less clarity, particularly with regards to the Battlegroups.

The decentralized nature of training structures in the Battlegroups means that it is difficult to assess the level of training for crisis management operations based on PoC mandates. There are signals that European forces are well prepared for PoC mandates, either through existing operational experience, or through supporting UN initiatives. Operations in Chad and the DRC are testament to this. However, Battlegroup units have not led military deployments undertaken by the EU. There is a lack of study into individual Battlegroup processes, or comparative studies of how Battlegroups prepare and what scenarios they are prepared for. Without such study, it is difficult to respond to critiques. This is not to say that EU Battlegroups are incapable of wider PoC activities. There are two models that Battlegroups are useful for both outlined in the Joint Declaration on UN-EU Cooperation in Crisis Management. Firstly, is the 'bridging model' concept, in preparation for a wider peacekeeping force. Secondly, through acting as an 'over-the-horizon' force to provide a deterrent to 'spoilers' and belligerent groups.

Nevertheless, the lack of deployment of EU Battlegroups is a continual problem. Gowan notes that in order 'to comprehend the EU's crisis-management tools, it helps to know which ones it discards. ${ }^{88}$ When linked to differing levels of training and a lack of overarching doctrine, the inaction of certain EU Battlegroups' highlights a gap between the ambitious ideas outlined by the Barcelona and Madrid reports, and the realities of Battlegroup preparedness and deployment. This may have consequences for those wishing to see whether the EU can mobilize Battlegroups for 'timely and decisive action' in responding to mass atrocity crimes.

On the other hand, the development of the EGT and ENTRi shows that there is coordination in training processes in civilian crisis management. Although academies are funded by national governments, the development of shared training across national boundaries will offer the EU a solid foundation of skilled civilian peace-builders. Through applying the theoretical concepts of Protection of Civilians, the PoC Course at the Folke Bernadotte Academy also highlights a positive development in civilian training for PoC mandates. It also goes some way to responding to the criticism that $\mathrm{PoC}$ is an 'afterthought' and demonstrating a commitment to PoC at the planning stage of an operation.

Definitional problems remain. This has been highlighted in the EU's overall approach to crisis management ${ }^{89}$. With PoC, difficulties have arisen in how to substantiate levels of training for military and civilian personnel, and their overall purpose in crisis management operations. Related to the creation of coherent responses to timely and decisive approaches to issues related to human security, the EU may suffer from this lack of strategic definition. With this lack of definition, it is difficult for the EU to be as proactive in its approaches to intervention as the Barcelona and Madrid reports would desire.

It would be too critical to claim that the EU's advocacy on RtoP is 'words without deeds'. Military and civilian operations have shown that in the right context, the EU can employ substantial resources in operations. However, the question could be whether the Battlegroups can be reinforced to meet the demands of an ambitious human security agenda, or the agenda be downsized to meet the limited capabilities of the Battlegroups.

\footnotetext{
${ }^{87}$ M. Kaldor, "Human Security in Complex Operations”, Prism, Vol. 2, No.2, (March 2011), p. 14.

${ }^{88}$ Op.Cit., "From Rapid Reaction to Delayed Inaction? Congo, the UN and the EU", p. 595.

${ }^{89}$ G. Quille, The European Security and Defence Policy: From the Helsinki Headline Goal to the EU Battlegroups, (Brussels: European Parliament, 2006), p. 14.
} 


\title{
Operationalizing the Responsibility to Protect's "Sharp End": Towards a No Footprint Approach?
}

\author{
ROBERT SCHÜTTE
}

\section{Introduction}

The international community's dealings with the military operations in Libya and Côte d'Ivoire have heralded a new phase of deliberations about the RtoP. Both the NATO-led intervention force and the UN Operation in Cote d'Ivoire (UNOCI) were authorized with a robust mandate by the UNSC to protect civilians under imminent threat. However, the implementation of their respective Protection of Civilians (PoC) mandates has become a subject of criticism. Some countries have lamented that UNOCI and NATO overstepped their mandates by abandoning their impartial role and pursuing regime change instead. The events of 2011 have revealed two important developments: first, that the RtoP has become a firmly established norm within the UN; and second, that there remains a fair degree of ambiguity and disagreement about the actual operationalization of RtoP's "third pillar", in particular its military dimension. In line with this argument, the Special Adviser to the Secretary-General on the Prevention of Genocide, Francis Deng, has argued in early 2012 that recent "Security Council decisions in response to developments in Côte d'Ivoire and Libya and the on-going discussions of the situation in Syria also show that debates now focus on the manner of response in implementation of RtoP rather than on the concept itself." ${ }^{1}$ This is in particular true for the military dimension of the norm.

There is a large body of literature on the issue of preventing mass atrocities dealing with both political and operational considerations. The same can be said about the question of re-building states and societies that have fallen victim to atrocity crimes, although one has to admit that the international community was only partly successful during the past two decades. The most neglected issues to date is how exactly the third pillar's military dimension can and should be implemented. Unfortunately, there has been only scant reflection about the practical requirements, implications and obstacles of military interventions to halt imminent or ongoing mass crimes. For the sake of accurate terminology, I refer to such military interventions as Mass Atrocity Response Operations (MAROs). I make three assertions in this chapter: first, it is argued that political decisions concerning military measures under RtoP's "third pillar" need to take more account of the operational requirements of MAROs; second, the chapter analyzes existing approaches to robust civilian protection and highlight the need for a comprehensive doctrine on civilian protection; and, third, given Western governments' increasing reluctance to consider ground troop deployments for the purpose of halting atrocities, the chapter holds that airborne MAROs will for the foreseeable future be the only politically feasible option. It is argued that NATO's campaign in Libya might function as a role model for future MAROs, and that the focus of further deliberations should be on predominantly airborne military interventions.

\section{Moving from "If" to "How": Re-aligning Political and Operational Aspects}

The UNSC's resolute handling of the crises in Libya and Côte d'Ivoire has surprised even the most optimistic proponents of RtoP. Its swift reaction to the threat of mass atrocities had many different reasons. The mandates to coercively protect civilians, however, would have been unthinkable without the normative context of the emergence of RtoP and rapidly increasing attention to questions of PoC. Since RtoP's adoption in 2005, deliberations about the UN's pivotal role in preventing massive human rights

\footnotetext{
${ }^{1}$ F. Deng. See: www.globalr2p.org/media/pdf/DengRwP.pdf. (Accessed 1 April 2012).
} 
violations have been reflected in numerous UNSC and UNGA resolutions as well as reports of the UNSG. In the same vein, a number of initiatives promoted by the UN Department of Peacekeeping Operations (DPKO) and the Office for the Coordination of Humanitarian Affairs (OCHA) have been instrumental in promoting PoC within the UN and, in particular, the UNSC. Hence, when put to the test in early 2011, the issue of protecting civilians in armed conflicts had already taken centre stage in Security Council deliberations. The authorization of coercive means in Libya and Côte d'Ivoire did not come out of the blue.

It is sometimes argued that the Security Council's recent dithering over Syria may be explained by NATO's implementation of RtoP in Libya. The critics maintain that the NATO-led coalition has overstepped its mandate by launching its bombing campaign with the ultimate aim of paving the rebels' way to Tripoli and removing Gaddafi from power. It is not necessary to dive into the details of the political pros and cons of the argument, but instead more fruitful to look at how the lack of shared understanding about how exactly to conduct an MARO is in part to blame for the misgivings that have emerged since. The starting point is the UNSC's language on the Protection of Civilians which is clear and ambiguous at the same time. With regard to the deteriorating situation in Libya, the Council in Resolution 1973 authorized "Member States (...) to take all necessary measures to protect civilians and civilian populated areas under threat of attack in the Libyan Arab Jamahiriya" [author's italics]. On the one hand, Resolution 1973 is absolutely clear about the objective to protect threatened civilians and civilian populated areas with all necessary means. On the other hand, the resolution neither spells out under which circumstance civilians or civilian populated areas are to be seen as threatened, nor what exactly the necessary means to protect those civilians would be. The threat to the population as well as the necessary means to avert this threat can be interpreted in both narrow and broad terms. Regardless of the fact that NATO's public statements remained non-committal, it is safe to say that the Alliance came to the conclusion that the Libyan population would be threatened by mass atrocities as long as Gaddafi remained in power. Against this background, all means necessary to protect civilians in Libya may reasonably encompass regime change. It is not surprising that Russia, China and a number of other countries such as Brazil, India and South Africa had a different understanding of Resolution 1973. In a narrow interpretation of Resolution 1973, NATO could have stopped Gaddafi's forces at the gates of Benghazi and subsequently let the Libyans fight it out among themselves. It is easy to imagine how NATO would have referred to its "impartial role" and an "unwillingness to become a party to the conflict". Such an interpretation would also have raised questions about the Alliance's commitment to its PoC mandate. There is simply no clear answer to the question, whether NATO overstepped its authority or not because the Security Council remained vague about the meaning of the resolution's key terms: "Threat to civilians" and "all necessary means".

At the end of the day, it was up to the Alliance to interpret Resolution 1973 and thereupon defines the ways and means to protect civilians. The lack of clarity about the operationalization of the RtoP in the case of Libya has prompted Brazil to propose a so called "Responsibility while Protecting" as a supplement to the RtoP. Amongst other things, the proposal calls for only limited legal, operational and temporal authorizations of force, and for enhanced UNSC procedures to monitor and assess the manner in which resolutions are interpreted and implemented. ${ }^{2}$ This would indeed be a step towards greater political control of RtoP mandates. However, this does not resolve the practical question of how RtoP interventions should be conducted. UN Secretary-General Ban Ki-moon has announced that the operationalization of the RtoP's "third pillar" will be the main subject of debate in 2012. Be that as it may, a workable operationalization of RtoP's military component necessitates not only an agreement on political issues and procedures but an understanding of operational questions as well. Paying heed to the word and spirit of a resolution authorizing military intervention will be difficult as long as there is no understanding about what the provisions entail in practice. Hence, the UNSC should make an effort to debate the operational requirements that accompany successful MAROs. For example, the intervention in Libya required a sustained bombing campaign to destroy the Gaddafi regime's air defense systems to pave

\footnotetext{
${ }^{2}$ UN, "Letter dated 9 November 2011 from the Permanent Representative of Brazil to the United Nations addressed to the Secretary-General”, A/66/551, New York, para. $11 \mathrm{~d} \&$ h, (9 November 2011).
} 
the way for further PoC operations. Nevertheless, some governments that only shortly before had advocated for the protection of the Libyan population by all necessary means criticized this approach.

Twelve years of experience with UN peacekeeping operations authorized to protect civilians have yielded an important lesson about separating political and operational considerations. The Security Council has time and again adopted unclear and unfeasible PoC mandates for peacekeeping missions that were impossible to implement on the ground. While the UNSC apparently saw a political necessity to protect civilians and incorporate corresponding wording into its resolutions, it lacked an understanding about the operational requirements to successfully implement civilian protection. This has all too often resulted in tragic and embarrassing situations where blue helmets were incapable of stopping atrocities taking place before their very eyes. Fortunately, the UNSC has in the past years grasped the problem and made significant headway. When discussing the military aspects of the RtoP's "third pillar", we should take care to not repeat the same failure again but instead consider political and operational aspects in a joint manner.

\section{Two Approaches to Robust Civilian Protection Operations}

If we agree that the operationalization of the military aspects of the RtoP's third pillar should take operational considerations of $\mathrm{PoC}$ into account, a reasonable starting point is to examine the international community's existing modus operandi with regard to robust civilian protection. There are basically two distinct approaches, robust peace operations and MAROs.

The UN Mission in Sierra Leone (UNAMSIL), established in 1999, was the first peacekeeping force with an explicit mandate to protect civilians. Since then, Protection of Civilian mandates have become a common feature of contemporary peace operations: In 2011, an all time high of 8 UN peace operations with more than 80,000 soldiers were deployed worldwide to provide threatened civilian populations with a modicum of safety. Nevertheless, the UN has not yet developed a comprehensive Protection of Civilians doctrine that could provide operational guidance. It is for this reason that the implementation of $\mathrm{PoC}$ mandates varies heavily among different missions and often hinges upon the prevailing commander's attitude and risk disposition.

Despite laudable ad hoc approaches to civilian protection, the lack of a comprehensive doctrine has inhibited the UN's capacity to do a better job in PoC. ${ }^{3}$ We can nevertheless draw some operational conclusions about the dynamics and workings of robust PoC. ${ }^{4}$ The most important Protection of Civilian approach is PoC by deterrence. Protection by deterrence means that the very presence of blue helmets is in most cases sufficient to deter attacks on civilians and boost physical security in a given area of operations. While militias - mostly in bad shape and ill-equipped - shun direct confrontations with comparatively well-armed professional blue helmets, national authorities shy away from the exposure and the reporting of assaults. Experience shows that when violence escalates, civilians either flee the region or assemble around UN compounds. This is a clear indicator for the functioning of protection by deterrence. It is for the same reason of utmost importance for peacekeepers to regularly patrol volatile areas and to actually show up. A peacekeeping mission's capacity to deter direct violence against civilians is to a large degree a function of two factors: first, its presence in endangered regions and second, its credibility to interfere to curb violence against non-combatants, if needed by force. Operationally, peace operations have to square the circle of showing presence in violence prone areas without stretching their forces so thin that they become incapable of enforcing their PoC mandate. This is especially difficult in vast places such as Darfur or the Democratic Republic of Congo where the UN lacks critical air mobility.

\footnotetext{
${ }^{3}$ cf. V. Holt \& G. Taylor, Protecting Civilians in the context of UN Peacekeeping Operations. Success, Setbacks and Remaining Challenges, (Independent study jointly commissioned by the Department of Peacekeeping Operations and the Office for the Coordination of Humanitarian Affairs, 2009).

${ }^{4}$ R. Schütte, "Minding the Gap. Approaches and Challenges to Robust Civilian Protection" FES Perspective, (December, 2011).
} 
A positive example where a UN presence effectively deterred a catastrophe occurred in Darfur in the embattled town of Mujajiriya in February 2009. The Sudanese government had called on the local UNAMID peacekeepers to immediately withdraw from the rebel-held city, effectively abandoning the civilian population. Despite massive force concentrations outside the city and initial aerial bombardments, the barely 200 man UNAMID contingent refused to heed the Sudanese government's call and stayed on the scene. At the end of the day, high-level negotiations to resolve the situation in combination with the operation's determination to enforce their PoC mandate "may well have prevented a far larger assault on the town that could have cost many more civilian lives. In this case, the mission's willingness to contravene the host nation's wishes was key to fulfilling its PoC mandate."

If deterring measures have proven insufficient to protect civilians, UN missions have in some rare but yet noteworthy cases resorted to the offensive use of force. This approach of protection by engagement was most recently used by UNOCI in 2011 to end attacks of pro-Gbagbo forces on the civilian population in Côte d'Ivoire. The UN Mission to the DRC (MONUSCO) successfully protected the local population of Bukavu in 2006 by resolutely using attack helicopters against militias, forcing the latter to abort their assault and withdraw. Such actions are a slippery slope whose potential short- and long-term effects have to be taken into account: on the one hand, they may be needed to avert a pending threat to civilians and bolster the UN's credibility vis-a-vis spoilers; on the other hand, they carry the risk of permanently antagonizing a party to a conflict and, thereby, causing an escalation of violence. Despite many successful instances of protection by engagement, the fear remains that the UN might be crossing a line by becoming a party to a conflict. The UN's Capstone Doctrine cautions that the "ultimate aim of the use of force is to influence and deter spoilers working against the peace process or seeking to harm civilians; and not to seek their military defeat."

A distinct type of international effort to protect civilians is Mass Atrocity Response Operations. NATO interventions in Kosovo and Libya figure among the most prominent and complex MAROs. There are major differences between MAROs and UN peacekeeping operations; MAROs can be conducted without the consent of the concerned country's government. This may be the case if the government is itself responsible for the orchestration and implementation of mass atrocities, regardless of the question if the actual killings are conducted by government forces itself or proxies. A non-consensual military intervention requires dramatically more military capabilities than a robust peace operation, for example to destroy dangerous air defense systems or other military assets. Once on the ground, MAROs step in with a much more robust and offensive posture than peacekeeping operations. While the establishment of protected safe havens and the deterrence of atrocities is part and parcel of any civilian protection operation, the defeat of hostile forces with the aim to prevent future assaults plays a much more important role in MAROs than in peacekeeping operations.

MAROs involve unique operational challenges that are distinct from traditional war fighting. Sewall and $\operatorname{Kardos}^{7}$ outline three distinct features of MAROs: first, the intervenor has to cope with multiparty dynamics because there are no friendly and enemy forces but a multitude of actors, in particular perpetrators, victims, bystanders, media, NGOs etc; second, even if an intervenor may act for just and impartial reasons, he will inevitably be perceived as siding with the victimized group against the perpetrator group. "As the intervenor changes the dynamics, there is a high potential for a MARO to quickly metastasize again into another type of conflict - civil war, insurgency, interstate conflict - and for the original distinctions between victims and perpetrator (...) to dissolve" to an escalating dynamic in which perpetrators may increase the speed and scope of their atrocities in fear of a closing window of opportunity. Such cases may "stand traditional planning precepts on their heads (...) [and] require privileging speed over mass in MARO planning."

\footnotetext{
${ }^{5}$ Op.Cit., Protecting Civilians in the context of UN Peacekeeping Operations, p. 358.

${ }^{6}$ United Nations Department of Peacekeeping Operations \& Department of Field Support: "United Nations

Peacekeeping Operations: Principles and Guidelines”, (2008), p. 36.

${ }^{7}$ S. Sewal et al., Mass Atrocity Response Operations: A Military Planning Handbook, (Harvard Kennedy School, May 2010).

${ }^{8}$ Ibid., p. 18.

${ }^{9}$ Ibid.
} 
Experiences over the past two decades have shown that there are generally two different forms of MAROs: "Heavy footprint" interventions involving substantial ground force components, and "no footprint" intervention that are predominantly airborne. Examples for the former category are ECOWAS' intervention in Sierra Leone in 1997; the Australian-led INTERFET operation in Timor Leste in 1999; Britain's intervention in Sierra Leone in 2000, as well as the EU's operation Artemis in Bunia (DRC) in 2003. All these missions were more or less successful in curbing mass atrocities in their respective area of operations by exploiting their superiority in weaponry, training, command, control, communication, computer and intelligence assets against their often ill-disciplined and out-gunned enemies.

Prominent examples of "no footprint" MAROs are the NATO-led interventions in Kosovo and Libya, which were almost exclusively conducted through the use of air power. Predominantly airborne MAROs have dramatically reduced the risks to the intervening forces' soldiers and are, therefore, much easier to justify to a war weary or casualty averse domestic public. However, the advantage of political convenience comes at the cost of diminished operational effectiveness in terms of civilian protection. Ulrich summarizes this dilemma in a simple formula: the value attached to the lives of civilians is inversely proportional to the altitude at which an intervenor operates his air force. ${ }^{10}$

To date, there is no MARO doctrine that could guide either heavy or no footprint interventions. This is problematic not only because, as outlined above, MAROs confront military planners and soldiers with unique operational challenges; it is also a political problem because it restricts national decision makers' options to respond adequately and in time to mass atrocity crimes. In the cases of Kosovo and Libya, MAROs have nevertheless been ordered and eventually executed by NATO forces. This begs the question how MARO mandates have recently been operationalized. The Libya intervention is an interesting case in point; it has already been mentioned that NATO has interpreted its PoC mandate in a very broad sense. The Alliance not only targeted pro-regime units attacking or approaching civilians but also attacked regime forces performing stationary tasks such as guarding bridges in civilian populated areas. NATO has not clarified the criteria it applied to identify potential targets in Libya. This raises concerns about the Alliance's accountability and transparency, especially because MAROs must be held to higher standards of conduct than ordinary military operations.

Despite such concerns, NATO has waged the most PoC oriented military intervention in history: the Alliance conducted its bombing campaign with an operational standard of "zero expectation" of death or injury to the civilian population. To implement this policy, NATO gave orders to abort any combat missions if there was a risk to non-combatants. Moreover, the Alliance exclusively used precision-guided missiles and took precautionary measures to avoid unintentional civilian casualties, for example: NATO concentrated its attacks during the night-time when fewer civilians were on the streets; it used drones to observe targets in civilian populated areas and to find "patterns of life" to identify the optimal point in time to launch a strike; it used delayed bomb fuses in order to let buildings collapse rather than explode, thereby preventing blast and fragmentation damage that could have injured civilians; it has apparently refrained from bombing dual-use infrastructure such as energy grids whose destruction is known to have caused serious civilian hardship in previous campaigns; and it did not use cluster ammunition or ordnance containing depleted uranium in order to avoid post-conflict hazards to the population. NATO certainly over-fulfilled its legal obligations under International Humanitarian Law. As a result of these precautions, the UN Human Rights Council's Commission of Inquiry estimates that NATO "conducted a highly precise campaign with a demonstrable determination to avoid civilian casualties." ${ }^{11}$ The Commission of Inquiry cites an interesting case that highlights the intervenor's approach, willingness and success to realize their zero expectation policy:

'From 24-25 May 2011 NATO aircraft struck the Bab-al-Aziziyah facility, a large military compound and barracks in central Tripoli used by Qadhafi as a residence and headquarters. Numerous multistory buildings used by Qadhafi's security forces were destroyed. The collapsed buildings show damage consistent with 2000lb bombs using delayed fuses: some of the buildings show clear entry

\footnotetext{
${ }^{10}$ B. Ulrich: Wofür Deutschland Krieg führen darf. Und muss (Rohwolt 2011), p. 143.

${ }^{11}$ UN Human Rights Council, "Report of the International Commission of Inquiry on Libya", A/HRC/19/68, Geneva, (2 March 2012), para. 122.
} 
holes extending through multiple floors, indicating an aerial bomb with a delayed fuse had exploded inside or underground, collapsing the buildings upon themselves and thus minimizing collateral damage. Several of the security buildings destroyed were less than 300 meters from civilian apartment buildings, close enough to be at risk of collateral damage from the strikes. While civilian apartment buildings were well within the collateral damage radius of the attack, not even the glass on these apartment buildings was broken. Weapons appeared to impact at angles pointing away from civilian housing to ensure flying debris did not impact them.'

The above precautions, however, have not in all cases avoided unintended civilian casualties. The UN Human Rights Council's Commission of Inquiry has confirmed 60 civilian casualties caused by NATO attacks. What is more, an inquiry of the New York Times has collected evidence on at least 40 cases of civilian fatalities. Besides technical problems with bombs and faulty or outdated intelligence, some of NATO's operational procedures did not sufficiently reflect a PoC logic and led to avoidable unintentional civilian casualties. For example, on some occasions NATO airplanes undertook several strikes in a row against one and the same target. Civilians trying to rescue survivors of the first air strike were then killed by a second strike against the same target. Another issue seems to have been air strikes in circumstances of rapidly shifting frontlines as well as Gaddafi forces intermingling with civilians. ${ }^{12}$ Such issues should be reviewed and integrated into NATO's guidance on conducting airborne operations.

\section{Towards a "No Footprint" Approach?}

Current efforts to operationalize the military dimension of RtoP's "third pillar" take place in a difficult political situation: the few states that are capable of mounting Mass Atrocity Response Operations, i.e. mostly Western countries, are by and large disinclined to use their military assets for costly military interventions in remote places. Leaving aside for the moment that numerous countries of the Global South that view Western military interventions with suspicion, three dynamics currently work to the detriment of implementing future MAROs: first, the West's sobering experiences with the wars in Afghanistan and Iraq have undermined popular and political support for sending American or European soldiers into new armed conflicts, especially if there are no core national interests at stake; second, the financial and economic crisis has prompted NATO countries to implement austerity policies that leave no room for increases in defense spending. Therefore, Western governments will think twice before getting themselves into costly military interventions in faraway places; third, the geostrategic situation has changed: the rise of China has already prompted the US to focus on East Asia. The result will be a shift of US capabilities and attention towards the Pacific region with the aim to bolster its regional credentials, leaving less spare military capabilities for future MAROs. Meanwhile, a military intervention in Syria will remain improbable as long as there is serious danger of war with Iran over its alleged nuclear programme. We can assume that a NATO planner's nightmare these days is being entangled in a simultaneous war with Damascus and Tehran. It is improbable that NATO countries will consider squandering their limited precision-guided missiles in Syria if this entails the risk of lacking necessary capabilities in a looming war with Iran. The bottom line is that America and Europe will have no appetite for any major wars of choice in the foreseeable future. In a nutshell: those capable of launching MAROs are not willing to do so. ${ }^{13}$

If the aim is to successfully operationalize the "sharp end" of RtoP's "third pillar", we have to answer the question how to make future MAROs more feasible. Given that Western countries do not even contemplate the option of launching massive land-invasions, a solution has to accommodate the operational effectiveness and political feasibility of conducting a military RtoP intervention. The Libya

\footnotetext{
${ }^{12}$ C. J. Chivers \& E. Schmit: "In Strikes on Libya by NATO, an Unspoken Civilian Toll”, New York Times (17 December 2011).

${ }^{13}$ Libya was an exception because it was both politically and operationally feasible.
} 
case is informative in this regard: the provision of Resolution 1973 that excluded the deployment of an occupying force to Libya reflected not only the BRICS' concern for sovereignty but also NATO's wariness of being sucked into a North African quagmire. Hence, a "heavy footprint" approach to MARO seems impossible to digest for Western countries. The Libya intervention may nevertheless be a model for what I call a "no footprint" approach to MARO, i.e. predominantly airborne interventions supported by Special Operations Forces and cruise missiles. Such operations would primarily be executed by fighter jets, helicopters and Unmanned Aerial Vehicles (UAV), guaranteeing a maximum degree of force protection and a low risk of getting entangled in a counter insurgency on the ground.

While we have become accustomed to the use of drones in the so called war on terror, we should not lose sight of the PoC potential of UAVs: drones are capable of observing and hovering over targets for extended periods of time. In contrast to fighter jets, whose window of opportunity to strike a target amounts to a couple of seconds, drones are capable of picking the most suitable time to attack a target. This is especially useful if military assets or perpetrators are located within civilian populated areas or heavily intermingled with a non-combatant population. A drone can observe and wait for hours until a group of perpetrators or tanks leaves a crowded street, and strike when there is a minimum risk to bystanders. Thus, drones have a much greater potential to avoid unintentional civilian casualties than fighter jets striking targets of opportunity. If drone strikes in Pakistan, Somalia or Yemen would be conducted in line with NATO's "zero expectation policy", it is probable that this would drastically reduce civilian fatalities.

Another aspect is the capability of UAVs to stealthily monitor threatened areas, detect perpetrators and graphically document sites of atrocities for later criminal investigations. As argued above, deterrence is a major contributor to $\mathrm{PoC}$ in peacekeeping operations. If appropriately planned and used in significant numbers, drones may become a power tool for robust PoC. Such humanitarian drones would follow what can be called a 4-D approach:

Detect and identify potential or actual perpetrators;

Deter mass atrocities through presence and threats of violence;

Destroy military assets or perpetrator forces immediately threatening civilians; and

Document cases of atrocity crimes for future criminal investigation.

Their invisibility and omnipresence would certainly have a tremendous deterrent effect on perpetrators who would have to fear finding themselves in a drone's cross-hair. Key would be to establish and maintain a drone fleet's credibility in using force against anyone committing atrocities, for example by using appropriate Military Information Support Operations, shows of force and actual air raids. For example, armed drones could be used to protect demarcated safety areas.

It is clear that a "no footprint" MARO cannot solely rely on UAVs given their limited combat power. Drones cannot replace fighter jets to attack military compounds or cruise missiles launched at air defense systems. Special Operations Forces would also be needed 'to disrupt perpetrators, attack key target, divert adversary focus, direct air strikes, (...) conduct advance preparations for the delivery of humanitarian assistance ${ }^{14}$ and potentially train local proxy forces. However, drones may become an indispensable tool for conducting "no footprint" interventions if we better comprehend and harness their power to protect civilians. This would require two things: first, more intensive reflection about the potential of and challenges to airborne MAROs; and second, the elaboration of a comprehensive PoC doctrine focusing on predominantly airborne robust civilian protection operations.

Cautionary consideration should be given to the fact that the political feasibility of airborne MAROs comes at an operational cost. It is beyond question that land borne expeditionary forces supported by air and sea forces would be more effective in halting mass atrocities and establishing security. From an operational vantage point, airborne MAROs are a second best solution. It is not the operational but the political logic that should drive more intensive reflection about airborne MAROs. A "no footprint" approach has clear limitations and disadvantages which have to be taken into account. First and foremost,

\footnotetext{
${ }^{14}$ A. D. Raymond et al, MAPRO: Mass Atrocity Prevention $\mathcal{E}$ Response Options, A Policy Planning Handbook, U.S. Army Peacekeeping \& Stability Operations Institute, (Carlisle, March 2012), p. 113.
} 
airborne MAROs seem feasible in open terrain such as desserts or rangelands. However, rugged terrain or jungles would certainly impede the effectiveness of applying air power and drones. Furthermore, if a state government is responsible for systematic atrocities, recourse to a ground proxy force to stop and avert further crimes may be required. Interventions in Kosovo, Afghanistan and Libya underline that military interventions can hardly be won without boots on the ground. It is obvious that the training, arming and support of local militias and proxy forces creates issues regarding the protection of civilians and compliance with International Humanitarian and Human Rights law. Moreover, significant Human Intelligence may be needed to detect potential targets if perpetrators are organized in militia groups that are difficult to distinguish from the local population. It will occasionally be extremely hard to avoid civilian fatalities if militias such as the Lord's Resistance Army in Uganda are accompanied by innocent women, children or abducted persons. Direct action approaches of Special Operations Forces may be the only possibility in such a case. A political issue is also the cost of pursuing a month-long "no footprint" MARO, including expensive $24 / 7$ drone operations in far-flung and vast theatres.

These are just some concerns which reveal that airborne MAROs are anything but a silver bullet to the question of mass atrocity prevention. It has been outlined that a "no footprint" approach may in the future be the most likely and exclusive option on the table. We should be prepared for it.

\section{Conclusion}

This chapter has argued that the present misgivings about RtoP interventions in Libya and Côte d'Ivoire can in part be attributed to a lack of agreement and understanding about the operational requirements of Mass Atrocity Response Operations. The countries that authorized the two missions to "protect threatened civilians with all necessary means" apparently had different ideas about the operational implications and requirements of the mandate. In order to improve the operationalization of RtoP's military dimension, future mandates should be clearer on the objective and instruments of robust civilian protection missions while taking account of the operational necessities that such mandates entail. I have claimed that there are principally two approaches to robust civilian protection, namely robust peace operations with civilian protection mandates and Mass Atrocity Response Operations. Both kinds of operations suffer from a doctrinal $\mathrm{PoC}$ gap that should be alleviated to improve their respective civilian protection performance. In Libya, NATO has crafted and successfully implemented procedures to avoid unintentional civilian casualties.

Given that Western states are increasingly disinclined to conduct costly and politically unsellable wars of choice, this chapter holds that the Alliance's campaign in Libya may function as a model for low-risk airborne MAROs. Even though such a "no footprint" approach to MAROs may be less effective than troop-intensive land borne interventions, it is probably the only politically feasible option to operationalize RtoP's "sharp end". The chapter has argued that airborne MAROs, and in particular the use of drones for PoC purposes, have a notable potential to prevent mass atrocities. This strategy's advantages and limitations should become the subject of further research and planning. 


\title{
A Common Approach to the Application of the Responsibility to Protect
}

\author{
SHERI ROSENBERG E⿱ EKKEHARD STRAUSS
}

\section{Introduction}

This chapter seeks to conceptualize and operationalize a narrow but critical subset of the Responsibility to Protect by exploring the creation of standards to determine when states should act pursuant to their RtoP obligations. Thus, less time is spent on whether states should act and rather on how states should act to prevent or react to mass atrocity. In line with the original concept of the RtoP and the definition adopted by all UN Member states in 2005, these obligations are based on international law and range from structural prevention through capacity building and international assistance, to a range of peaceful measures carried out by regional organizations and the international community to more coercive measures, to long-term commitments to rebuild and assist populations with recovery and reconciliation.

A standard for the implementation of the RtoP, ideally, strikes at the mid-term prevention point, where risk factors can be assessed with regard to future developments and identifiable prevention tools are known to us, but not so far down the road that extreme coercive measures such as military intervention appear to be the only "preventive" option. After all, the UN Secretary-General and UN Member States have unambiguously stated that prevention is the single most important dimension of the RtoP. As the UN Secretary-General Ban Ki-moon said in his 2009 Report on Implementing the RtoP '...if the international community acts early enough, the choice need not be a stark one between doing nothing or using force. ${ }^{1}$ Nonetheless, frequent debates over when a state must act pursuant to the obligations embodied within the RtoP have often slowed the application of appropriate responses to prevent and react, and permitted legal and political debates to lose focus on the real concern over protecting human lives. A coherent, common standard of assessment that can be utilized on a case-by-case basis provides clear boundaries to discussions over when the RtoP applies in a given situation based on a range of sources that suggests the most appropriate form for the guidelines given the particular focus on mass atrocity prevention.

Notwithstanding the reference to genocide, war crimes, crimes against humanity and ethnic cleansing, the RtoP cannot apply only at the stage at which responsibility under international criminal law for an individual culprit could be established. Such a standard would ensure the immediate demise of the normative concerns embedded within the RtoP - most of all its ability to proactively attempt to prevent imminent or on-going forms of mass atrocities based on existing legal obligations. Instead, the RtoP requires the prospective assessment of future developments based on present facts and circumstances. Similar challenges are faced in national tort law or the national and international implementation of "nonrefoulement."

Based on a detailed review of relevant, diverse areas of law, and consultations with stakeholders across the globe, the authors developed the following standard of assessment for the RtoP. The RtoP framework shall apply if the examination of a situation establishes a real risk that exceptionally grave human rights violations, as described in genocide, war crimes, crimes against humanity and ethnic cleansing, are occurring or could occur in the future. Moreover, we set forth a set of principles, which shall guide stakeholders as they utilize the standard of assessment for the consideration of a situation regarding the RtoP. Any situation can be assessed for risks of mass atrocities following the proposed standards. It is for the relevant stakeholders to determine, based on their assessment, the appropriate time for different forms of more or less intrusive action to prevent or halt mass atrocities. With a view to the wording of the World Summit Outcome Document, the standards contain principles for the determination of whether a state is "manifestly failing" to protect its population from one or more of the four RtoP acts.

\footnotetext{
${ }^{1}$ Implementing the Responsibility to Protect. Report of the Secretary-General, U.N.-Doc. A/63/677 of 12 January 2009, para. 11(c)
} 
It remains unclear, at this time, which precise practical consequences flow from invoking the RtoP in a particular situation, because the RtoP may require stakeholders to do something based on existing legal obligations and according to a concept of consecutive steps by national and international actors, but it does not dictate the precise means by which the RtoP should be implemented in a given situation. However, relevant stakeholders have been working to strengthen the understanding and the appropriate application of the concept, and this chapter helps to accurately assess when to apply the RtoP. The goals of the project are to:

- Promote the full continuum of RtoP actions: while it is universally agreed that the best form of protection is prevention, the lack of common standards of assessment at early stages of potential developments is one factor for the continued focus and association of the RtoP with military intervention exclusively. A common standard that spans the full range of beneficial protection endeavours will help to ensure prevention is promoted forcefully where it is really needed;

- Targeted application of limited resources: given the constraints on time and resources that stakeholders can direct to address mass atrocities, a common standard of assessment concerning which situations will benefit most from international assistance will ensure the most effective allocation of those limited resources.

- Legitimizing effect: on the one hand, there are many valid concerns over the potential for selective and subjective applications of the RtoP. On the other hand, there are legitimate concerns that necessary measures to prevent and react to mass atrocities are not undertaken due to political considerationscalculations that may leave innocent victims without protection. A common standard of assessment, while inevitably open to interpretation by all parties, will at the very least begin to require parties to explain their reasoning from a common reference point. Actions that are taken will be seen as more legitimate if successfully applying the standard; decisions not to take a certain course of action will also be seen as more legitimate.

The application of a common standard will contribute to greater consistency in outcomes of state action within the RtoP framework. Despite the use of the terminology, this chapter does not suggest that the proposed standard and guiding principles are to be implemented as a legally binding test against which to gauge the appropriateness of action. Instead, the standard aims at assisting relevant actors to determine, whether a situation could benefit from applying the RtoP. Like all standards guiding international relations it will be open to interpretation by a wide array of actors, but its flexibility will be bound by the common values shared by states and their populations: to prevent mass atrocities.

The standard can be used by governments, bodies of regional and international organizations, and civil society, which are all called upon to make assessments as to the risks of mass atrocities occurring in a particular situation, and thus assist common and coordinated approaches to implement the RtoP.

Part I examines the relevant standards from across the legal spectrum, and Part II sets forth the standard and the guiding principles for its application to the RtoP.

\section{Part I: Standards from Across the Spectrum}

In approximately forty interviews carried out in the context of this research with representatives from UN Member States, academics and NGOs, including during regional workshops, not one interlocutor identified a current standard against which to measure the analysis of information regarding potential RtoP situations. Only one NGO provided a semblance of a standard and two other NGOs referenced the use of early warning models. Several individuals spoke of responding with "gut" reactions or "feelings." As a result, entirely successful situations of early warning and prevention have not garnered the moniker of the RtoP - as is perhaps the nature of successful prevention at all times. Certain situations of successful prevention of a return to atrocities, such as concerned the fears over potential atrocities and a return to violence in South Sudan or Guinea, have also not received high profiles within the RtoP framework, 
though many suggest that RtoP guided the swift actions taken to avert mass atrocities in each situation. At the other end of the spectrum, rebuilding exercises after atrocities, such as in Macedonia or Burundi, have generally not been seen and discussed as RtoP situations, applying instead long-term peace-building measures to prevent a relapse into violence at critical junctures, such as elections. Nor has the RtoP seemed to guide current action in Burundi where a fragile peace appears precarious.

Debates over the application of the RtoP have been most prominent in situations where conflict and the loss of life have already commenced, and the main issue has been the legality, morality and prudence of coercive forms of intervention, particularly military action. Strong debates have occurred over whether the RtoP was at issue in such situations as Sri Lanka, Burma, Georgia, Somalia, the Democratic Republic of Congo, Côte d'Ivoire, Libya and Syria.

The RtoP remains open to different interpretations, and in the absence of universally accepted criteria to determine when an RtoP scenario is stated to be occurring, differing interpretations are to be expected. The inconsistent application of the RtoP has frequently left situations unaddressed at those times when effective preventive measures could have been undertaken. Additionally, RtoP debates have too frequently focused on the role of the Security Council to the exclusion of other key actors. Thus, in order to permit more energy to be spent on the fundamental question of what is the appropriate action (or inaction) to be taken for any set of facts, promoting all actors to utilize a common standard of application will reduce the confusion over the RtoP that has marked the first decade of its existence. Reducing such confusion will necessarily lead to greater consistency of state action with the RtoP framework, thereby producing a legitimizing effect on the norm's development.

In seeking to determine the most appropriate and fair set of standards for RtoP, we examine below a series of source areas, highlighting the potential overlap in normative, political and legal concerns between each area and that of the RtoP. In this way, the articulated standard finds its foundation upon the most relevant and widely accepted sources. There are of course standards or guidelines of proof or evidence from a variety of fields of enquiry, including science, history, political science and law. However, it is within law that standards of proof are most associated with measuring an act or series of acts against ex ante standards. Moreover, the scope of the RtoP is bound by the four categories of crimes defined in international law and set out in the World Summit Outcome Document (WSOD); thus, when approaching the RtoP, stakeholders are necessarily searching for its practical meaning within the bounds of international law. For these reasons, this project draws on legal areas for the source of its inspiration on the appropriate standard. This does not mean, however, that the standard is legally binding (or intended to be so), or that it should be utilized by legal departments to the exclusion of political officials. Instead, the steady evolution of the RtoP within the General Assembly and across stakeholders has been to implement its moral concerns with practical mechanisms. It is for this reason that examining sources of law makes the most sense.

Before examining the various sources of standards, it is important to disaggregate the different elements encompassed in the analysis of a situation through a potential RtoP lens, and therefore isolate what this chapter in particular is focused on.

- The first element (the substantive dimension) is the type of gross violations of human rights that have been included within the scope of the RtoP. The decision was taken at the 2005 World Summit to limit the scope of the RtoP to four acts: genocide, war crimes, crimes against humanity and ethnic cleansing. Each of these acts has substantive content from legal and policy-based sources.

- The second element (the gravity dimension) focuses on the realization that the RtoP will be rendered essentially meaningless if its three-prong approach of prevent, react and rebuild is only applicable at the point at which the commission of one of the RtoP acts has definitively occurred. Instead, it is imperative to understand that the RtoP must be called into action at a specific level of gravity or seriousness of potential violations, with this level set at below that which would place an individual as criminally liable or a state internationally responsible.

- The third element (the temporal dimension) concerns the standard of proof that is applied to determine when that level of seriousness or gravity set out in the second element has been reached, and therefore when the RtoP framework (and its corresponding set of responsibilities or potential legal 
obligations) is applicable. The standard of proof could range from as low as "potentially applicable" to "definitively proven." This third element concerns the standard of proof required for all potential forms of state or collective action, whether coercive or otherwise.

- The fourth element concerns the consequences of a situation falling within the RtoP. The RtoP is not prescriptive. It does not prescribe which measures must be taken to implement the respective obligations in a particular situation. Rather, it offers a methodology to address an exceptional set of situations more effectively through a continuum of steps. The RtoP moves from the respective state and individual bystander states to the international community when timely and decisive action is required.

While appreciating the holistic and interconnected nature of the four elements set out above, this chapter is focused primarily on the third element. Such a standard is intended to reduce the technical haggling that occurs over whether or not situations are within the RtoP framework by encouraging (if not requiring) all stakeholders to set information about abuses against an articulated standard. As will be set out in Part III below, the application and content of standards of evidence may differ according to the nature and form of the RtoP intervention that is at issue.

As will become clear, the assessment of the likelihood of prospective conduct is by its nature a very different enquiry than the assessment of the evidence to determine whether a fact has been proven about a past event. The enquiry involving the RtoP will often, perhaps always, have elements of both forwardlooking and backward-looking investigations, assessing whether sufficient acts have occurred to fall within the RtoP and whether future atrocities are potentially to occur. Therefore we examine in areas of the law with both prospective and retrospective assessments.

In examining the language that has been used in debates over the applicability of RtoP, we have been struck by the frequency of concepts emanating from criminal law that have appeared to frame the debate. As will be examined in the proceeding section, this urge to turn to criminal law is both dangerous and entirely understandable.

However, it is not clear that the normative rationale for international (or national) criminal responsibility of an individual is analogous to that embodied in the concept of the "responsibility to protect." In seeking to determine the most appropriate and fair set of standards for RtoP, this project will examine a series of source areas, highlighting the potential overlap in normative, political and legal concerns between each area and that of the RtoP.

\title{
The Imperfect Fit of International Criminal Law Evidentiary Standards
}

\author{
The Urge to Turn to Criminal Law in RtoP
}

The use of international criminal law terminology within the WSOD has both comforted and confused all those dealing with the RtoP. The result of both compromise and principle, three of the RtoP acts set out-genocide, war crimes and crimes against humanity-find detailed definition within international criminal law. ${ }^{2}$ Ethnic cleansing is one possible form of crime against humanity, and may be a component of both genocide and war crimes. The limitation to protection from genocide, war crimes, ethnic cleansing and crimes against humanity was introduced in a revised draft Outcome Document towards the end of the negotiations. ${ }^{3}$ The negotiation history suggests that the additional language was introduced in

\footnotetext{
${ }^{2}$ Article $6-8$ of the Rome Statute of the International Criminal Court, adopted by the United Nations Diplomatic Conference of Plenipotentiaries on the Establishment of an International Criminal Court on 17 July 1998.

${ }^{3}$ Revised draft outcome document of the high-level plenary meeting of the General Assembly of September 2005 submitted by the President of the General Assembly, U.N.-Doc. A/59/HPLM/CRP.1/Rev.2 of 5 August 2005.
} 
order to limit the application of the RtoP to exceptional grave situations, where international law had already defined limitations to the principle of sovereignty. ${ }^{4}$

However, this compromise has resulted in much confusion. First, it should be self-evident that the RtoP cannot apply only at the stage at which responsibility under international criminal law for an individual culprit could be established. Such a standard would ensure the immediate demise of the normative concerns embedded within the RtoP, most of all its ability to proactively attempt to prevent imminent or on-going forms of mass atrocities based on existing legal obligations. Second, the level of "seriousness" or scale embodied within each of the acts is not automatically clear when examining the definition of the crimes from within either customary international law or, more narrowly, the Rome Statute of the International Criminal Court. Based on the broad agreement that the RtoP builds on existing legal obligations related to genocide, war crimes, crimes against humanity and ethnic cleansing, it was suggested that any act falling within the definition of these crimes would "trigger" the RtoP. Others expressed concern that the broad definition of war crimes included acts, which had little to do with the population suffering serious harm as described in the work of the ICISS report, such as compelling prisoners of war to serve in the forces of a hostile power or the killing or wounding of combatants who had surrendered.

As a consequence of the use of criminal law language, stakeholders have primarily turned to the standard of proof associated with individual criminal guilt to assess whether or not the RtoP should be invoked-that is, the standard of "beyond a reasonable doubt." It is prima facie clear that this is a very high hurdle to pass in order to see the RtoP doctrine applicable. The normative goals of each system differ so markedly so as to render this standard of evidence inappropriate.

International criminal law is ultimately focused on assessing the individual culpability of those alleged to have committed the most heinous of crimes. This assessment of responsibility will occur after the incidents within which such crimes may have occurred. The potential consequences of a prosecution for an international crime (or domestic crime in fact) are the loss of liberty for the individual, and the social stigma attached to a finding of criminal guilt. Moreover, the goals of criminal sanction-whether retributive, rehabilitative, deterrence-based or another goal-do not align completely with the RtoP's focus on prevention. While certain leaders, governmental or otherwise, may play very important roles in the commission and the ability to end mass atrocities (or prevent them from occurring in the first place), the RtoP is still focused on the protection of potential victim populations, and their threat from large-scale acts of violence. There is little concern with allocating responsibility in terms of restitution or criminal sanction, but instead concern with ensuring the right actors take the most effective action to stop mass atrocity as soon as possible.

Similarly, it had been argued during the drafting period of the Genocide Convention that Article II of the Convention did not contain an abstract definition of genocide, but an enumeration of acts, which allow a finding of genocide based on the specific intent, without the actual destruction of the protected group. ${ }^{5}$ Thus, the drafters attempted to capture risks based on historic experience by means of criminal law rather than ensuring only accountability for perpetrators ex post facto. Similarly, German criminal law defines a category of crimes punishing the creation of an abstract risk rather than the violation of a concrete legal interest. The crime is accomplished, when the hazard has been created by an act considered to create a general risk for certain legal interests, e.g. drunken driving, without the requirement to prove the existence of a specific risk to a particular person or property in the situation at hand. ${ }^{6}$

Despite the divergence of goals and concerns, stakeholders have either felt compelled to use the prosecutor's standard of proof or have hid behind this standard-as either a potential violating state or an entity fearful of triggering its own perceived international legal or moral obligation to act. The implicit use of this prosecutor's standard of proof, if continued, will severely limit the ability of the RtoP doctrine to effectively work at an appropriately early stage of the specific type of situation it had been developed for,

\footnotetext{
${ }^{4}$ E. Strauss, The Emperor's New Clothes? The United Nations and the Implementation of the Responsibility to Protect (2009), p. 11 et seq.

${ }^{5}$ H. Abtahi \& P. Webb, The Genocide Convention: the traveaux preparatoire (2008).

${ }^{6}$ P. Cramer, Der Vollrauschtatbestand als abstraktes Gefährdungsdelikt, (1962).
} 
and will permit stakeholders to inadequately act to protect as opposed to merely retroactively respond to mass atrocities.

\section{The Search for Alternative Sources}

How to assess their relevance and applicability to the RtoP

There are a variety of considerations in determining the relevance of standards of proof from an area of law onto the political and normative framework of the RtoP: the relationship between state and individual responsibility, the ex ante or ex post nature of the judgment, whether it is private or public law at issue, whether domestic or international in origin, and the legal nature of the act concerned. There is a presumption that the stringency of a standard of proof has been chosen to reflect the nature of the consequences that will result if the standard is met.

Despite this understanding, it is quite apparent that while the substantive legal areas that could potentially support the RtoP are relatively well-developed, and developing all the time, the standard of proof or evidence that has been set down for each area at issue is often far more uncertain and obscure. These alternative standards will at least begin to animate our thinking about the standards applicable to the RtoP framework.

\section{Remaining Relevance of International Criminal Law}

Despite the strong case for attempting to limit the application of prosecutorial standards of individual guilt to assess the correct application of the RtoP doctrine, it is important to emphasize the multiple evidentiary standards that are already incorporated within international criminal law and how they will play an important role in this Project. We will limit this examination to the standards associated with the Rome Statute and the International Criminal Court (ICC).

Investigation. As set out in Article 53 of the Rome Statute, the Prosecutor will undertake an investigation unless there is "no reasonable basis to proceed under the Statute." The three elements of the "reasonable basis: are jurisdiction, admissibility and the interests of justice. Decisions of the ICC have begun to give content to the requirements of a "reasonable basis" in the context of jurisdiction and admissibility. The Pre-Trial Chamber approved the investigation into post-election violence in Kenya, but required the Prosecutor to provide additional information and clarification on the question of the Court's jurisdiction. ${ }^{\text {? }}$

The two elements of admissibility are complementarity and gravity of the case. These aspects have also been examined by the ICC; while the substantive content of these two factors has begun to be addressed by the Prosecutor's Office (and is already partially elaborated upon in the Statute itself) and in the decisions of the ICC, the standard of evidence used to determine the correctness of this evaluation (the essence of this project) has not been made clear-but it may be implicit from the decisions of the ICC. Nonetheless, early drafts of paragraphs 138-139 of the WSOD utilized the language of "unable or unwilling" instead of "manifestly failing," and therefore the strong connection between ICC complementarity and "manifestly failing' is clear."

Finally, Article 53 requires that an investigation should not continue if there are "substantial reasons to believe that an investigation would not serve the interests of justice." With "substantial reasons to believe" at a heightened level to "reasonable basis," it is clear that choosing not to undertake an investigation for the "interests of justice" is seen as requiring a greater rationale than undertaking an investigation that passes the jurisdiction and admissibility requirements.

\footnotetext{
${ }^{7}$ Decision Pursuant to Article 15 of the Rome Statute on the Authorization of an Investigation into the Situation in the Republic of Kenya, ICC-01/09 Corr. of 31 March 2010.

${ }^{8}$ Revised draft outcome document of the high-level plenary meeting of the General Assembly of September 2005

submitted by the President of the General Assembly, U.N.-Doc. A/59/HPLM/CRP.1/Rev.1 of 22 July 2005, para. 113.
} 
Arrest Warrant. Once an investigation has been initiated, Article 58 sets out the evidentiary standard required for the issuance of an arrest warrant. The Pre-Trial Chamber is guided by whether it is satisfied that "[there] are reasonable grounds to believe that the person has committed a crime within the jurisdiction of the Court." The evidentiary standard was met in the application against President Omar Hassan Ahmad al-Bashir of Sudan, and the content of this standard can be implied by the evidence presented to the Chamber. ${ }^{9}$ However, the successful appeal by the Prosecutor to the ICC Appeals Chamber over the decision of the Pre-Trial Chamber not to issue the warrant against President al-Bashir on the charge of genocide suggests the strictness of this standard. The Pre-Trial Chamber's holding, that as genocidal intent was not the only reasonable inference available no charge of genocide should be included within the arrest warrant, was rejected by the Appeals Chamber as beyond the requirements of a "reasonable basis" under Article 58. The Appeals Chamber however did not expand on the proper interpretation of the 'reasonable basis' standard, referring the matter back to the Pre-Trial Chamber for future interpretations of the standard. ${ }^{10}$

Indictment/Confirmation of Charges: The Prosecutor at the ICC is tasked with providing the Pre-Trial Chamber "with sufficient evidence to establish substantial grounds to believe that the person committed the crime charged." The decisions in the Lubanga and Bemba cases have begun to spell out what "sufficient evidence" will require, including that the evidence must be "concrete and tangible," and sufficient to demonstrate "a clear line of reasoning underpinning its specific allegations." The Chamber has warned that, at this stage of the proceedings, "it may be impractical to insist on a high degree of specificity." "Substantial grounds to believe" has been tackled by the Chamber through the application of dictionary definitions, supplemented by reference to relevant case law, including that of the European Court of Human Rights. "Substantial" was shown to mean significant, solid, material or strong. ${ }^{11}$

It is important to be reminded, however, as seen in the Abu Garda Pre-Trial Chamber decision on the confirmation of charges, that the concerns of this confirmation process have already narrowed in on one or more particular individuals at this stage. The Chamber's decision concerning Mr. Abu Garda focused on the "scant and unreliable" evidence connecting him to the alleged crimes, and not to their commission at all. ${ }^{12}$

Prosecution. The most stringent standard utilized is that of "beyond reasonable doubt" as required of the Trial Chamber under Article 66. The ICC has yet to reach the stage of assessing the guilt of an individual utilizing this standard

\section{Preliminary Judicial Measures: International and Domestic}

Courts are often asked to impose coercive measures prior to their examination of the substantive merits of a dispute. Fearful that prior to hearing the arguments of both parties actions may be taken that might exacerbate the dispute, the application of preliminary measures is similar to attempts within the RtoP framework to prevent RtoP acts or to prevent the escalation of atrocities.

International. Termed provisional measures under Article 41 of the Statute of the International Court of Justice (ICJ), the ICJ has been regularly called upon to protect parties from potential harm to their rights before the Court has had the opportunity to decide on the case before it. The substantive standard required under the Court's jurisprudence for the application of provisional measures has focused on, first, the potential for "irreparable prejudice," and second, that urgency is present in the need for such provisional measures. ${ }^{13}$

\footnotetext{
${ }^{9}$ Warrant of Arrest for Omar Hassan Ahmad Al Bashir, ICC.02/05-01/09-1 of 04 March 2009..

${ }^{10}$ ICC-02/05-01/09-T-1-ENG ET WT 03-02-2010 1-6 RM PT OA.

${ }^{11}$ The Prosecutor vs. Thomas Lubanga Dyilo, Decision on the Confirmation of Charges, ICC-01/04-01/06 of 29 January

2007; Decision Pursuant to Article 61(7)(a) and (b) of the Rome Statute on the Charges of the Prosecutor Against JeanPierre Bemba Gombo, ICC-01/05-01/08-424 of 15 June 2009.

${ }^{12}$ On 8 February 2010, Pre-Trial Chamber I refused to confirm the charges against Mr Abu Garda. On 23 April, 2010, PreTrial Chamber I issued a decision rejecting the Prosecutor's application to appeal the decision declining to confirm the charges.

${ }^{13}$ B. Kempen/Zan He, The Practice of the International Court of Justice on Provisional Measures: The Recent Development, ZaöRV 69 (2009), p. 919-929.
} 
With respect to the requirement of urgency, the Court has often utilized the standard that prejudicial action is "likely" to be taken prior to the Court delivering a final decision. However, in the context of serious allegations of mass atrocity in the case of Armed Activities on the Territory of the Congo (Democratic Republic of Congo v. Uganda), the Court implemented provisional measures on finding that "there is a serious risk that the rights at issue in this case ... may suffer irreparable prejudice." ${ }^{14}$ This wording suggests a different standard than "likely" in assessments of the Court.

National. US courts may issue preliminary injunctions in civil cases in order to prevent irreparable harm to either party and maintain the status quo prior to the determination of the case. The US Supreme Court has recently required that the party seeking the injunction must demonstrate that this potentially irreparable injury is "likely to occur," and is not a mere "possibility." 15

Courts may issue civil protection orders (CPO) (often referred to as "restraining orders") in order to give relief to past and potential victims of violence, primarily domestic violence. The application for a CPO requires a relationship requirement (to determine the level of protection needed) and an act requirement to state which potential harms are at issue. The party seeking the order has the burden of proving actual or imminent domestic violence most frequently by a "preponderance of the evidence" standard, to show that the facts alleged in the petition occurred and that the behaviour is likely to continue.

The CPO, like the application of the RtoP framework, is both retrospective and prospective, whereas other preliminary injunctions attempt only to predict and prevent future harms. It is clear that the language and understanding of standards of proof to prevent future harms will be distinct from retrospective determinations of whether something did in fact happen. Perhaps most pointedly, the higher standard of proof required for the $\mathrm{CPO}$ over the preliminary injunction corresponds to the greater intrusion on privacy that the $\mathrm{CPO}$ represents. More intrusive and coercive forms of action for the RtoP should also perhaps be associated with stricter standards of proof.

\section{The Duty to Care and Rescue}

In some instances it is possible to hold public authorities responsible for their failure to protect an individual from harms committed by a private actor. This responsibility is in the form of civil actions to seek monetary damages. In addition, seeking to require citizens to act as "good Samaritans," certain (predominantly civil law) countries impose a "duty to rescue" upon individuals, and in certain circumstances, a failure to undertake this duty to help others will lead to criminal sanctions against the timid Samaritan. These duties of care and of rescue share common moral foundations with the RtoP's claims upon national governments to protect their own citizens and on third-states to ensure protection of citizens anywhere in the world. Of course, this sub-section presents many conceptual difficulties in applying domestic, private law actions to the international, public law actions embodied by the RtoP; however, the conceptual and normative commonalities are not unimportant, and are therefore worth exploring.

Public duties of care. Domestic tort law in some states provides the opportunity for individuals to sue the state for failing to protect them from third party harm in certain instances. In the US, the general "public duty rule" means that while the government owes a general duty to all citizens, the limitations of resources and the impossibility of ensuring protection at all times means that no duty is owed to any one individual in particular, and therefore the government cannot be brought to court for a failure to protect. The exception to this rule centres on the state adopting a "special relationship" to the individual, essentially involving an affirmative and direct assumption of protection by the state in a particular instance, and the individual's reliance on this affirmative undertaking that then did not materialize. These suits will involve the four elements of a tortuous action: a duty to act because of the special relationship, a breach of this duty by the public authorities through their omission, the omission was the cause-in-fact of the injury, and actual damage to the individual bringing the suit. The standard of proof needed to prove a "special

\footnotetext{
${ }^{14}$ Armed Activities on the Territory of the Congo (New Application: 2002) (Democratic Republic of the Congo vs. Rwanda), Provisional Measures, Order of 10 July 2002, I.C.J. Reports 2002, p. 219.

${ }^{15}$ Sampson v. Murray, 415 U.S. 61, 90 (1974).
} 
relationship," as well as the standard needed to prove the elements of the lawsuit, is by a "preponderance of the evidence."

In contrast, civil law countries in general have a general duty of reasonable care placed upon municipalities, and such a duty is actionable. Of course proving what conduct is reasonable of a municipal entity will often itself be subject to heavy qualification. When such acts or omissions are actionable, the civil law judge will rely on his or her conviction over whether a fact has been sufficiently proven, and no clear standard of evidence is present.

Duty to rescue. States have long debated whether they should require individuals to seek to rescue those in danger. The common law family of states has generally placed no general duty upon individuals to help others in need. Using the US as emblematic of this set of standards, two general exceptions to this rule apply. First, if an individual volunteers to help, or is herself responsible for the danger itself, then one is required to intervene in some form. Second, if a "special relationship" exists either between the failed rescuer and the victim or the failed rescuer and the aggressor. A complicated set of factors is utilized to determine when this exceptional duty to rescue does exist. In these potential tort actions, the standard of proof applied by the court for each element is generally that of a "preponderance of the evidence."

Many civil law states have made the "duty to rescue" an individual in peril a criminally enforceable requirement. These criminal statutes examine the dangers placed upon the rescuer, and the level of harm placed upon the "victim" requiring the rescuing. There is also a wide gamut of required actions to be undertaken in order to fulfil this duty of rescue or assistance. As set out above, civil law jurisdictions have generally avoided providing detailed indications of the standard of proof required in different actions; instead, they rely on the conviction of the civil law judge that applies the (in this instance criminal) code to a particular action. It can be generally stated that those courts enforcing a criminal penalty concerning the duty to rescue must be persuaded that the evidence, by the "balance of probabilities," suggests that each of the required elements has been proven.

\section{The Obligation to Prevent Violations under International Human Rights Law}

The core concerns of the RtoP are of course animated in the longer history of international human rights. There are, however, specific threads within the human rights framework that play a more forceful role within any discussion of the RtoP.

Some human rights treaties include specific obligations to prevent, e.g. genocide, torture and racial segregation. In its analysis of Article I of the Genocide Convention, the International Court of Justice determined that it implies a positive obligation erga omnes for states to take action to prevent genocide. To prevent genocide is interpreted by the Court to be a positive obligation outside of the obligation to refrain from committing genocide. For determining a breach of the obligation to prevent genocide, the Court moved from a criminal standard of proof "beyond any reasonable doubt" to "proof at a high level of certainty," as the violation of the obligation to prevent did not cause individual criminal responsibility of the state organ. The Court expressly refused to find whether there is a general obligation of states to prevent the commission by other persons or entities of acts contrary to certain norms of general international law. ${ }^{16}$ However, it is arguable that such duties are customary international law obligations incumbent upon all states, and include a duty to prevent all of the RtoP acts.

In addition, the general obligation to "respect" and "ensure" the rights within a treaty has been interpreted to contain a positive duty to take steps towards effective implementation as much as the duty to refrain from acts of violation. On this basis, the obligations upon state actors encompassed within any human right have been broken down into obligations to respect rights by not committing direct violations against individuals, to protect individuals from violations of their rights by third party non-state actors, and to fulfil rights when the state must step in and provide the content of the right. ${ }^{17}$

The question whether the positive duty includes a duty to prevent violations has been interpreted differently by the relevant treaty bodies. The Human Rights Committee and the European Court of

\footnotetext{
${ }^{16}$ Application of the Convention on the Prevention and Punishment of the Crime of Genocide (Bosnia-Herzegovina vs. Serbia), Judgment, I.C.J. Reports 2007, p. 43.

${ }^{17}$ E. Klein (ed.), The Duty to Protect and to Ensure Human Rights, (2000).
} 
Human Rights (ECtHR) did not accept a general obligation to prevent violations of the rights guaranteed by their respective treaties, but found specific preventive obligations deriving from the application of particular rights to specific situations. ${ }^{18}$ By contrast, the Inter-American Court of Human Rights (IACrtHR) did accept a general obligation of states to prevent, investigate, punish and remedy violations of human rights under the American Convention on Human Rights.

These standards of behaviour having been set down, Courts have indicated differing standards of proof in the area of the duty to protect. The IACrtHR in Velasquez Rodriguez stated it was "convinced" and that the facts were "clearly proven"; this corresponded to the Court's stating that such serious charges required a standard of proof "capable of establishing the truth of the allegations in a convincing manner." The ECtHR in Osman stated that the lack of reasonable pre-emptive steps "must be established to [the Court's] satisfaction."

Similar to the outline of different pillars of the RtoP, the primacy of the state to fulfil its duty to protect is not absolute and international mechanisms can be used to compensate for lack of effective action. Some UN human rights treaty bodies can receive complaints of individuals that rights of the respective treaty were violated. ${ }^{19}$ The admissibility of such complaints depends inter alia on the exhaustion of domestic remedies. According to the jurisprudence of the treaty bodies, local remedies must only be exhausted to the extent that they are both available and effective; it is an established principle in this context that complainants must exercise due diligence in the pursuit of available remedies. Treaty bodies request complainants to "demonstrate" that they exhausted all available domestic remedies, but accepted arguments that further recourse to domestic remedies would have been futile in the light of previous precedent. Treaty bodies also considered extensive delays in decision-making indicators for the lack of available effective remedies. ${ }^{20}$

The "duty to protect" is just one element of a state's obligations to assist in the prevention of possible human rights violations occurring beyond its direct actions or omissions. It is self-evident that the rationale for protection of human rights and of the impetus for the doctrine of the RtoP is similar if not identical; the duty to protect concerns a state's obligations to help even when they are not the direct actor causing the violations and thus mirrors the role the international community is meant to play under the RtoP.

It is important to note therefore the general standard of proof applied by human rights tribunals in finding a state responsible for those violations that would reach the seriousness of the RtoP acts has usually been proof "beyond a reasonable doubt," as seen for example in the ECtHR's decision of UKv Ireland (1978) concerning torture or inhuman or degrading treatment or punishment.

\section{Torture and Non-Refoulement Obligations}

The international prohibition of torture is reflected in different international conventions. One aspect of this absolute ban has been the obligation placed upon states not to expel or return an individual to another state if there is a danger that the individual will be tortured in the latter state. The prospective nature of the evidentiary standard applied by bodies deciding whether to impose a non-refoulement

\footnotetext{
${ }^{18}$ See e.g., C.F. et al. vs. Canada, No. 113/1981, U.N.-Doc. CCPR/C/24/D/113/1981 of 12 April 1985, para. 6.2

${ }^{19}$ Five of the human rights treaty bodies may consider individual complaints or communications from individuals, including the Human Rights Committee relating to States parties to the First Optional Protocol to the International Covenant on Civil and Political Rights; CEDAW may consider individual communications relating to States parties to the Optional Protocol to the Convention on the Elimination of Discrimination Against Women; CAT may consider individual communications relating to States parties who have made the necessary declaration under article 22 of the

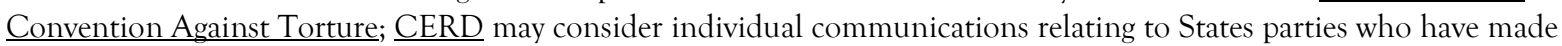
the necessary declaration under article 14 of the Convention on the Elimination of Racial Discrimination; CRPD may consider individual communications relating to States parties to the Optional Protocol to the Convention on the Rights of Persons with Disabilities; the Convention on Migrant Workers also contains provision for allowing individual communications to be considered by the CMW, which will become operative when 10 states parties have made the necessary declaration under article 77.

${ }^{20}$ M. Nowak, U.N. Covenant on Civil and Political Rights. CCPR Commentary, $2^{\text {nd }}$. revised edition (2005), Art. 5 First OP, para. 23.
} 
obligation on an individual correlates strongly with the decision stakeholders must make over whether or not to intervene to prevent future atrocity crimes. In both situations, the establishment and assessment of facts related to the past and present have to be used to determine the probability of certain events occurring in the future.

The Convention Against Torture requires that no one shall be expelled if there are "substantial grounds for believing that he would be in danger of being subjected to torture." ${ }^{21}$ The Committee monitoring this Convention has noted that this standard entails a "foreseeable, real and personal risk." The risk must be assessed on grounds surpassing "mere theory or suspicion" or "a mere possibility"; the risk need not be "highly probable" or "highly likely to occur," however. The Committee does not require that all the facts invoked by the author of a communication be proved; rather, facts should be "sufficiently substantiated and reliable." The Committee will look at a non-exhaustive list of criteria it considered pertinent to assess the personal risk to an individual of being tortured, including evidence of a consistent pattern of gross, flagrant or mass violations of human rights in the receiving state, previous instances of torture/ mistreatment involving the author, medical or other independent evidence to support a claim of past torture/ mistreatment, current assessment of the author's situation and/or the internal situation of the receiving state with respect to human rights, personal vulnerability of the author, and evidence of the author's credibility. ${ }^{22}$

The ECtHR has also interpreted its Convention's prohibition against torture under Article 3 to include a non-refoulement obligation. The standard of proof utilized by the Court is to impose the obligation if there are "substantial grounds [to believe] that an individual would face a real risk of being subjected to treatment contrary to Article 3." Of course, the Court itself (most prominently in the concurring opinion of Judge Zupancic in the case of Saadi v. Italy ${ }^{23}$ ) has acknowledged that this prognosis or probabilistic exercise is not the usual retrospective domain of assigning legal responsibility. The Court explained that using all evidence available, it would "examine the foreseeable consequences" of the proposed expulsion, "bearing in mind the situation [in the receiving country] and [the applicant's] personal circumstances." Thus, although necessarily speculative, the assessment must be conducted with care and rigor.

Domestic courts have actively interpreted and implemented their obligations under the Refugee Convention to ensure asylum for those with a "well-founded fear of persecution" on the grounds of race, religion, nationality, political opinion or membership in a social group. The US Supreme Court has required an individual to show that this fear is based on a "reasonable possibility" of occurrence. Moreover, the US State Department has explained that the "substantial grounds to believe" standard from the Torture Convention should mean the risk is "more likely than not" to come to fruition. Meanwhile, the UK House of Lords requires the risk to have a "reasonable chance" or a "serious possibility" of coming to fruition.

These predictions are intended to protect individuals from serious harms, which, while not reaching the level of the RtoP acts at all times, may certainly form elements of such acts.

\section{International Environmental Law: Transboundary Harm}

It is a clearly established obligation of international law that states are required to take adequate steps to control and regulate the effect of their actions upon the physical environment of other states. International conventions dealing with specific areas of the environment have emphasized that the nature of environmental problems are such that reparations and restitution will often be inadequate to compensate for irreversible damages. Therefore, a norm of harm prevention is ever present in examining the obligations states have to protect the environment; this core conception of harm prevention is a central component of the RtoP. In an analogous fashion, the harms included within the RtoP acts cannot be made whole by reparations or (the often impossible) restitution, and thus the standards utilized for transboundary harm may assist in the construction this Project is working on.

\footnotetext{
${ }^{21}$ Art. 3, para. 1, CAT

${ }^{22}$ See e.g. Z.K. vs. Sweden, no. 301/2006, CAT/C/40/D/301/2006 of 16 May 2008.

${ }^{23}$ Saadi v. Italy [GC], no. 37201/06, ECHR 2008.
} 
The standard of proof used to assess this prevention obligation in the context of environmental law and transboundary harm has not been readily examined by tribunals or courts, with the ICJ's opinions in international environmental law so far focused on specific treaties and not general standards. However, it can be inferred that the Court has not treated this area of concern as one for which a heightened standard of proof is appropriate, as it has not invoked the need for a strict standard given the "exceptional gravity" of the issue at hand (as had been the case with questions involving the use of force or genocide, as discussed below).

A further relevant concept from within international environmental law is that of the "precautionary principle." This principle stands as a reaction to the very high standard of proof previously required in environmental cases, one that did not appreciate the reality of scientific uncertainty, and therefore limited the ability of states to require prevention of environmental damage. The principle stands to require or permit preventive action even in the face of scientific uncertainty in the foreseeability of harm and the likelihood of its gravity. In essence, the utilization and application of this principle works to lower the standard of proof required before preventive action must be undertaken.

\section{The Duty to Prevent or React to Serious or Gross Violations of Human Rights and Humanitarian Law}

This subsection examines the standards applied when assessing gross violations of human rights or international humanitarian law, including outside the territory of a state or committed by non-state actors. This is directly relevant to the RtoP since the RtoP concerns the actions of third or bystander states in their individual or collective roles outside their respective territory.

Tribunals examining these questions are faced with allegations over situations that have already occurred, and usually have already come to a conclusion. In addition, the role of individual criminal responsibility has already been addressed above. In addition, we have examined obligations placed upon states not to contribute by their actions to harming other states, in this chapter within the context of international environmental law and transboundary harm. Instead, this subsection introduces state responsibility for those violations included within the RtoP.

It has already been noted that the ECtHR has applied the standard of "beyond a reasonable doubt" in addressing allegations of violations all of its range of human rights. This standard as to the proof of the facts of alleged violations has been applied for both allegations committed within the territory of a signatory of the ECHR or for violations committed outside the territory of the state charged with the violation.

Some of the most difficult questions in addressing these areas concern states' obligations outside their territorial borders, and their responsibilities for conduct not directly carried out by the state itself. These questions are of particular relevance to the implementation of the RtoP, as states are particularly sensitive to the issues surrounding any decision to intervene in other states in order to protect populations from potential or existing mass atrocity and non-state actors are involved in committing these crimes.

The question of control over territory outside the sovereign borders of a state can be seen in the ECtHR's cases (e.g. Loizidou ${ }^{24}$ and Bankovic ${ }^{25}$ ) and in the ICJ's case law (e.g. the Israeli Wall case ${ }^{26}$ ). The second element is one of attribution of conduct undertaken by a non-state actor or a third-state so as to lead to a state itself being held responsible for the allegedly illegal international conduct. This is an area set out in detail under the ILC's Draft Articles on the Responsibility of States for Internationally Wrongful Acts, as well as jurisprudence from the ICJ (e.g. Bosnia-Herzegovina v. Serbia and USA v.

\footnotetext{
${ }^{24}$ Loizidou v. Turkey (merits), decision of 18 December 1996, Reports of Judgments and Decisions 1996-VI.

${ }^{25}$ Banković and Others v. Belgium and 16 Other Contracting States, no. 52207/99, ECHR 2001-XII

${ }^{26}$ Legal Consequences of the Construction of a Wall in the Occupied Palestinian Territory, Advisory Opinion, I.C.J. Reports 2004, p. 136.
} 
Nicaragua ${ }^{27}$ ), the ECtHR (e.g. Ilascu), ${ }^{28}$ and the International Criminal Tribunal for the Former Yugoslavia in the Appeal Chambers' Judgment in the case of Tadic. ${ }^{29}$

These tests of attribution and control have implicitly been answered using the same standards of proof associated with the serious allegations of state misconduct at issue.

The Complaints Procedure to the UN Human Rights Council (HRC) replaced the former 1503 procedure in addressing "consistent pattern of gross and reliable attested violations of human rights and fundamental freedoms." ${ }^{30}$ While the procedure its confidential in nature, the admissibility criteria include a factual description of the alleged violations, including the rights which are alleged to be violated; it must be submitted by a person or a group of persons claiming to be the victim of violations and claiming to have direct and reliable knowledge of those violations, accompanied by clear evidence; and domestic remedies have been exhausted, unless it appears that such remedies would be ineffective or unreasonably prolonged.

Some UN human rights treaty bodies developed early-warning and early-action procedures to prevent and respond to violations of treaty obligations. In 1993, the Committee on the Elimination of Racial Discrimination (CERD) developed a procedure relating to early-warning measures and urgent action for situations requiring immediate attention to prevent or limit the scale or number of serious violations of the Convention. The procedure was established as a response to the call of the Secretary-General to contribute to the prevention of genocide by responding early and effectively to discrimination. CERD identified indicators for patterns of systematic and massive racial discrimination relevant in the context of genocide. In each situation brought to its attention, the Committee 'assesses their significance in light of the gravity and scale of the situation, including the escalation of violence or irreparable harm that may be caused to victims of discrimination on the grounds of race, colour, descent or national or ethnic origin.' According to its own account, the Committee addressed situations falling within the scope of mass atrocities, such as the bombing of villages, the use of chemical weapons and landmines, extrajudicial killings, rape and torture committed against minorities and indigenous peoples. ${ }^{31}$

The International Covenant on Civil and Political Rights can request reports from States Parties at any time the Committee deems appropriate, which forms the basis of its emergency procedure developed in 1991. So, far urgent reports have been requested from about 20 states, including the provision of specific information on specified articles of the Covenant within three months. However, the Committee did not reveal the standards applied to request urgent reports; it referred to 'recent and continuing events. ${ }^{32}$ Meanwhile, the Committee on the Elimination of Discrimination Against Women has developed a similar procedure in order to obtain and examine information on an actual or potential violation, where there is special cause for concern. ${ }^{33}$

Different UN entities mandate commissions on inquiry to establish whether gross or serious violations of human rights and humanitarian law have been committed and to identify perpetrators. As a general approach, the commissions examine existing reports on violations of international human rights and humanitarian law and to verify the veracity of these reports through their own findings, and establish further facts. The commissions select incidents and areas they deem most representative of acts, trends and patterns relevant to the determination of violations of international human rights and humanitarian law and with greater possibilities of effective fact-finding. For example, the ICI on Darfur has identified "likely suspects" based on "a reliable body of material consistent with other verified circumstances, which

\footnotetext{
${ }^{27}$ Military and Paramilitary Activities in and against Nicaragua (Nicaragua v. United States of America). Merits, Judgment. I.C.J. Reports 1986, p. 14.

${ }^{28}$ Ilascu and Others v. Moldova and Russia, no. 48787/99, ECHR 2004-VII.

${ }^{29}$ Judgment, The Prosecutor v. Dusko Tadic, Case No. IT-94-1-A, ICTY Appeals Chamber, 15 July 1999.

${ }^{30}$ See Inter-sessional open-ended intergovernmental working group on the implementation of operative paragraph 6 of General Assembly resolution 60/251 established pursuant to Human Rights Council decision 1/104. Non-paper on the complaint procedure, U.N.-Doc. A/HRC/5/15 of 6 June 2007.

${ }^{31}$ Guidelines for the early-warning and urgent-action procedures, Annual report A/62/18, Annexes, Chapter III.

${ }^{32}$ Rule 66, para. 2, of the Rules of Procedure.

${ }^{33}$ A/54/38/Rev., Chapter I.
} 
tends to show that a person may reasonably be suspected of being involved in the commission of a crime." ${ }^{34}$

Within human rights law, the Committee on Economic, Social and Cultural Rights has examined the obligations included within the Covenant with respect to 'international assistance and cooperation,'35 obligations that flow from the undertakings of Articles 55-56 of the UN Charter itself and additionally advanced by specific General Assembly resolutions on economic development. However, the Committee did not indicate what standard of proof would apply in the situation, for example, when one state sought to demand the implementation of this concept against a set of duty-holders.

Turning to identifiably serious breaches of international law, the ILC's Draft Articles on State Responsibility ${ }^{36}$ under Articles 40-41 focuses on "serious breaches of obligations under pre-emptory norms of general international law" - and all states' duty to cooperate to end these violations. The breach must be of a pre-emptory norm of international law (frequently referred to as a jus cogens violation), and it must be serious. "Serious" is defined as a "gross or systematic failure by the responsible state"; it is self-evident that the question of whether RtoP acts are occurring and whether a state is "manifestly failing" to protect its population will have great commonalities to this examination. Of course the standard of proof that will be applied to determine finding under these Articles will depend on the context in which they are invoked: i.e. use by an organ of the United Nations will have different standards than by an international judicial tribunal or arbitral body.

\section{The Use of Force: Ex Ante $\mathcal{E}$ Ex Post Evaluations}

The use of force under international law is valid, in the age of the UN Charter, in only very limited circumstances. Its potential validity can be placed into two categories: the inherent right of self-defense (either individual or collective), or as authorized by the UN Security Council as provided for by Chapter VII of the Charter, including to protect populations at risk from RtoP acts.

To work backwards, tribunals have been asked to assess the question over the validity of a claim of selfdefense on several occasions, but there have not been (at this time) judicial findings on the validity of Security Council-authorized uses of force. The ICJ examined the alleged illegal use of mines in the Corfu Channel case, decided in $1949^{37}$ - although the case did not centre on the assertion of self-defense by Albania. Here, the Court declared its need for allegations to be proven by "conclusive evidence" and a "degree of certainty." The Court's assertion of a standard of proof in this case was unfortunately missing in their more recent cases over Military and Paramilitary Activities and Oil Platforms ${ }^{38}$; both "sufficiency" and "conclusiveness" were invoked, but any choice or clarification of this standard has so far been lacking.

It is the exclusive competence of the Security Council under Article 39 of the UN Charter to determine the existence of a threat to international peace and security. However, the General Assembly is not prevented from making determinations for the purposes of its own functions. Both organs have considered situations of mass atrocities in the past in the context of their mandates to maintain international peace and security. However, analyzing these cases in more detail does not allow a clear conclusion that instances of mass atrocities always constitute threats to international peace and security. In past cases, the Security Council referred to 'massive flows of refugees towards or across international frontiers' or 'the consequences for the countries of the region" or underlined "the unique character of the present situation.' In addition, the standards of proof applied by the Security Council and the General Assembly remains unclear.

\footnotetext{
${ }^{34}$ Report of the International Commission of Inquiry on Darfur to the United Nations Secretary-General pursuant to Security Council Resolution 1564 of 18 September 2004, Geneva, 25 January 2005.

${ }^{35}$ Art. 2, para. 1 CESCR.

${ }^{36}$ Text adopted by the International Law Commission at its fifty-third session, in 2001, and submitted to the General Assembly as a part of the Commission's report covering the work of that session (A/56/10). The report, which also contains commentaries on the draft articles, appeared in the Yearbook of the International Law Commission, 2001 , vol. II, Part Two, as corrected.

${ }^{37}$ Corfu Channel case, Judgment of April 9th, 1949: I.C.J. Reports 1949, p. 4.

${ }^{38}$ Oil Platforms (Islamic Republic of Iran v. United States of America), Judgment, I. C. J. Reports 2003, p. 161.
} 
From an ex ante perspective, it would be useful to set out the standards of proof required to support a claim for self-defense under the customary international law rule embodied in Article 51 of the UN Charter, or for the use of force as authorized by the Security Council. While there is a voluminous amount of material on the requirements that must be shown for such undertakings, in neither case has there been any robust indication of whether any standard of proof is in fact needed at all, or to whom this proof would be submitted and/or examined. The same problems that surround this issue are present in all coercive measures of prevention and reaction that may be taken under the RtoP framework.

\section{International Organizations and Responsibility}

A final potential area from which to glean insight for this project comes from the consistently evolving area of the international legal responsibility of international organizations. The question of whether and when international organizations can be held responsible for actions or omissions under international law is complex and controversial. Indeed, the ILC's Draft Articles on the Responsibility of International Organization ${ }^{39}$ have received a multitude of comment and critique, although they have been referred to by certain national courts and the ECtHR in turn.

Despite the title of the ILC's work, and in turn the title of this subsection, it is as important to examine the question of holding states responsible for actions taken in conjunction with or in the context of international organization activity, provisionally set out in Articles 57 to 62 of the Draft. With respect to the RtoP, given the framing of paragraph 139 to involve the Security Council as the primary actor to address RtoP acts in the face of manifest failure, this topic would be potentially applicable in situations whereby the UN or a regional organization fails to act appropriately in the face of RtoP acts, or in situations whereby a state incurs responsibility for actions taken or omissions through international organizations. Yet the question of whether and what obligations are placed on different international organizations in the area of the RtoP is a separate topic outside the scope of this concept chapter.

There has been an increasing volume of case law concerning the attempts to hold states responsible for actions conducted under the auspices of international organizations. These cases have utilized the standards of proof that is associated with the primary rule of conduct at issue, i.e. if concerning core human rights at the ECtHR, that Court applied the "beyond a reasonable doubt" standard. There has not yet been a separate examination or analysis on the standard of proof for the assessment that might be utilized to determine whether a state is failing its international obligations in the context of an act of an international organization, or for the responsibility of an international organization independently for its acts. Whether this standard of assessment should necessarily be identical to that associated with the responsibility of a state will remain an open question at this time.

\section{Part I: Conclusion}

The analysis of different evidentiary standards has shown that the determination of the risk of a violation of international legal obligations in the future based on present facts and circumstances has been addressed successfully by international and national courts. Standards that seek to determine the prospect of serious crimes and seek to avoid such crimes prospectively, the risk that must be demonstrated ranges from the low end of "reasonable possibility" to the high end of "substantial risk." In the middle lies the "real risk." In general, courts, both international and national, engage in balancing of the probability of an event occurring based on the evidence available at the time of the decision, with the level of harm that would occur if such a situation would develop. In the context of the RtoP, the level of harm that would occur must be, by definition, exceptionally grave. At the same time, engagement to prevent such crimes must be measured and reasonable in light of the precautionary principle as well as the prerogatives of sovereignty. As a result, the mid-level standard of "real risk" makes the most sense and is most fair, as it

\footnotetext{
${ }^{39}$ Adopted by the International Law Commission at its sixty-third session, in 2011, and submitted to the General Assembly as a part of the Commission's report covering the work of that session (A/66/10). The report, which also contained commentaries to the draft articles (para. 88), will appear in Yearbook of the International Law Commission, 2011, vol. II, Part Two.
} 
requires individualizing risks and considering concrete scenarios. Additionally, it mirrors the language of the jurisprudence in similar cases, in particular non-refoulement.

\section{Part II: The Standard and Guiding Principles for the Application of the RtoP}

According to past experience, mass atrocities do not evolve in a linear fashion and they hardly encompass a whole country at one given time. Therefore, preventive measures cannot be distinguished in neat categories of structural and direct prevention. What appear to be ongoing mass atrocities in one part of a country could only be the precursor of similar violence in another part; post-conflict peace-building, longterm and sustainable in its impact, might have the objective of preventing directly the relapse into mass atrocities.

The RtoP can contribute to address a situation of mass atrocities in any stage of its development. The urgency and gravity of the situation can only be determined concretely according to the circumstances in a particular country in a given time. This assessment determines the nature and timeline of activities required by the government or, as subsidiary, bystander states and/or the international community collectively.

A state's responsibility to protect its own population is based on existing legal obligations, which prevail independently of the RtoP at all times. It therefore is necessary to reflect a standard of application related to these primary legal obligations. At the same time, with regard to the objectives of the RtoP outlined above, the standard should focus on the future risk aspect of the prevention component of the RtoP and combine prospective and retrospective elements. The definition of consecutive, measurable steps is both preventive and reactive; collective action must balance the urgent imperatives of population protection against the legal and normative value of sovereign equality and territorial control. The subject of evidence is the foreseeable consequences of present action, which generally requires a lower threshold of evidence but a higher risk requirement. The standard should also reflect and address the tension between flexibility and prescriptive rigor. As the authors discovered, the need for flexibility is more relevant in respect of the response not necessarily in the question of whether RtoP acts are imminent or occurring.

It was reiterated explicitly in the Secretary-General's 2009 report on Implementing the Responsibility to Protect that the threshold for RtoP measures under Chapter VI is lower than for enforcement action under Chapter VII. At the same time, the pillars outlined in the report have not been interpreted as neatly separated sets of activities that will be applied according to linear developments on the ground moving the situation from one pillar to the next according to clearly defined thresholds. Therefore, it is not necessary for the standard to be different for the forms of intervention indicated in the different pillars. Instead, the standard provides for a framework to determine existing risk levels as a basis for assessing future developments with an acceptable level of certitude. Given the specific rules within international law on the use of force as well as evident unwillingness presently (as of February 2012) to adopt guidelines on the use of military force under the RtoP set out in the 2001 ICISS report and elsewhere, and the approach of the RtoP to define a continuum of measurable steps to mitigate risk factors of mass atrocities, it was not required to assign separate standards of proof for this category. Any situation can be assessed for risks of mass atrocities following the proposed standard. It is for the relevant stakeholders to determine, based on their assessment, the appropriate time for different forms of more or less intrusive action to prevent or halt mass atrocities. Given the need to target limited resources to those states and situations that truly require forceful early prevention against mass atrocity, the standard can as well be very useful in assessing where international assistance and capacity-building should best be utilized.

The following provides a standard against which incoming information may be assessed in respect of RtoP. The accompanying guidelines offer an approach to assess whether a situation would benefit from applying the RtoP and suggests a procedure how to identify required action. 


\section{Application}

1. This standard provides a systematic and coherent approach to incoming information that can be utilized on a case by case basis for assessment and analysis of potential RtoP situations. The application of the standard aims to increase transparency and accountability of deliberations on the application of the RtoP to a given situation and promote consistency in state action.

2. This standard is intended to be utilized by states, international and regional organizations, civil society, academia and other actors called upon to determine the applicability of the RtoP. The standard may assist common and coordinated approaches to implementing the practical steps embodied in the RtoP.

\section{Standard of Assessment}

1. The situation will be considered in the context of the RtoP, if the examination of the situation establishes a real risk that exceptionally grave human rights violations, as described in genocide, war crimes, crimes against humanity and ethnic cleansing, are occurring or could occur in the future.

2. The assessment of available information aims at the determination of the likelihood of future conduct. This determination will build on evidence of past events as relevant.

3. For fact-finding on present and past events, the standard of reasonable suspicion should be applied, which is met when a reliable body of evidence indicates the occurrence of a particular incident or event. Relevant facts cannot be established solely on the basis of reports in mass or social media and must be corroborated.

\section{Principle 1: Determination of relevant human rights violations}

1. The objective of the determination of relevant human rights violations is not the identification of separated legal categories of mass atrocity crimes on the on hand and other human rights violations on the other, but a common consciousness of the risks involved in any massive violation of human rights.

2. The following human rights violations have been of particular relevance in past cases of mass atrocities: killings, torture, mutilation, rape and sexual violence, abduction, forced population movement, expropriation, destruction of property, looting, lack of freedom of speech/ press/ assembly/ religion, destruction of subsistence food supply, denial of water or medical attention, man-made famine, redirection of aid supplies, discrimination in access to work and resources, political marginalization, restricted movement, discrimination in education and lack of access to justice and redress.

\section{Principle 2: Determination of the level of gravity or seriousness of potential violations}

1. The persecution of large parts of the population based on identities applied by the perpetrators is the main element of the exceptional situations relevant to the application of the RtoP.

2. The significance of human rights violations will be assessed in light of the number of potential victims of violence or level of irreparable harm that may be caused to potential victims taking into account the following risk-factors: identification of the victims based on identity criteria linked to race, colour, descent, religion, ethnic, or national origin, gender, sexual orientation or other ground and their association with a specific political opinion or group; public hate speech, incitement to violence, or humiliation of a group publicly or in the media; exclusionary ideologies that purport to justify discrimination; a past history of violence against perceived groups; and a climate of impunity in which these events unfold.

3. The following circumstances can increase the risk-level for potential victims: Armed conflict, which may disproportionately affect a specific group or a large part of the population; existence of and support to militias that could carry out attacks against potential victims; elections. 


\section{Principle 3: Application of the RtoP}

1. The RtoP requires states to take concrete measures to mitigate the real risk of mass atrocities, based on existing legal obligations. The RtoP encourages a concept of consecutive, measurable steps by national and international actors, based on existing resources and strategies, but does not itself prescribe particular measures.

2. The nature and timeline of the steps depends on the gravity and urgency of the situation. Such measures could include: public acknowledgement and condemnation of human rights violations; clear and public orders to military, police or security forces to respect international human rights and humanitarian law; immediate enforcement of accountability for the most relevant violations; ensuring humanitarian assistance and protection for victims of violence; and, in cooperation with relevant stakeholders, including potential victims and drawing an action plan with timelines for mitigating the most urgent risk factors.

3. Action of the international community is subsidiary to action by the national government, i.e. to support and complement rather than substitute.

\section{Principle 4: Determination whether a State is "manifestly failing" to meet the RtoP}

1. In case the national authorities are manifestly failing to meet their responsibility to protect, the responsibility is moving to the international community.

2. The determination - whether a state is "manifestly failing" - should be based on the information of relevant human rights violations, the state of implementation of measurable steps to mitigate risk factors, and its impact on the real risk that exceptional grave violations of human rights could occur in the future. Based on the outline of consecutive measures to mitigate the real risk of exceptionally grave human rights violations, the compliance of national governments and the international community can be established. Manifest failure occurs when foreseeable consequences have not been addressed and the risk level prevails or increases.

3. The impact of measures taken by the government and their impact on the risk-level should be monitored on a permanent basis against the timelines and indicators of the concept. 


\title{
Libya and the Responsibility to Protect: Lessons for "Pillar Three"
}

\author{
RUBEN RIEKE
}

\section{Introduction}

Until 2011, debate on the third pillar of RtoP was rather neglected. The United Nations chose to promote and build consensus around the controversial principle by emphasising its preventive and noncoercive aspects. ${ }^{1}$ In particular, it was suggested that the prevention of mass atrocity crimes is the most important dimension of RtoP, and that prevention is primarily based on pillars one and two (state responsibility and long-term capacity-building). ${ }^{2}$ The main focus therefore was on addressing the so-called root causes of mass atrocities, managing diversity, building capacity in at risk states, and supporting (not coercing) sovereign states to protect their populations. As the RtoP's sharper end, "pillar three" seemed too close to the dead-end debate on humanitarian intervention and too controversial to convince critics to weaken their resistance to RtoP.

In 2011, however, "pillar three" has made a meaningful comeback. The humanitarian crises in Côte d'Ivoire and Libya triggered coercive international responses that can be seen as good examples of the operationalization of RtoP's third pillar. ${ }^{3}$ In Côte d'Ivoire, UN peacekeepers and French troops launched military attacks against forces loyal to President Laurent Gbagbo in order to protect civilians. ${ }^{4}$ In Libya, the international community adopted a whole range of "pillar three" measures - from targeted sanctions and ICC referral to a no-fly zone and military intervention - in order to prevent the Gaddafi regime from committing mass atrocity crimes. ${ }^{5}$ According to Ramesh Thakur, Libya was 'the first time the Security Council authorized an international RtoP operation'. ${ }^{6}$ Whilst some are worried that the comeback of "pillar three" may trigger a wave of neo-militarism, ${ }^{7}$ others applaud this development as a welcome broadening of the debate to include RtoP's coercive edge. ${ }^{8}$ Regardless of where one stands on this issue, Libya in particular seems to be a crucial case to study for generating conceptual and operational lessons about RtoP's third pillar, which is what this chapter aims to do.'

In what follows, the chapter shows that Libya teaches at least three lessons about RtoP's third pillar. First, and more conceptually, Libya shows that "pillar three" deals not only with responses to ongoing mass atrocities, but contains an important preventive dimension as well. The prevention tools that the

\footnotetext{
${ }^{1}$ According to Jennifer Welsh, 'The current Secretary General, Ban Ki-moon, hopes that by focusing his implementation plan on so-called Pillars One and Two, and downplaying Pillar Three, he can build greater support for the principle among UN member states'. See, J.M. Welsh, "A Normative Case for Pluralism: Reassessing Vincent's Views on Humanitarian Intervention”, International Affairs, Vol. 87, No. 5, (2011), p. 1201.

${ }^{2}$ See, Ban Ki-moon, Implementing the Responsibility to Protect: Report of the Secretary-General, A/63/667, 12 January 2009 , p. 9. ${ }^{3}$ See, A. Bellamy \& P. Williams, "The New Politics of Protection? Cote d'Ivoire, Libya and the Responsibility to Protect", International Affairs, Vol. 87, No. 4 (2011).

${ }^{4}$ Self-defence was another justification provided for the decisive military action in Cote d'Ivoire. See, Bellamy and Williams, "The New Politics of Protection?", pp. 829-838.

${ }^{5}$ For a comprehensive discussion of the preventive engagement in Libya. See: R. Reike, "Libya and the Responsibility to Protect: Lessons for the Prevention of Mass Atrocities”, St Antony's International Review, Vol. 9, No. 11, (2012), pp. $122-149$.

${ }^{6}$ R. Thakur, "R2P, Libya and International Politics as the Struggle for Competing Normative Architectures", e-International Relations, 7 September 2011. See: www-e-ir.info/?p=13728.

${ }^{7}$ See, Ms. Louise Arbour's remarks at the Stanley Foundation conference on 'R2P: The Next Decade', New York, January 18, 2012. See: http://fora.tv/2012/01/18/R2P as a Tool Identifying Past and Potential Value.

${ }^{8}$ See: T.G. Weiss, Humanitarian Intervention: Ideas in Action, $2^{\text {nd }}$ edn. (Cambridge: Polity Press, 2012); and T.G. Weiss, "R2P Alive and Well After Libya”, Ethics $\mathcal{E}$ International Affairs, Vol. 25, No. 3, (2011), pp. 1-6.

${ }^{9}$ The author should state from the outset that this paper does not address the question of whether and how international action "á la Libya" could potentially be repeated. In my view, the question of consistency is often over-emphasised in RtoPrelated debates, as an element of inconsistency is in fact built into RtoP's third pillar. The 2005 World Summit Outcome Document clearly states that decisions on pillar three will be made on a case-by-case basis.
} 
international community employed in Libya were all of a "pillar three" kind. This indicates that at an immediate stage where potential perpetrators, potential victims and situational crime factors can be identified with some clarity, "pillar three" tools are most appropriate to change the cost-benefit analysis of potential perpetrators, reduce the vulnerability of potential victims and decrease the permissiveness of crime situations. Thus, it is important to approach "pillar three" with a mind-set of prevention. Second, and more operationally, Libya suggests that preventing mass atrocity crimes might require the international community to take sides in internal struggles and apply certain "pillar three" tools partially. Libya also forces us to discuss the difficult question of whether regime change needs to be the ultimate tool of the "pillar three" toolbox, namely in cases where potential perpetrators prove unwilling to change course. This challenges the UN approach to most situations of armed conflict. Third, Libya reveals that "pillar three" prevention efforts might entail agonizing dilemmas and unintended consequences. The "responsibility to prevent" is therefore likely to be much more controversial than it is often depicted. The Brazilian initiative on "Responsibility While Protecting" (RWP) should be applauded as a useful starting point in addressing such dilemmas, and thereby making future "pillar three" activities more likely.

This argument will be developed in four parts. To begin, the chapter briefly discusses the international preventive engagement in Libya to show that "pillar three" in fact contains an important preventive dimension. In the next section, the analysis turns to the actual application of "pillar three" prevention tools to demonstrate how preventing mass atrocity crimes might require the abandoning of the central conflict prevention principles of consent and impartiality. In the subsequent part, there is discussion about the problems and unintended consequences that resulted from the preventive engagement in Libya. To conclude, the chapter summarizes the main findings of the analysis.

\section{Pillar Three and Late-Stage Prevention}

The world's early warning mechanisms for mass atrocity risk all failed to identify Libya as a country of concern. Neither quantitative nor qualitative risk assessments provided any warning on Libya. ${ }^{10}$ Thus, the crisis that unfolded in Libya from 15 February onwards caught the world by surprise. Suddenly confronted with high mass atrocity risk in Libya, the international community very quickly engaged in preventive efforts to stop the fragile situation from sliding into one of large-scale atrocities. However, due to the time constraints, more structural prevention measures had not much to say about the case. ${ }^{11}$ There simply was not enough time to implement any long-term measures. Instead, the international community reverted to more short-term and targeted prevention measures aiming to prevent an escalation. Even though the bulk of the discussion usually focuses on the military measures taken to protect civilians and enforce the no-fly zone, it is important to recognize that the international community adopted a whole range of prevention tools before reverting to the last resort of military intervention. As the following discussion shows, most of the tools employed in Libya belong to the R2P's third pillar, which is usually not associated with preventive action.

\footnotetext{
${ }^{10}$ More generally, see A.J. Bellamy, 'Libya and the Responsibility to Protect: The Exception and the Norm', Ethics $\mathcal{E}$ International Affairs, Vol. 25, No. 3, (2011), p. 266. More specifically Barbara Harff's 2009 list of 22 states at risk of mass atrocities does not include Libya (her top five are Sudan, Burma, Somalia, Iran, and China). See Barbara Harff, 'How to Use Risk Assessment and Early Warning in the Prevention and De-Escalation of Genocide and other Mass Atrocities', Global Responsibility to Protect, Vol. 1, No. 4, (2009), pp. 506-531. Equally, Minority Rights Group International's early warning list "Peoples Under Threat" identified 68 countries at risk of mass killing, not including Libya, www.minorityrights.org/9885/peoples-under-threat/peoples-under-threat-2010.html. More qualitative early warning mechanisms such as the International Crisis Group's monthly Crisis Watch bulletin did not identify Libya as a country at risk either. See Crisis Watch No. 90 (February 1, 2011), www.crisisgroup.org/en/publicationtype/crisiswatch/2011/crisiswatch-90.aspx.

${ }^{11}$ See, J.M. Welsh, 'Civilian Protection in Libya: Putting Coercion and Controversy Back Into RtoP', Ethics E⿱ International Affairs, Vol. 25, No. 3, (2011), pp. 255-263.
} 
Initially, the international community tried to deter Gaddafi and his inner circle from committing large-scale atrocities through threats and warnings. ${ }^{12}$ On 25 February, alarmed by the public incitement of the Gaddafi regime and an increasing death toll amongst civilians, the UN Human Rights Council recommended Libya's suspension from the Council and established an international commission of inquiry. ${ }^{13}$ Only one day later, the UN Security Council unanimously adopted Resolution 1970 (26 February), which referred the situation in Libya to the ICC, established an arms embargo on the Libyan territory, and imposed targeted sanctions (asset freeze and travel ban) against certain members of the Gaddafi regime. ${ }^{14}$ However, these sticks did not help to prevent Gaddafi from continuing its violent crackdown on the popular uprising. On 10 March, the UN and the AU responded to the continuing deterioration by initiating parallel mediation initiatives to find a political solution to the crisis. UNSG Ban appointed a Special Envoy, Abdel-Elah Al-Khatib, to lead the UN mediation effort and the AU mandated a six person High-Level Committee. ${ }^{15}$

However, the Gaddafi regime continued to ignore the international community's warnings and robust prevention efforts. To the contrary, it intensified its efforts to retake cities and openly threatened to crush the rebellion in its stronghold Benghazi. Faced with the imminent fall of Benghazi and the widely anticipated massacre therein the Security Council adopted Resolution 1973 (17 March) which authorized military measures to prevent a large-scale massacre of civilians. UNSCR 1973 strengthened the sanctions regime, imposed a no-fly zone over Libyan airspace and authorized the use of all necessary measures to protect civilians and civilian populated areas. ${ }^{16}$ Air strikes to enforce the no-fly zone and the protection of civilians mandate commenced on 19 March. NATO took over all operations on 31 March. Whilst Benghazi and eastern Libya were secured within weeks, the overall situation became increasingly deadlocked with neither the Gaddafi regime nor the rebels able to make significant military progress.

At that point, some states decided to pursue a strategy of regime change, arguing that civilian protection in Libya ultimately required the removal of the root cause of the problem, namely the Gaddafi regime. ${ }^{17}$ As a result, some air strikes looked like they were directly targeting Gaddafi and his inner circle, and some states actively supplied weapons, intelligence and other equipment to the rebels. ${ }^{18}$ This "mission creep", however, triggered intense debate and proved to be very controversial. Nevertheless, the international community's preventive engagement only ended with the fall of the Gaddafi regime and the violent death of Colonel Gaddafi on October 20, 2011.

Interestingly, the tools employed to prevent mass atrocity crimes in Libya - that is threats and warnings, membership suspensions, fact-finding missions, ICC referral, arms embargo, targeted sanctions, mediation, no-fly zone, and military intervention to protect civilians - belong to the RtoP's third pillar, which is usually conceptualized as dealing with responses to ongoing mass atrocities. In Libya, however, these tools were used in a preventive manner, aiming to prevent an escalation of a high risk situation. Conceptually, therefore, the Libya case suggests that "pillar three" has an important preventive dimension. ${ }^{19}$ In situations of imminent mass atrocity risk where time constraints are high and in which

\footnotetext{
${ }^{12}$ See, for instance, "Live Blog Libya - February 20," Al-Jazeera, February 20, 2011, http://blogs.aljazeera.net/middleeast/2011/02/17/live-blog-libya\#feb20; and H. R Clinton, "Situation in Libya," Press Statement, PRN: 2011/249, Washington D.C., February 21, 2011. See: www.state.gov/secretary/rm/2011/02/156836.htm.

${ }^{13}$ UN Human Rights Council, Resolution A/HRC/S-15/1, February 25, 2011.

${ }^{14}$ UN Security Council, Resolution 1970 (2011), February 26, 2011.

${ }^{15}$ See, Peace and Security Council of the AU, 265th Meeting, Communiqué psc/pr/comm.2 (CCLXR), March 10, 2011.

${ }^{16}$ UN Security Council, Resolution 1973 (2011), March 17, 2011. Importantly, UNSCR 1973 was passed with five abstentions (China, Russia, India, Brazil, and Germany). Moreover, some would probably argue-not unreasonably-that the tools in UNSCR 1973 were reactive rather than preventive. In my view, the tools in that resolution constitute very latestage prevention measures.

${ }^{17}$ Barack Obama, David Cameron, and Nicolas Sarkozy, op-ed, “Libya's Pathway to Peace,” New York Time, April 15, 2011.

${ }^{18}$ See, J. Pattison, "The Ethics of Humanitarian Intervention in Libya”, Ethics $\mathcal{E}$ International Affairs, Vol. 25, No. 3 (2011), pp. 273-274. See also, "France Won’t Rule Out More Libyan Weapon Drops,” Channel 4 News, June 30, 2011, www.channel4.com/news/france-wont-rule-out-more-libyan-weapondrops; and "French Military Airdropped Arms to Libya Rebels," France 24, June 29, 2011, www.france24.com/en/20110629-french-military-confirmsairdropping-arms-libyakadhafi-rebel\#. For a legal assessment, see Dapo Akande, 'France Admits to Arming Libyan Rebels: Was this Lawful?', EJIL:Talk!, July 1, 2011, www.ejiltalk.org/france-admits-to-arming-libyan-rebels-was-this-lawful/.

${ }^{19}$ See also, Reike, "Libya and the Responsibility to Protect".
} 
the identity of potential perpetrators and potential victims becomes increasingly clear, tools to change the behaviour of the potential perpetrators (e.g. verbal threats, targeted sanctions, ICC referral, and preventive diplomacy) and protect the potential victims (e.g. no-fly zone, safe areas, and military intervention) are crucial for preventive purposes. It is "pillar three" that contains the means to achieve these ends. Thus, it is important to approach "pillar three" with a mind-set of prevention; even though Libya also shows that at times there might only be a very fine line between prevention and response.

This finding is also relevant for the debate on the so-called "responsibility to prevent" as it challenges the conventional wisdom that RtoP prevention is primarily rooted in pillars one and two. As SecretaryGeneral Ban Ki-Moon writes, 'prevention, building on Pillars one and two, is a key ingredient for a successful strategy for the responsibility to protect. ${ }^{20}$ Adopting Ban's perspective, prevention would mainly involve the following tools: becoming party to human rights treaties and the ICC; ending impunity; strengthening civil society; ensuring the independence of the press; engaging in state-to-state learning processes; education programmes; building conflict-sensitive development analysis; and strengthening local dispute resolution capacity. ${ }^{21}$ Libya shows, however, that limiting prevention to pillars one and two excludes a key set of tools that are crucial to late-stage prevention, namely those contained in "pillar three". Put differently, Libya suggests that the "responsibility to prevent" needs to encompass all three pillars of RtoP.

\section{Tool Application}

Furthermore, studying the Libya crisis helps to illuminate how certain tools might need to be employed in a mass atrocity context. In other words, it helps to start answering some operational "how" questions for "pillar three".

In the Libya crisis, the international community adopted a gradual approach of prevention, which continuously increased the coerciveness of prevention tools and the pressure on the Gaddafi regime. Amongst Security Council members there was general agreement that not all prevention tools should be exhausted at the outset, and that the option to ratchet-up further pressure needed to be retained. It is noteworthy, though, that the international community's strategy for preventing mass atrocities in Libya abandoned the principles of consent and impartiality that traditionally guide the UN's response to most situations of conflict.

With regard to the principle of consent, it needs to be acknowledged that none of the measures adopted had the consent of the Libyan government. This is not really surprising with regard to, for instance, the targeted sanctions. However, it is very curious with regard to the military measures adopted. According to Paul Williams and Alex Bellamy, Libya was the first time ever that the UN Security Council authorized a military intervention for human protection purposes against a fully functioning state without the consent of that state. ${ }^{22}$ Of course, consent is not a legal requirement as long as the Security Council acts under Chapter VII of the UN Charter, but in the past some sort of host state consent has usually been sought (though sometimes coerced). ${ }^{23}$ Thus, Libya shows that in order to prevent mass atrocity crimes, it might become necessary to abandon the principle of consent.

The issue of impartiality seems even more interesting. The prevention measures adopted in UNSCR 1970 and 1973 were all specifically directed against the Gaddafi regime. In other words, the international community took sides in Libya's internal struggle; siding with the National Transitional Council (NTC)led rebel movement and denouncing the Gaddafi regime. UNSCR 1970 imposed targeted sanctions on some specifically named individuals and entities, all of which belonged to the Gaddafi regime. The

\footnotetext{
${ }^{20}$ Ban, Implementing the Responsibility to Protect, p. 9.

${ }^{21}$ Ban, Implementing the Responsibility to Protect, p. 21.

${ }^{22}$ See, Bellamy, "Libya and the Responsibility to Protect", p. 263; and Bellamy and Williams, "The New Politics of Protection?", p. 825.

${ }^{23}$ See: S. Chesterman, "Leading From Behind: The Responsibility to Protect, the Obama Doctrine, and Humanitarian Intervention in Libya”, Ethics $\mathcal{E}$ International Affairs, Vol. 25, No. 3, (2011), p. 2; see also Bellamy, "Libya and the Responsibility to Protect", p. 263.
} 
Prosecutor of the ICC clearly identified Muammar Gaddafi, Saif al-Islam, and Abdullah al-Senussi as those most responsible for crimes committed in Libya, leading the ICC to issue arrest warrants against them. ${ }^{24}$ The comprehensive territorial arms embargo was enforced in a one sided manner, supplying weapons to the rebels and cutting off the Gaddafi regime. Furthermore, the mandate to use all necessary measures to protect not only civilians but also civilian populated areas further pushed the international community towards abandoning the principle of impartiality. The protection of civilian populated areas prohibited Gaddafi from attacking entire cities and areas, regardless of whether they contained legitimate military targets. As Jennifer Welsh explains, 'though one can understand the logic behind the focus on civilian-populated areas, it nonetheless concretely moves the international community toward aiding one side in a conflict and restricting the movements of the other'. ${ }^{25}$ Finally, the strategy of regime change, which some states seem to have pursued, is probably the clearest indicator that impartiality was abandoned as a guiding principle. In short, the international community chose sides in the internal Libyan struggle.

All of this suggests that efforts to prevent mass atrocity crimes may at times have to relinquish the traditional conflict prevention principles of consent, impartiality, and minimal coercion; principles that are still at the core of conventional accounts of the "responsibility to prevent". ${ }^{26}$ According to Welsh, an:

'important aspect of Resolution 1973, and the accompanying air campaign, is the degree to which it shifts the nature of the UN's involvement from one of genuine (or at least professed) impartiality - a hallmark of the United Nations' original approach to peacekeeping - to one of taking sides ... With the Libya case, the Council is reasserting its right to point fingers at the "wrongdoer.", 27

Hence, the Libya crisis suggests that "pillar three" based strategies for preventing mass atrocity crimes can be at odds with traditional conflict prevention strategies.

\section{Problems and Unintended Consequences}

There can be little doubt that the international community successfully prevented a bloody massacre in Benghazi and large-scale atrocities in other parts of Libya. But it seems equally clear that this was achieved in a way that many perceived as very problematic. Thus, the Libya case also reveals, in all clarity, the dilemmas and unintended consequences that efforts to prevent mass atrocity crimes may bring about, particularly if they rely on "pillar three" tools. The controversy about Libya led some commentators to even predict the death of RtoP as an operationally relevant principle. ${ }^{28}$ In what follows the chapter highlights some of the unintended consequences that arose from the international prevention efforts in Libya.

First, one problem that some states raised with regard to the international community's preventive engagement in Libya relates to the issue of civilian casualties. The high likelihood of civilian casualties is one of the dilemmas that most - if not any - form of military intervention faces. This was no different in Libya. Whilst NATO and its international partners did not suffer a single casualty, NATO air strikes evidentially caused some casualties amongst the Libyan civilian population. The Indian Ambassador to the UN, Hardeep Singh Puri, even accused NATO of having 'killed thousands in order to save a few hundred'. Whilst this assessment is polemic and exaggerated, the Human Rights Council's inquiry into

\footnotetext{
${ }^{24}$ See, L. Moreno-Ocampo, "Statement of the Prosecutor on the opening of the investigation into the situation in Libya", March 3, 2011, The Hague.

${ }^{25}$ Welsh, "Civilian Protection in Libya", p. 259.

${ }^{26}$ See also, A.J. Bellamy, "Mass Atrocities and Armed Conflict: Links, Distinctions, and Implications for the Responsibility to Prevent", Policy Analysis Brief: The Stanley Foundation, January 2011, p. 7.

${ }^{27}$ Welsh, "Civilian Protection in Libya", p. 258.

${ }^{28}$ D. Rieff, "R2P, R.I.P”, The New York Times, November 7, 2011. See: www.nytimes.com/2011/11/08/opinion/r2prip.html?pagewanted=all.
} 
civilian casualties in Libya shows that NATO airstrikes indeed caused civilian deaths of a number somewhere around $100 .^{29}$ The Human Rights Council's inquiry clearly stated that NATO did not deliberately target civilians, and some argue that 100 civilian casualties are a relatively low number for such a military operation. ${ }^{30}$ However, Brazil and others have articulated the view that even one civilian casualty is one too many. Russia and China have equally criticized NATO for the existence of civilian casualties. ${ }^{31}$

Second, another shortcoming of the international prevention efforts in Libya was that the provision of protection was selective. Whilst the international community rather successfully prevented large-scale mass atrocities in Benghazi and eastern Libya, such protection was not provided in other parts of Libya. In those unprotected parts, some atrocities and civilian deaths occurred (often against Libyan women). Ivo Daalder, the US Ambassador to NATO, and James Stavridis, Supreme Allied Commander Europe, argue that NATO was very effective in implementing the arms embargo and the no-fly zone, but encountered difficulties in providing comprehensive protection for civilians. According to them, 'the proximity of the regime's forces, facilities, and equipment to civilian infrastructure; the initially limited ability of the Libyan opposition to defend itself and the population centres under its control; and the need for NATO to minimize harm to civilians all slowed the operation and at times led to a perception of deadlock and stalemate. ${ }^{32}$ NATO's difficulties in providing comprehensive protection were also due to the air based nature of the military prevention measures. As UNSCR 1973 explicitly prohibited the deployment of ground troops, international protection efforts were limited to the air campaign. This raises questions about how much protection an air campaign can provide for threatened populations.

Third, there are reports about atrocities committed by the internationally supported rebel movement. ${ }^{33}$ Human rights organizations such as Amnesty International and Human Rights Watch have documented several instances in which forces loyal to the NTC committed reprisal attacks on alleged Gaddafi supporters, often foreigners from sub-Saharan Africa assumed to be mercenaries. According to Amnesty International those reprisal attacks may constitute war crimes as well. ${ }^{34}$ Moreover, in January 2012, the humanitarian organisation Medecins Sans Frontières (MSF) suspended its operations in detention centres in Misrata as it was asked to treat patients between torture sessions. According to MSF, it treated at least 115 people with torture related injuries. ${ }^{35}$ By having supported one side in a civil war, the international community unintentionally empowered that side to commit atrocities of its own. Understandably, many see the relative silence over NTC atrocities as a hypocritical double standard. ${ }^{36}$

Fourth, a major problem since the collapse of the Gaddafi regime is the proliferation of arms in Libya and the wider region. The power vacuum that the fall of the Gaddafi regime left as well as the active supply of weapons to the rebels by some states led to a high circulation of arms and the emergence of highly armed militias. This raises serious concerns not only for stability in Libya but also in the wider region. As the Chairperson of the AU Commission, Jean Ping, stresses:

\footnotetext{
${ }^{29}$ See: I. Davies, "The UN Human Rights Council's Report on Civilian Casualties in Libya”, NATO Watch Briefing Paper, No. 21, March 21, 2012. See: www.natowatch.org/sites/default/files/NATO Watch Briefing Paper No.21. UN_Human_Rights_Council_report_on_Libya.pdf.

${ }^{30}$ See, Davies, "The UN Human Rights Council's Report on Civilian Casualties in Libya".

${ }^{31}$ See, Davies, "The UN Human Rights Council's Report on Civilian Casualties in Libya”.

${ }^{32}$ I. Daalder and J. Stavridis, "NATO's Victory in Libya”, Foreign Affairs, Vol. 91, No. 2 (2012), pp. 2-7.

${ }^{33}$ See in particular the following reports: Amnesty International, The Battle for Libya: Killings, Disappearances and Torture, MDE 19/025/2011; Amnesty International, Detention Abuses Staining the New Libya, MDE 19/036/2011; Human Rights Watch, Libya: Militias Terrorizing Residents of "Loyalist" Towns, Press Release, October 30, 2011; Medecines Sans Frontières, Libya: Detainees Tortured and Denied Medical Care, Press Release, January 26, 2012.

${ }^{34}$ For example, Amnesty International, The Battle for Libya: Killings, Disappearances and Torture, MDE 19/025/2011;

${ }^{35}$ Medecins Sans Frontières, Libya: Detainees Tortured and Denied Medical Care, Press Release, January 26, 2012.

${ }^{36}$ On October27, 2011, the Security Council adopted Resolution 2016 (2011) which simply urges the Libyan authorities 'to refrain from reprisals, including arbitrary detentions', and calls upon the Libyan authorities 'to take all steps necessary to prevent reprisals, wrongful imprisonment and extrajudicial executions, and underscores the Libyan authorities' responsibility for the protection of its population, including foreign nationals and African migrants'.
} 
'The AU has continuously drawn attention to the proliferation, in the region, of weapons emanating from the Libyan military depots. To some, these concerns seemed exaggerated when they were first expressed. Today, there is a growing realization within the international community of the gravity of the threat posed by this situation and the need for a concerted international action to address it. This is all the more urgent as some of the countries in the Sahelo-Saharan belt are in a fragile situation, having to deal with both latent rebellions and terrorist groups. ${ }^{37}$

In Resolution 2017 (31 October), the UN Security Council acknowledges the problem of arms proliferation, in particular man-portable surface-to-air missiles (MANPADS), and expresses concern about 'the risk of destabilization posed by the dissemination in the Sahel region of illicit small arms and light weapons ${ }^{38}{ }^{38}$ Moreover, many see the military coup d'état in Mali in March 2012 as a spill-over from the Libya intervention.

These are just some of the broader dilemmas and unintended consequences that the preventive engagement in Libya brought about. This is not to suggest that the prevention efforts in Libya are not to be applauded, but it raises awareness for the problems that might be associated with robust "pillar three" prevention efforts. Those challenges need to be included in debate and planning in order to enhance the effectiveness of "pillar three" action, also in the long-term. One channel for addressing some of the aforementioned problems could be the Brazilian initiative on RWP, which emerged relatively directly from problems associated with the Libya campaign. ${ }^{39}$

\section{Conclusions}

To sum up, at least three lessons for RtoP's third pillar can be learned from a closer look at the international community's preventive engagement in Libya. First, and more conceptually, Libya shows that "pillar three" is as relevant for the prevention of mass atrocity crimes as it is for responses to ongoing mass atrocities. Strategies for late-stage prevention rely heavily on "pillar three" tools. It seems likely that such pillar three late-stage prevention will be the norm rather than the exception for as long as we have not developed better structural indicators to foresee mass atrocity risk early enough to engage in meaningful structural prevention. Thus, illuminating and developing the preventive dimension of "pillar three" is an important task. This alludes to the second lesson from Libya. With an eye to operationalization, Libya indicates that it is important to pay more attention to the details of how pillar three tools are employed. "Pillar three" is sometimes approached too narrowly, focusing mostly on military intervention. In reality, however, "pillar three" contains a whole range of measures that can be used to ratchet-up pressure on potential perpetrators. Thereby, Libya demonstrates that "taking sides", abandoning impartiality, and acting without host state consent might become necessary elements of strategies that aim at the immediate prevention of mass atrocity crimes. This challenges the approach of the UN to most situations of conflict, and suggests that the prevention of mass atrocity crimes is different from conflict prevention more broadly conceived. Finally, Libya shows that action under "pillar three" is likely to entail some agonizing dilemmas and unintended consequences that need to be accounted for. Discussing the problematic aspects that action under "pillar three" might raise seems important to establish the political basis for future RtoP action. The Brazilian initiative on RWP could be used to address some of those concerns.

\footnotetext{
${ }^{37}$ J. Ping, 'The African Union and the Libyan Crisis: Putting the Records Straight', Letter from the Chairperson, Issue 1, November 2011.

${ }^{38}$ UN Security Council, Resolution 2017 (2011), October 31, 2011.

${ }^{39}$ On the Brazilian RWP initiative, see, "Responsibility While Protecting: Elements for the Development and Promotion of a Concept”, General Assembly/ Security Council, A/66/551-S/2011/701, November 11, 2011. See also the Global Centre for the Responsibility to Protect's website on the UN Interactive Dialogue on RWP, www.globalr2p.org/resources/RwP.php.
} 


\title{
The Role of Business in Third Pillar Interventions under the Responsibility to Protect
}

\author{
CONOR SEYLE \& EAMON ALOYO
}

\begin{abstract}
Introduction
The RtoP is unusual because of the speed at which it was adopted internationally as a serious topic for discussion ${ }^{1}$. This adoption was broad as well as rapid: organizations including the UN Security Council ${ }^{2}$, the UN General Assembly ${ }^{3}$, the popular press ${ }^{4}$, NATO, and many NGOs have written on and invoked RtoP. However, despite the speed and breadth of this discussion, the conception of RtoP has remained relatively limited in its understanding of what and who the relevant actors are in RtoP issues. Although there has been some discussion of non-state actors in the general discussion of RtoP, in the formulation of RtoP as defined by the International Commission on Intervention and State Sovereignty (ICISS) ${ }^{5}$ and elaborated by Ban Ki Moon ${ }^{6}$, the central actors are states. This conception is limited: in the globalized world of the $21^{\text {st }}$ century, non-state actors can play a major role in international issues ${ }^{7}$.

One such non-state actor is business. When discussing issues of armed conflict, human rights abuses, and mass atrocities, existing research focuses on how business can or should mitigate such issues. Businesses have economic, legal, and moral reasons to participate in the prevention, cessation, and recovery from mass atrocities. This chapter argues that business represents an untapped sector relevant to RtoP issues, and business can help implement third-pillar interventions as well as playing a role in prevention and recovery from RtoP violations.
\end{abstract}

\section{Why Business should be Interested in Participating in RtoP Interventions}

There are two main bodies of literature examining when, why, and how national and international businesses engage with conflict and human rights. Broadly, these literatures can be broken into Corporate Social Responsibility (CSR), and "Business and Peace" or Corporate Security Responsibility (CSecR) ${ }^{10}$. The CSR literature discusses how and why corporations should be aware of their impact on societies in which they work. Research and practice in CSR has tended to look at how businesses can be motivated to limit their social harms, and contribute to positive outcomes. The business and peace or CSecR literature has a more limited focus, looking specifically at how and why businesses participate in stopping armed conflict or/and increasing security and stability ${ }^{11}$. Research in these areas has attempted to develop

\footnotetext{
${ }^{1}$ R. Thakur \& T.G. Weiss, "R2P: From Idea to Norm and Action?,” Global Responsibility to Protect Vol.1, No. 1 (2009).

${ }^{2}$ I. Cotler \& J. Genser, "Libya and the Responsibility to Protect," The New York Times (28 February 2011).

${ }^{3}$ UN General Assembly, Session 63, Resolution 63/308: The Responsibility to Protect (7 October 2009).

${ }^{4}$ D. Rieff, "R2P, R.I.P.," The New York Times, (7 November 2011).

${ }^{5}$ ICISS (ed.) The Responsibility to Protect: The Report of the International Commission on Intervention and State Sovereignty (IDRC Books, 2001); U.N. General Assembly, 2005 World Summit Outcome (New York: United Nations, 2005).

${ }^{6}$ UN General Assembly, Implementing the Responsibility to Protect: Report of the Secretary-General (United Nations, 12 January 2009).

${ }^{7}$ e.g. J.G. Ruggie, "Reconstituting the Global Public Domain: Issues, Actors, and Practices," European Journal of International

Relations Vol. 10 (2004), pp. 499-531. However, the legitimacy and appropriateness of non-state actors is a topic of debate. See for example J. J. Mearsheimer, The Tragedy of Great Power Politics (W. W. Norton \& Company, 2001).

${ }^{8}$ See for example D. Jamali \& R. Mirshak, "Business-Conflict Linkages: Revisiting MNCs, CSR, and Conflict," Journal of Business Ethics Vol. 93 (2010), pp. 443-464; J. Nelson, The Business of Peace: The Private Sector as a Partner in Conflict Prevention and Resolution (International Alert, Council on Economic Priorities, The Prince of Wales Business Leaders Forum, 2000); W. Rosenau et al., Corporations and Counterinsurgency (Santa Monica, CA: RAND Corporation, 2009); J. Oetzel et al., "Business and Peace: Sketching the Terrain," Journal of Business Ethics Vol. 89 (2009), pp. 351-373; T. L. Fort \& C. A. Schipani, "The Role of the Corporation in Fostering Sustainable Peace," Vanderbilt Journal of Transnational Law, Vol. 35 (2002).

${ }^{9}$ A.B. Carroll, "Corporate Social Responsibility,” Business $\mathcal{E}$ Society 38, no. 3 (1 September 1999), pp. 268-295.

${ }^{10}$ K.D. Wolf, N. Deitelhoff, \& S. Engert, "Corporate Security Responsibility," Cooperation and Conflict, Vol. 42, No. 3 (1 September 2007), pp. 294-320.

${ }^{11}$ Op.Cit., The Business of Peace: The Private Sector as a Partner in Conflict Prevention and Resolution; Op.Cit., "The Role of the Corporation in Fostering Sustainable Peace."
} 
empirical descriptions of where and how business is legally or practically implicated in issues of human rights ${ }^{12}$ and armed conflict ${ }^{13}$. It has also developed more prescriptive arguments about why businesses should choose to engage in these issues ${ }^{14}$.

Third pillar RtoP interventions can be considered a special case of these general literatures: although questions of CSR and CSecR certainly are central to RtoP interventions, both CSR and CSecR can happen outside of RtoP contexts. For this chapter, we will limit our discussion of business specifically to violations of RtoP as defined by the 2005 World Summit Outcome Document and reaffirmed in the 2009 UN Report of the Secretary-General ${ }^{15}$, which includes "genocide, war crimes, ethnic cleansing and crimes against humanity." Additionally, the chapter mostly limits its discussion to "third pillar" interventions, which are attempts to stop ongoing RtoP violations. Existing literature has identified several reasons why domestic and international businesses may be interested in participating in RtoP issues in general and third pillar interventions specifically. Drawing on this literature, we argue that there are economic, legal, and moral reasons for businesses to be interested in RtoP interventions.

There are bottom-line reasons for businesses to work for a quick cessation of RtoP violations. The most pertinent economic reason is simply stability: most businesses require a relatively stable environment in order to carry out regular business activities, and activities which support stability may act as long-term investments supporting more profitable business activities ${ }^{16}$. The kind of mass violence that triggers third pillar interventions is extremely disruptive to business activities: civil wars decrease per-capita GDP, ${ }^{17}$ and damage the infrastructure and physical and social capital on which businesses rely ${ }^{18}$. One primary economic reason for businesses to participate in RtoP issues is that in doing so they can help to reestablish stability and improve their bottom line. This requires that the cost of the investment not exceed the expected return. However, for businesses with significant infrastructure investments or long-term activity within a specific country, the potential for conflicts to persist for generations in the absence of intervention is a strong argument for the economic utility of action.

In addition to minimizing losses from the cost of conflict, participation in RtoP interventions can actively promote profit. If there is widespread awareness and condemnation of RtoP violations or mass atrocities in a state, then there can be reputational and hence economic benefits for companies resisting these abuses. One illustration of this point in general, although not a RtoP issue specifically, can be found in the response of both national and international companies in Egypt to the successful revolution that occurred in 2011. The Egyptian revolution was a popular movement that occurred as a part of the "Arab Spring" wave of democratization that happened in 2011. In order to capitalize on the passion generated as a part of this movement, national and international businesses in Egypt issued advertisements and public statements associating themselves with the revolution ${ }^{19}$. This approach has risks: it relies on the public accepting these messages; and companies associated with the previous regime or with repressive activities during the revolution may face a backlash from attempting to position themselves as supporters of the revolution. Vodafone, an international telecommunications company suspected by many Egyptians to have actively worked with the Mubarak regime to assist crackdowns, faced exactly this kind of backlash to an advertisement claiming its association with the revolution ${ }^{20}$.

\footnotetext{
${ }^{12}$ J. G. Ruggie, "Business and Human Rights: The Evolving International Agenda," American Journal of International Law No. 101 (2007).

${ }^{13}$ Op.Cit., Corporations and Counterinsurgency.

${ }^{14}$ Op.Cit., The Business of Peace: The Private Sector as a Partner in Conflict Prevention and Resolution; Fort \& Schipani, "The Role of the Corporation in Fostering Sustainable Peace."

${ }^{15}$ UN General Assembly, Implementing the Responsibility to Protect: Report of the Secretary-General; U.N. General Assembly, 2005

World Summit Outcome.

${ }^{16}$ Op.Cit., The Business of Peace: The Private Sector as a Partner in Conflict Prevention and Resolution; Op.Cit., Corporations and Counterinsurgency; Op.Cit., "Corporate Security Responsibility"; Op.Cit., "Business and Peace."

${ }^{17}$ D. Sevastianova, "Impact of War on Country Per Capita GDP: A Descriptive Analysis," Peace Economics, Peace Science and Public Policy Vol. 15, No. 1 (2009)..

${ }^{18}$ A. Hoeffler \& M. Reynal-Querol, "Measuring the Costs of Conflict" (Centre for the Study of African Economies, Oxford University, Oxford, UK, 2003).

${ }^{19}$ M. Bradley, "Revolution Sells in Egypt," Wall Street Journal (17 June 2011).

20 "Fury over Advert Claiming Egypt Revolution as Vodafone's," The Guardian (3 June 2011).
} 
Reputational benefits translate directly into profits: research in CSR has tracked the way that, for many consumers, a perception of CSR increases the willingness of the consumer to buy from that company, or the price a consumer is willing to pay ${ }^{21}$. Of course, this effect is mediated by how a consumer views an issue a company is focusing on, and a consumer's general attitude toward $\operatorname{CSR}^{22}$. This suggests that the economic impact of pro-RtoP activity will be strongest when RtoP issues are widely known and acknowledged to be important. The restriction of RtoP to major abuses including genocide or mass human rights abuses suggests that RtoP interventions may meet these criteria. Similarly, watchdog NGOs such as Global Witness or Enough may "name and shame" companies failing to abide by the protection of human rights, thereby decreasing profits or hampering companies' ability to work in areas where there is a focus on human rights.

Another economic argument for engagement with RtoP issues is first-mover advantage. This occurs when a company becomes one of the first to engage within a specific domain, group, or sector, which allows a company to learn how to effectively operate in the domain and build relationships with consumers and with influential people in the area without competition from other companies. This can allow for companies to become strongly associated with a particular issue, which can result in strong reputational benefits even after other companies become involved in similar work ${ }^{23}$. In the case of RtoP, businesses providing support for resistance to RtoP violations may be rewarded with access to, and positive relationships with, officials in a new political regime. Although regime change is not necessarily a part of RtoP interventions (or, arguably, an appropriate part) recent third pillar interventions including Libya and Côte d'Ivoire have resulted in regime change. The Libyan rebels have explicitly stated that they will provide preferential treatment to companies from states that supported their movement ${ }^{24}$, and individual businesses may be in a similar position to profit (or fail to profit) from being early supporters of new regimes.

The second reason businesses may be interested in working on the third pillar of RtoP is their legal obligations. Many states have laws barring companies from engaging in corruption or human rights violations domestically or abroad. In the US, certain types of victims can bring claims under the Alien Tort Claims Act against businesses that supported these violations. ${ }^{25}$ Similarly, the UN has established a formal statement of the norms on the human rights responsibilities of businesses. This statement is not treaty-based international law, but Weissbrodt and Kruger argue that it is customary international law and hence binding ${ }^{26}$. They claim further that it is a potential reference for legal claims against companies which violate it ${ }^{27}$. Moreover, businesspeople could be directly indicted by the ICC. For instance, the head of operations of a Kenyan radio station, Joshua Arap Sang, has been charged with crimes against humanity ${ }^{28}$. The ICC may also be able to deter by threatening to indict business leaders, such as may have occurred with some of Côte d'Ivoire's media moguls that were inciting violence ${ }^{29}$.

\footnotetext{
${ }^{21}$ L.A Mohr, D.J. Webb, \& K.E. Harris, "Do Consumers Expect Companies to Be Socially Responsible? The Impact of Corporate Social Responsibility on Buying Behavior,” Journal of Consumer Affairs Vol. 35, No. 1 (1 June 2001), pp. 45-72.

${ }^{22}$ S. Sen \& C.B. Bhattacharya, "Does Doing Good Always Lead to Doing Better? Consumer Reactions to Corporate Social Responsibility,” Journal of Marketing Research Vol. 38 (2001), pp. 225-243.

${ }^{23}$ An excellent example of this is G.E.'s strong association with "green business" due to their early efforts in this area. Currently, several other companies have a track record of green business similar to G.E.s but without the associated reputation. See A. Cramer, \& Z. Karabell, Sustainable Excellence: The Future of Business in a Fast-Changing World. (New York: Rodale Books, 2010). ${ }^{24}$ C. Krauss, "The Scramble for Access to Libya's Oil Wealth Begins," The New York Times (22 August 2011.

${ }^{25}$ R. Shamir, "Between Self-Regulation and the Alien Tort Claims Act: On the Contested Concept of Corporate Social

Responsibility," Law $\mathcal{E}$ Society Review, Vol. 38, No. 4 (1 December 2004), pp. 635-664. Although note that the U.S. Supreme Court is currently reviewing the scope of this act. See "Supreme Court Eyes Scope Of Controversial Alien Tort Statute," Forbes (23 March 2012).

${ }^{26}$ D. Weissbrodt \& M. Kruger, "Norms on the Responsibilities of Transnational Corporations and Other Business Enterprises with Regard to Human Rights," The American Journal of International Law, Vol. 97, No. 4 (2003), pp. 901-922.

${ }^{27}$ Op.Cit., "Norms on the Responsibilities of Transnational Corporations and Other Business Enterprises with Regard to Human Rights".

28 "ICC - The Republic of Kenya - ICC-01/09-01/11". See: www.icccpi.int/menus/icc/situations\%20and\%20cases/situations/situation\%20icc\%200109/related\%20cases/icc01090111/icc0109011 1?lan=en-GB. (Accessed April 2012).

${ }^{29}$ P. Akhavan, "Are International Criminal Tribunals a Disincentive to Peace?: Reconciling Judicial Romanticism with Political Realism," Human Rights Quarterly, Vol. 31, No. 3 (2009).
} 
Economic sanctions represent an additional legal obligation. Third pillar interventions often use a variety of non-military coercive methods including economic sanctions, which place a legal obligation on companies not to engage with states or individuals that violate RtoP. Sanctions can work ${ }^{30}$ or they can contribute to repression and result in human rights violations. ${ }^{31}$

The third reason businesses may choose to involve themselves in RtoP interventions is the moral leadership of some companies. We know that most people prefer to act in line with their moral beliefs when they are given the opportunity ${ }^{32}$. Businesspeople have this preference as well: Fort and Schipani have argued that in fact, businesses can be considered as collections of people acting interpersonally and developing their moral perspective ${ }^{33}$. Empirical evidence supports this claim; businesspeople have made decisions based in part on their moral beliefs. For instance, in 2000, the Chairman of the DeBeers diamond company pointed out that when they made the decision to move away from diamonds sourced from conflict areas, DeBeers' market share had already been increasing and their reasoning behind the decision had more to do with moral choice than business imperatives: 'the market has been extremely good and there would not have been any inventory problem if we bought these goods. It was the moral imperative and also the fear of what might happen to the diamond industry ${ }^{34}$. Of course it is also the case that DeBeers was attracting negative attention for association with conflict minerals when their Chair made that statement, and such moral arguments, though reasonable, must also be balanced against the thought that they can serve to cover or work in tandem with other more strategic reasoning ${ }^{35}$.

In sum, businesses can have moral, legal, and economic reasons to work to end violations of RtoP.

\section{Points of Business Engagement with Third Pillar Interventions}

There is a spectrum of activities that businesses may choose to take when confronted with RtoP violations. Businesses may choose to withdraw from the region, attempt to conduct "business as usual," or actively engage with attempts to stop RtoP violations.

One common response to conflict or severe human rights abuses is to withdraw from the area of conflict, either voluntarily or in response to social pressure or legal mandates. Voluntary withdrawal can reflect concerns about the safety of the companies' workers, concern for the reputation of the company, or a conscious attempt to pressure those committing violations of RtoP. Perspectives on the utility of this approach are mixed, with some groups calling for a withdrawal of multinational corporations from conflict areas or a divestment from funding groups in these areas as a way of pressuring states to behave appropriately ${ }^{36}$ and some groups arguing that remaining in the area allows for more effective engagement and pressure on the government. If a company withdraws, it may be replaced by a morally worse company. For instance, a Canadian oil company operating in Sudan, Talisman Oil, withdrew after social pressure, only to be replaced by Oil and Natural Gas Company of India, which did less to protect human rights. ${ }^{37}$ Moreover, the Canadian government lost influence over the Sudanese government due to the withdrawal of Talisman.

An interesting example that falls somewhere between a voluntary and legally imposed sanction can be found in the case of Côte d'Ivoire, where postelection violence between supporters of ousted President

\footnotetext{
${ }^{30}$ F. Salem \& R. Mourtada, Arab Social Media Report (Dubai, UAE: Dubai School of Government, 2011).

${ }^{31}$ D. Peksen \& A.C. Drury, "Economic Sanctions and Political Repression: Assessing the Impact of Coercive Diplomacy on Political Freedoms," Human Rights Review Vol. 10, No. 3 (2009), pp. 393-411; D. Peksen \& A. C. Drury, "Coercive or Corrosive: The Negative Impact of Economic Sanctions on Democracy," International Interactions Vol., 36, No. 3 (2010), pp. 240-264; J. Gordon, Invisible War: The United States and the Iraq Sanctions (Harvard University Press, 2010).

${ }^{32}$ R. J. Vallerand et al., "Ajzen \& Fishbein's Theory of Reasoned Action as Applied to Moral Behavior: A Confirmatory Analysis.," Journal of Personality and Social Psychology, Vol. 62, No. 1 (1992), pp. 98-109.

${ }^{33}$ T.L. Fort \& C.A Schipani, “Adapting Corporate Governance for Sustainable Peace,” Vanderbilt Journal of Transnational Law, Vol. 36 (2003); T.L. Fort, Ethics and Governance: Business as Mediating Institution (Oxford University Press, USA, 2001).

${ }^{34}$ M. Rapaport, "Fundamental Change: An Interview With Nicky Oppenheimer," Rapaport News (27 July 2007).

${ }^{35}$ A. Cowell, "Controversy Over Diamonds Made Into Virtue by De Beers," New York Times, (22 August 2000).

${ }^{36}$ K.A. Rodman, "'Think Globally, Punish Locally': Nonstate Actors, Multinational Corporations, and Human Rights Sanctions,” Ethics $\mathcal{E}$ International Affairs Vol. 12, No. 1 (March 1998), pp. 19-41.

${ }^{37}$ Thanks to Scott Wisor for this example.
} 
Laurent Gbagbo and the electorally victorious Alassane Ouattara included significant human rights violations sufficient to be considered a violation of RtoP principles. As a part of Ouattara's movement to pressure Gbagbo to step down peacefully, he instituted a ban on the export of cocoa. Despite his limited legal mandate, cocoa companies voluntarily abided by the ban ${ }^{38}$.

A second approach businesses can take is to maintain business as usual. Even regular business activities may make a business complicit by providing support for the "war economy" ${ }^{39}$. By engaging in regular business activities, businesses can provide funds to the government or rebel groups via official or unofficial taxation. Individuals within the country can direct their profits to support those violating or resisting the violation of RtoP. Contemporary conflicts such as those associated with RtoP violations tend to include a distributed and fragmented set of actors, all of which require funding and support either from traditional economic activities (whether legal or illegal) or from support from diaspora groups or states $^{40}$, and business activities conducted within the state can fund these sources.

Businesses can instead actively engage with attempts to intervene to stop atrocities through direct military or security support or political pressure. Direct provision of support for military activities can take the form of business engagement with forces opposing RtoP violations. For example, during the Libyan conflict, one source of funding for the rebel army was oil sold through the captured national oil company. International oil companies were considered as a potential source of increased funding for the rebel forces through this company: closer collaboration between international oil companies and the rebel-held oil company would increase oil exports ${ }^{41}$. This kind of approach, while feasible, is not common and may open companies to claims of complicity in human rights violations committed by rebel forces. Alternately, companies may use company security forces or hired guards to provide security in regions where the company has a strong presence. This can include protecting company infrastructure or employees from attack, such as the attacks that focused on Unilever compounds in Kenya during the post-election violence ${ }^{42}$. As with all issues of direct security provision, there is the potential for abuse: in Nigeria, Shell's corporate-supported security forces have been used to protect company staff and property, but these forces have also been accused of human rights violations ${ }^{43}$.

Communication companies deserve special attention. Because of the powerful role of telecommunications in social organizing ${ }^{44}$, telecommunication companies have been implicated in the commission of, and resistance to, RtoP violations. For instance, in Rwanda Radio Télévision Libre Des Mille Collines (RTLM) incited violence. ${ }^{45}$ In Kenya, text messages sent over the phone were used to incite and organize ethnic violence. ${ }^{46}$ In response, the Kenyan phone company Safaricom sent messages calling for calm, ${ }^{47}$ and has now implemented a filtering system that will allow them to block hateful messages in the future $^{48}$. Companies can also choose to actively allow the use of their system for resistance: in 2010, the security team at Facebook identified attempts by the Tunisian security services to hack into Facebook pages of people affiliated with protests against the Ben Ali government. The security team responded to this as they would any other unauthorized attempt to gain access, and prevented the hacking ${ }^{49}$. Facebook casts this as a business decision, not a political one, but it was a decision which supported the organized resistance to the then government of Tunisia.

\footnotetext{
${ }^{38}$ A. Aboa \& N. Hunt, "Ivorian Exporters Heed Ouattara's Cocoa Ban Call," Reuters, (25 January 2011).

${ }^{39}$ J. Cilliers \& C. Dietrich (eds.), Angola's War Economy: The Role of Oil and Diamonds (Institute for Security Studies, 2000).

${ }^{40}$ M. Kaldor, New and Old Wars: Organized Violence in a Global Era, 1st ed. (Stanford University Press, 1999), pp. 91-110.

${ }^{41}$ U. Galani, "Libya Rebel Funding Will Require Legal Creativity," Reuters Breakingviews, (9 May 2011).

${ }^{42}$ A. Blomfield, "Looters Attack Kenyan Tea Estates," Telegraph.co.uk (7 January 2008). See:

www.telegraph.co.uk/finance/economics/2782175/Looters-attack-Kenyan-tea-estates.html. (Accessed March 2012).

${ }^{43}$ Op.Cit., Corporations and Counterinsurgency.

${ }^{44}$ Op.Cit., Arab Social Media Report.

${ }^{45}$ F. Chalk, "Monitoring African Governments' Domestic Media to Predict and Prevent Mass Atrocities: Opportunities and

Obstacles," in R. Rotberg (ed.) Mass Atrocity Crimes: Preventing Future Outrages (Brookings Institution Press, 2010), pp. 220-238.

${ }^{46}$ O. Quist-Arcton, "Text Messages Used to Incite Violence in Kenya," National Public Radio (20 February 2008). See

www.npr.org/templates/story/story.php?storyld=19188853. (Accessed March 2012).

${ }^{47} \mathrm{Ibid}$.

${ }^{48}$ BBC World Service Trust, The Kenyan 2007 Elections and Their Aftermath: The Role of Media and Communication, Policy Briefing (London, UK: BBC World Service Trust, April 2008).

${ }^{49}$ A. Madrigal, "The Inside Story of How Facebook Responded to Tunisian Hacks," The Atlantic (24 January 2011).
} 
A second track for direct engagement with the conflict is companies using political influence to encourage the cessation of RtoP violations ${ }^{50}$. Businesses, particularly multinational corporations, are often accused of exerting a powerful impact on the political processes of countries in which they work. For example, a diplomatic memo released by Wikileaks in 2010 included a report from a Shell Oil executive describing the influence that Shell had with the Nigerian government ${ }^{51}$. The United Fruit Company was famously influential in encouraging the US government to overthrow the democratically elected Guatemalan president, Jacobo Árbenz Guzmán, in $1954 .^{52}$ This political influence is a reflection of the size and impact of the companies involved, and could be used for good. Businesses have been actively involved in the resolution of significant human rights abuses. In South Africa, Shell Oil funded a major education campaign encouraging peaceful democratic transition in 1994, and other South African companies directly engaged in setting up and encouraging negotiations between the apartheid government and organized opposition ${ }^{53}$.

Finally, and no less importantly, businesses may participate in peacebuilding and recovery following RtoP interventions. Economic growth and the resumption of regular economic activity is an important part of ensuring stability, and both local and multinational businesses can play a major role in assisting with investment and the re-establishment of sustainable economies in formerly violent areas ${ }^{54}$. While this is outside the scope of a focus on third pillar interventions, it is nevertheless an important issue that should be considered.

\section{Maximizing Business Participation in Third Pillar Intervention}

The previous discussion identified potential ways that businesses may participate in RtoP interventions, as well as some limited examples of when they have participated in the past. This calls for a focus on why businesses have not engaged more frequently, systematically, and beneficially.

One reason for this is that the participation of business in third pillar interventions has been hampered by a lack of systematic outreach or explicit invitations to participate. Businesses may not see RtoP interventions as within their remit. For example, Milton Friedman argues that "the social responsibility of business is [only] to increase its profits" $" 55$ However, as the above discussion has pointed out, there are clear bottom-line economic reasons for businesses to participate in the prevention, cessation, and recovery from RtoP violations. This suggests that businesses may not have been exposed to sufficiently convincing arguments. It is also possible that businesses do not participate in RtoP interventions because they are ignorant of how to do so effectively, legally, and legitimately. Jamali and Mirshak's interviews with businesses dealing with armed conflict in Lebanon found that one reason businesses did not choose to participate directly in the conflict was a perception that they had low bargaining power when participating in discussions about conflict, as well as concerns about the legitimacy of any action they could take ${ }^{56}$.

This suggests that the fundamental challenge with business engagement is a lack of outreach and the establishment of credible pathways by which business can participate in RtoP interventions. Providing businesses with economic, moral, and legal arguments, combined with practical pathways for how businesses may benefit from RtoP interventions may provide significant benefits to businesses. One model of a related approach is the role of business in humanitarian relief: since the mid-1990s, there has been a

\footnotetext{
${ }^{50}$ G. Ben-Porat, "Between Power and Hegemony; Business Communities in Peace Processes," Review of International Studies, Vol. 31, No. 2 (2005), pp. 325-348.

51 "WikiLeaks Cables: Shell's Grip on Nigerian State Revealed," The Guardian, (8 December 2010). See: www.guardian.co.uk/business/2010/dec/08/wikileaks-cables-shell-nigeria-spying. (Accessed April 2012).

${ }^{52}$ S. Schlesinger \& S. Kinzer, Bitter Fruit: The Story of the American Coup in Guatemala, Revised and Expanded, (David Rockefeller Center for Latin American Studies, 2005).

${ }^{53}$ Op.Cit., The Business of Peace: The Private Sector as a Partner in Conflict Prevention and Resolution. Pg 69, 112.

${ }^{54}$ M. Berdal \& N. Mousavizadeh, "Investing for Peace: The Private Sector and the Challenges of Peacebuilding," Survival, Vol. 52, No. 2 (2010), pp. 37-58; C. Gündüz, C. Vaillant, \& J. Banfield, Addressing the Economic Dimensions of Peacebuilding Through Trade and Support to Private Enterprise (International Alert, 2006).

${ }^{55}$ M. Friedman, "The Social Responsibility of Business Is to Increase Its Profits," New York Times Magazine (13 Sep 1970).

${ }^{56}$ Op.Cit., "Business-Conflict Linkages: Revisiting MNCs, CSR, and Conflict", p. 460.
} 
gradual expansion of business involvement in humanitarian relief in general, although this has predominantly been in response to natural disasters ${ }^{57}$. This has taken the form of partnerships between businesses and large NGOs such as the ICRC or CARE as well as direct or company-driven engagement with disaster recovery or conflict prevention or recovery ${ }^{58}$.

How a business is connected to an RtoP violation can be used to identify specific contributions that individual businesses can make, which can then be directly presented to business by NGOs or states interested in involving these companies. ${ }^{59}$

RtoP interventions have a strength that traditional attempts to engage business in conflict do not: by the nature of RtoP's formulation, it deals with events where there is widespread condemnation. Third pillar interventions have to date been characterized by attention and, in many cases, the endorsement of major IGOs. To the extent that such IGOs legitimize an intervention, business involvement may be concomitantly legitimized.

That IGOs are involved in third pillar interventions also raises the possibility that outreach to businesses may be undertaken by IGOs instead of NGOs or other groups. A formal invitation from an IGO may be seen as more legitimate by businesses and their stakeholders than pressure from NGOs. To the extent that business participation is limited by perceptions that there is no legitimate pathway to participate, IGO invitations may increase participation. Unlike NGOs, IGOs and states can change the laws regarding businesses, and in doing so create new pathways to participation or formally legitimize existing paths. One example is the recommendation of the Working Group on the Prevention of Odious Debt in 2010: they argue that if a state is in violation of RtoP or otherwise illegitimate, other states or IGOs can engage in "pre-emptive contract sanctions" by declaring that they will not recognize contracts made with an existing regime from some specific point in time ${ }^{60}$. In addition to formal outreach to encourage businesses to engage with RtoP issues using existing potential approaches, states and IGOs may choose to create new pathways.

\section{Conclusion}

Businesses have significant resources, and represent one organized sector of society operating in areas where RtoP violations occur. There is a general connection between a well-functioning economy and political stability ${ }^{61}$, and several indicators of successful governance are based on the argument that good governance is in part related to support for business activity ${ }^{62}$. Aside from this general connection between economic activity and stability, research on humanitarian intervention and research in business and peace suggests that businesses can contribute to stopping RtoP violations.

Ultimately, business is an inescapable part of the modern world, and a sector which can and has mitigated conflict and human rights abuses in the past. The question is not whether business has a role to play in these issues, but rather how business' contributions to stop RtoP violations can best be maximized.

\footnotetext{
${ }^{57}$ A. Binder and J. M. Witte, Business Engagement in Humanitarian Relief: Key Trends and Policy Implications (London, UK: Humanitarian Policy Group: Overseas Development Institute, 2007).

${ }^{58}$ R. Kent and J. Burke, Commercial and Humanitarian Engagement in Crisis Contexts: Current Trends, Future Drivers (London, UK: Humanitarian Futures Programme, 2011).

${ }^{59}$ Op.Cit., The Business of Peace: The Private Sector as a Partner in Conflict Prevention and Resolution.

${ }^{60}$ Working Group on the Prevention of Odious Debt, Preventing Odious Obligations: A New Tool for Protecting Citizens from Illegitimate Regimes (Washington, DC: Center for Global Development, 2010).

${ }^{61}$ B. F. Walter, Conflict Relapse and the Sustainability of Post-conflict Peace (Washington, DC: The World Bank, 2010).

${ }^{62}$ For example, see Rotberg's definition of key components of governance in R.L. Rotberg, "The Challenge of Weak, Failing, and Collapsed States," in C.A. Crocker (ed.) Leashing the Dogs of War: Conflict Management in a Divided World, (Washington, DC: United States Institute of Peace Press, 2007).
} 


\title{
Gender Dimensions of Third Pillar Capacities: Women's Contributions to Conflict Prevention, Early Warning and Rapid Response
}

\author{
MELINA LITO
}

\section{Introduction}

In the winter of 2011, a group of NGO and UN agency representatives came together in New York to begin a preliminary discussion on how best to integrate women's skills and perspectives, shifting from that of survivors to that of agents of change who can make significant contributions, into the RtoP norm and its tools of implementation. The purpose of the group was to identify the links and the gaps that both bind and separate these communities and their modes of discourse as part of our contribution to this summer's General Assembly debate on the "third pillar" of RtoP.

The group acknowledged that much of the analysis of potential linkages has come from an academic perspective, and that more could be done from the policy side to increase linkage robustness and make connections more actionable. The political sensitivity of including a gender lens within RtoP implementation language was also addressed, as well as similar concerns about including RtoP language within the frameworks and priorities of the Women, Peace and Security (WPS) agenda, which is devoted to increasing women's participation in all aspects of peace policies and processes as set out in Security Council Resolution (SCR) $1325 .^{1}$

The group identified the need to create broader and more collaborative networks of actors binding the WPS and RtoP communities as well as to bridge divisions that might otherwise cause these communities to keep their distance. As part of this process, it was agreed that we should create, assess and revise a background "concept note" that lays out some productive policy linkages that can help bind the gender and RtoP communities in ways that would be of benefit to issue practitioners, but especially to diplomats with responsibility to cover both of these issues.

The note principally argues that the RtoP framework would be further enhanced by incorporating gender perspectives, including both skills for implementation and a greater understanding of the unique ways in which mass atrocity violence impacts female populations. Often under-represented, women can make significant contributions in their capacities as both survivors of conflict and agents of change; thus more attention should be given to making fully operational their capacities and experiences. Of course, as RtoP moves from norm building to implementation, we must be sensitive to full spectrum issues of gender inclusivity. As UN Special Representative of the Secretary-General (SRSG) Margot Wallström noted in her recent report to the Security Council, while sexual violence generally has a disproportionate effect on women and girls, recent trends show that men and boys are victims of rape as well so violence against both genders should be examined as part of our responsibilities to protect civilian populations. ${ }^{2}$

Global Action to Prevent War and Armed Conflict (GAPW) was the original convener of the working group that has developed this concept note. In preparation, GAPW undertook broad consultations within the RtoP and WPS communities. At the same time, GAPW promotes its own perspective on this and other linkages within the UN security system. As best we can, we are committed to highlighting the need for a robust, multi-faceted human security agenda with strong connections between nuclear and nonnuclear disarmament, but even more with linkages that bind the protection of civilians, gender-based violence, illicit arms transfers and other current security concerns. RtoP is an important normative development, but one which does not occur in a vacuum. Just as the pillars of RtoP highlight complementary responsibilities by states and the international community to address atrocity crimes, states have urgent, complementary responsibilities to create stable, transparent, sustainable security sectors

\footnotetext{
${ }^{1}$ UN, "Women and Peace and Security", S/RES/1325, New York (31 October 2000).

${ }^{2}$ UN, "Conflict-Related Sexual Violence, Report of the Secretary-General”, A/66/657 S/2012/33, New York, (13 January 2012), para.6.
} 
and adopt policies that contribute to trust by states and other stakeholders - even those states that will never possess a nuclear weapon or contribute troops to peacekeeping operations. In this inter-connected security architecture, the roles and challenges of women must be highlighted and enhanced.

In our view, the most effective tools to address mass atrocities are the ones that never need to be used. To help ensure that "third pillar" coercive capacities are deployed as seldom as possible, we all have important, complementary responsibilities to security sector reform, ending diversion in the global arms trade, creating sustainable weapons of mass destruction free zones, all of which are occasions for increased levels of women's participation. The responsibility to protect is part of a larger "responsibility to peace building" that the UN is taking increasingly seriously and to which our norm-based community must contribute as much as possible. An important component of that "responsibility to peace building" is the integration of women's perspectives, shifting from that of survivors to that of agents who can make significant contributions in protecting against, and preventing, mass atrocity crimes.

\section{Background Concept Note}

\section{Reflections of Current Gender Issues in the RtoP Framework}

The RtoP norm was affirmed by the international community in 2005 with the aim to protect populations from genocide, war crimes, ethnic cleansing and crimes against humanity (hereinafter "mass atrocity crimes"). The UNSG's report on Implementing the Responsibility to Protect ${ }^{3}$ (2009) noted that sexual violence against women could constitute a war crime, or a crime against humanity. ${ }^{4}$

As outlined in the Secretary-General's 2009 report, there is a three pillar strategy on implementing the doctrine:

- 'Each individual State has the responsibility to protect its populations from genocide, war crimes, ethnic cleansing and crimes against humanity. ${ }^{5}$

- The international community has a responsibility to assist states in meeting those obligations. ${ }^{6}$

- 'The international community, through the United Nations, also has the responsibility to use appropriate diplomatic, humanitarian and other peaceful means in accordance with Chapters VI and VIII of the Charter, to help protect populations from genocide, war crimes, ethnic cleansing and crimes against humanity. "If such means prove inadequate and a state is "manifestly failing" in its efforts to protect civilians from mass atrocity crimes, then the international community, working with regional organizations, can engage in "collective action, in a timely and decisive manner. ${ }^{8}$

While the implementation of RtoP has in many instances addressed the need to protect women from rape and other sexual violence, much remains to be done to fully integrate women's skills and capacities in preventing and addressing mass violence. ${ }^{9}$ Attention to the particular needs of women is important because women are often underrepresented in policy discussions and are not necessarily a priority focus

\footnotetext{
${ }^{3}$ UN, "Implementing the responsibility to protect Report of the Secretary-General", A/63/677, New York (12 January 2009).

4 "The Role of Women in the RtoP Framework," International Coalition for the Responsibility to Protect (ICR2P). See: http://responsibilitytoprotect.org/index.php/women-and-conflict. (Accessed 6 April 2012).

${ }^{5}$ A/63/677, para. 13; See also, UN, "2005 World Summit Outcome Document”, A/60/L.1 (15 September 2005), para. 138. See: http://globalr2p.org/media/pdf/WSOD_2005.pdf. (Accessed 6 April 2012).

${ }^{6} \mathrm{~A} / 63 / 677$, para. 28; See also, A/60/L.1, para. 138.

${ }^{7} \mathrm{~A} / 63 / 677$, para. 49; See also, A/60/L.1, para. 139.

${ }^{8} \mathrm{~A} / 63 / 677$, para. 49; See also, A/60/L.1, para. 139.

${ }^{9}$ See, E. Stammes, "The Responsibility to Protect: Integrating gender perspectives into policies and practices," Norwegian Institute of International Affairs Report 2010, pp. 9-13.
} 
group for state protection strategies. ${ }^{10}$ Women often experience disproportionate impacts from armed conflict insofar as they are targets of rape and sexual violence, tend to have less access to policy, employment and educational options, and 'experience widespread violations of non-derogable rights to life, torture, summary or arbitrary executions, displacement' and other gross violations. ${ }^{11}$ RtoP can be further enhanced as an effective security framework by incorporating women's skills and experiences as returning ex-combatants, immigrants, refugees, mediators, and political leaders. As SRSG Wallström has noted, in practical ways 'the Council has understood that there can be no security without women's security. The aim is not to protect women from violence; it is to protect them to participate in public and economic life. ${ }^{12}$

Thus far, the incorporation of women's perspectives, skills, and needs has been limited. The UNSG's 2009 report on Implementing the Responsibility to Protect, did make some direct and welcomed references to SCR 1325 and 1820. SCR 1325 acknowledges women's participation at all decision-making levels; their protection from sexual and gender-based violence; and stresses the importance of including gender perspectives in peace processes. ${ }^{13}$ SCR 1820 focuses specifically on widespread sexual violence in conflict as a major impediment to sustainable peace and security. ${ }^{14}$ The 2009 report made reference to the following:

- The role of women's groups in shaping an international response to crimes relevant to RtoP is not very well known and requires more attention. ${ }^{15}$

- There is a need to provide care to victims and survivors, and to recognize and support women's groups who have played a critical role in assisting survivors of systematic sexual violence. ${ }^{16}$

- It must be recognized that women's non-government organizations can be important sources for detecting and warning of conflict at early stages. ${ }^{17}$

- There is a need to expand research (including women's voices) to help determine 'why it has been so difficult to stem widespread and systematic sexual violence in some places. ${ }^{18}$

- There is acknowledgment that '[i]n its resolutions 1612 (2005) and 1820 (2008), the Security Council underscored that rape and other forms of sexual violence could constitute war crimes, crimes against humanity or constitutive acts with respect to genocide. In its resolution 1820 (2008), the Council recognized that widespread and systematic sexual violence was a security problem that should be monitored by the Council, ${ }^{19}$ especially as it can be 'as destructive to communities as more conventional weapons. ${ }^{20}$

In the context of SCR 1325, the UNSG's report did give some attention to promoting women as agents of change in the most critical areas of peace and security. ${ }^{21}$ In the context of SCR 1820, the identification of mass rape and sexual violence as mass atrocity crimes is, of course, supported. But, the UNSG's conclusion that systematic sexual violence can destroy communities as much as conventional weapons

\footnotetext{
${ }^{10}$ N. Kikoler, Presentation at Incorporating a Gender lens into the Responsibility to Protect Framework for Addressing Mass Atrocities panel discussion hosted by Global Action to Prevent War, New York, (21 February 2012).

${ }^{11}$ Convention on the Elimination of Discrimination Against Women. Concept Note: General Discussion on the protection of women's human rights in conflict and post-conflict contexts, pp. 6-7. See:

www2.ohchr.org/english/bodies/cedaw/docs/GRConceptNote.pdf. (Accessed 9 April 2012).

${ }^{12}$ UN, "Statement by UN Representative of the Secretary-General, Margot Wallström", Security Council Open Meeting, New York, (23 February 2012).

${ }^{13}$ See, UN, "Women and Peace and Security," S/RES/1325, New York (31 October 2000).

${ }^{14}$ See, UN, "Women and Peace and Security," S/RES/1820, New York (19 June 2008)

${ }^{15} \mathrm{~A} / 63 / 677$, para. 59.

${ }^{16}$ Ibid., para. 26.

${ }^{17}$ Ibid., Annex, para. 3.

${ }^{18}$ Ibid., para. 15.

${ }^{19}$ Ibid., para. 34.

${ }^{20}$ Ibid., para. 34.

${ }^{21}$ See, Stammes, "The Responsibility to Protect", p.12.
} 
can, does not expressly mandate the responsibility of states to protect populations from acts of sexual violence under RtoP. ${ }^{22}$ Therefore, while it is true that some forms of sexual violence can be construed as a mass atrocity crime, and that states have a responsibility to protect populations from mass atrocities, a direct link is not made that states thereby have a special responsibility to protect populations from sexual violence.

The UNSG's 2010 report on Early Warning, Assessment and the Responsibility to Protect focused attention on detecting sexual and gender-based violence (SGBV) at an early stage, ${ }^{23}$ while the UNSG's 2011 report on The Role of Regional and Sub-Regional Arrangements in Implementing the Responsibility to Protect noted that SGBV is aggravated by a weak judicial system and security sector and that consultations with women's groups are necessary to prevent mass atrocity crimes. ${ }^{24}$

Despite these positive developments, official discourse on gender and RtoP still focuses on women as a vulnerable population- as victims of violence. More attention needs to be paid to women as agents of change and how their contributions in this capacity, at an early stage, can be influential in detecting patterns of conflict, in mediating conflict at early stages, and in contributing to greater protection and prevention activities under RtoP.

Even in looking at some of the SCRs where RtoP has been invoked, attention to women's role as effective agents of change is limited. SCR 1973 (2011) authorizing the no-fly zone over Libya called for Member States 'to take all necessary measures... to protect civilians and civilian populated areas, ${ }^{25}$ although SCR 2009 (2011), which established the UN Support Mission in Libya (UNSMIL), did make reference to the promotion of women's full participation after conflict. ${ }^{26}$ Similarly, the recent SCR 2040, extending UNSMIL's mandate for six months, made reference to the 'empowerment and political participation of women' as part of UNSMIL's mandate. ${ }^{27}$

Moreover, in SCR 1975 (2011) regarding the immediate end of violence in Côte d'Ivoire, the Security Council called for the 'immediate end to the violence against civilians, including women, children and [i]nternally displaced persons, ${ }^{28}$ and emphasized the support to United Nations Operation in Côte d'Ivoire (UNOCI) to 'use all necessary means to carry out its mandate to protect civilians under imminent threat of violence. ${ }^{29}$ In SCR 2000 (2011) where the Council extend UNOCI's mandate, more emphasis was placed on protection strategies that reflect the needs of the vulnerable groups on the ground and that aim to eliminate gender-based violence. ${ }^{30}$ Also, enacting protection strategies that include sexual and gender-based violence and violations against women and children, became part of the mandate as did supporting the government in combating sexual and gender-based violence including appointing 'Women Protection Advisers and to ensure gender expertise and training, as appropriate and from within existing resources. ${ }^{31}$

While attention must continue to be paid to strategies for protecting women from sexual violence in the broader context of protection of civilians and vulnerable groups, like women and children, more attention is needed on the contributions women can make in their role as mediators of conflict, peacekeepers, and effective participants in protection, prevention and post-conflict rebuilding.

More analysis and discussion is also needed from the international community's stakeholders on how conflict-related sexual violence could amount to mass atrocities and how the responsibility to protect applies in such situations. As noted in the SRSG's recent report, '[c]onflict-related sexual violence refers to incidents or patterns (for the purposes of listing in accordance with Security Council resolution 1960

\footnotetext{
${ }^{22}$ Op.Cit., "The Responsibility to Protect", p. 12.

${ }^{23}$ UN, "Early Warning, assessment and the responsibility to protect, Report of the Secretary-General", A/64/864, (14 July 2010), para. 12.

${ }^{24} \mathrm{UN}$, "The role of regional and sub-regional arrangements in implementing the responsibility to protect, Report of the Secretary-General,"A/65/7877 S/2011/393, (27 June 2011), paras. 26, 12.

${ }^{25}$ UN, "The situation in Libya”, S/RES/1973, (17 March 2011), para. 4.

${ }^{26}$ UN, "The situation in Libya”, S/RES/2009, (16 September 2011), para. 3.

${ }^{27}$ UN, "The situation in Libya”, S/RES/2040, (12 March 2012), para. 6(a).

${ }^{28}$ UN, "The situation in Cote d'Ivoire", S/RES/1975, (30 March 2011), para.1.

${ }^{29}$ UN, "The situation in Cote d'Ivoire", S/RES/1975, (30 March 2011), para.6.

${ }^{30}$ UN, "The situation in Cote d'Ivoire", S/RES/2000, (27 July 2011), para. 7(a).

${ }^{31}$ UN, “The situation in Cote d'Ivoire," S/RES/2000, (27 July 2011), para 7(g).
} 
(2010)) of sexual violence, that is rape, sexual slavery, forced prostitution, forced pregnancy, enforced sterilization or any other form of sexual violence of comparable gravity against women, men or children. ${ }^{32}$ The responsibility still remains with the international community to protect populations from widespread violence; examples include the situation in Libya where reports show that men have been raped in detention facilities, and women have been abducted and subsequently raped; ${ }^{33}$ also in Syria where reports indicate male detainees have been subjected to sexual torture and forced to witness the rape of other boys; ${ }^{34}$ and in the DRC where retaliatory rapes by armed groups and sexual violence are used as a way to exercising control over the population. ${ }^{35}$

More attention should be placed on linking the responsibility of states to protect populations from conflict-related violence, which can amount to mass atrocity crimes. Protection is most effective when it is "gender-responsive and community-based." ${ }^{36}$ Therefore, more attention among the international community of policymakers and academics must be paid to women's experiences and skills as agents of change to ensure that RtoP operates effectively and legitimately to protect populations.

\section{How Women be More Effective Participants in the RtoP Framework}

The international community cannot effectively promote international peace and security, nor successfully protect civilian populations from the four crimes within the mandate of RtoP, without taking into account the gender specific needs of the population, particularly the skills and perspectives of women. In preparation for its General Discussion on the Protection of Women's Human Rights in Conflict and Post-conflict Contexts, the Committee on the Elimination of Discrimination against Women (CEDAW) issued a Concept Note noting that 'women are not always passive-by-standers or victims... in the diverse conflict and post-conflict contexts, women have historically and continue to express their agency as combatants, as part of organized civil society as human right defenders, as members of resistance movements and as active agents in both formal and informal peacebuilding processes. ${ }^{37}$

Inclusion of a gender perspective at an early stage can make significant headway in the protection of women against violence, but also to encourage their participation as agents of change in protection, prevention, and promotion of their rights in post-conflict rebuilding or reintegration, in the following ways: ${ }^{38}$

- Women as mediators can be key players in conflict resolution and protection of populations from violence as part of a robust commitment to the women, peace and security agenda.

- More attention to women's agency in all phases of conflict-related violence can help highlight instances of abuse, heal those who have been violated, and contribute to a greater understanding of the causes of and solutions to such violence.

\footnotetext{
${ }^{32}$ UN, "Conflict-Related Sexual Violence, Report of the Secretary-General", A/66/657 S/2012/33, New York, (13 January 2012), para. 3.

${ }^{33}$ See, Ibid., para. 36.

${ }^{34}$ Ibid., para. 87.

${ }^{35}$ Ibid., para. 27.

${ }^{36}$ UN, "Statement by UN Representative of the Secretary-General, Margot Wallström", Security Council Open Meeting, New York, (23 February 2012).

${ }^{37}$ Committee on the Elimination of Discrimination Against Women. Concept Note: General Discussion on the Protection of Women's Human Rights in Conflict and Post-Conflict Contexts, 18 July 2011, p.4. See: www2.ohchr.org/english/bodies/cedaw/docs/GRConceptNote.pdf. (Accessed 6 April 2012).

${ }^{38}$ Women's participation as mediators was the subject of the Arria Formula meeting held on 8 March 2012, discussing Women's Role in Mediation and Conflict Resolution, at the United Nations Headquarters as well as a workshop put together by the Department of Political Affairs and the Permanent Mission of Finland to the United Nations on 9 March 2012, discussing guidance for effective mediation. The discussions and takeaways from those events, as well as the advocacy in the UN civil society community on women's participation, inspired the following list of women as agents in preventing mass atrocity crimes.
} 
- A commitment to incorporate women into policy can promote a stronger, more reliable, and more transparent security sector as well as contribute to more effective conflict prevention and peace policy.

- Promoting women's participation as peacekeepers and peacebuilders can ensure that gender expertise is available to help train other personnel and community leaders about gender equality and women's participation.

Overall, incorporating a gender perspective in the RtoP framework helps ensure the full protection of all populations from mass atrocities, which can happen most effectively when we do our best to highlight gender perspectives on atrocity crime violence and ensure gender equality in all measures to prevent, respond to and rebuild from such violence. ${ }^{39}$

\section{Recommendations}

References to women's potential and actual agency in the prevention of mass atrocity crimes and the protection of civilians could be highlighted more in future reports by the UNSG. In carrying out the RtoP pillars, and most especially the challenging third pillar, the international community can and must do more to integrate women's perspectives and voices into all policy discussions focused on prevention and protective response.

To help ensure this integration, we propose the following concrete steps:

i. In discussing early warning and assessment in his 2009 report, the UNSG noted that women's organizations can be among the actors who can provide 'timely and sensitive information on evolving conflict situations. ${ }^{40}$ Women's organizations, including many most civil society organizations, can corroborate information about situations on the ground or can be 'the first to sound the alarm in the early stages of atrocity crimes. ${ }^{41}$ Similarly, more engagement and collaboration with civil society, in particular women's groups, at an early stage can also provide a link to a wider range of actors who can give input on the necessary skills and experiences of women that need to be addressed, and identify qualified candidates with gender-expertise who would be able to make significant contributions to policy discussions on prevention and protection.

ii. Likewise, in the 2009 report, the UNSG called upon UN departments and agencies to integrate RtoP into 'their ongoing activities and reporting procedures to the extent that their mandates permit' in hopes of anticipating situations of violence and 'encouraging more regular dialogue, informationsharing and common analysis among disparate programmes and agencies. ${ }^{42}$ Similarly, in his 2010 report, the SG identified the information sharing among the various agencies as a gap, and noted that to fully prevent against mass atrocity crimes, we need 'full utilization of the information gathered and the insight gained by existing UN entities, not the relabeling or duplication of their work. ${ }^{43}$ Along those lines, communication should be strengthened between UN agencies regarding how instances of conflict-related sexual violence can rise to the level of mass atrocity crimes where RtoP would apply; how the international community can invoke gender-inclusive protection strategies; and how women can be significant voices of change in conflict and post-conflict. Communication and consultations amongst the relevant agencies on these issues could go a long way to building bridges between the

\footnotetext{
${ }^{39}$ M. Butler, Presentation, at Incorporating a Gender lens into the Responsibility to Protect Framework for Addressing Mass Atrocities panel discussion hosted by Global Action to Prevent War, New York, (21 February 2012).

${ }^{40}$ UN, "Implementing the responsibility to protect Report of the Secretary-General", A/63/677, New York (12 January

2009), Annex, para.3.

${ }^{41}$ Ibid., Annex, para 3.

${ }^{42}$ Ibid., Annex, para. 4.

${ }^{43}$ UN, "Early Warning, assessment and the responsibility to protect, Report of the Secretary-General", A/64/864, (14 July 2010), para.10(a).
} 
gender and RtoP communities, and can also help ensure that these and other sectors of the UN system are more fully engaged in all aspects of violence prevention.

iii. In the 2011 report, the UNSG stressed the need for more collaboration with regional and subregional organizations. ${ }^{44}$ Regional organizations can do more to encourage women's direct participation in a wide range of peace and security initiatives and can also highlight the roles that women can play as mediators to prevent mass atrocities. In addition, states can appoint more women to decision-making positions as mediators and negotiators and help to document women's achievements in the conflict resolution and peacebuilding fields. Such attention to women's participation in peace processes can promote a culture of women as effective participants in the prevention of atrocity crimes within the RtoP framework.

iv. In the recent "Monthly Action Points" published by the NGO Working Group on Women, Peace and Security (NGOWG), the NGOWG noted that, given the current challenges of women in Syria, Libya, and Yemen, the Security Council should be briefed on "how the Council could build on previous good practice, and address the remaining gaps in implementation of Women, Peace and Security obligations, notably relating to women's empowerment and participation in peace talks. ${ }^{45}$ The NGOWG also encouraged that 'country reports and mandate renewals evaluate the levels of protection and promotion of women's human rights. ${ }^{46}$ In the context of mass atrocity crimes, civil society should evaluate lessons learned from the operation of RtoP, assess and supplement previous reports and mandates issued to protect civilians from mass atrocity crimes, and develop strategies that build upon already-enacted measures to promote women's participation in prevention and protection processes.

v. Illicit arms are one of the most pervasive threats to a dependable security sector, and diverted arms contribute to diverse crimes of violence on populations, including rape and other mass atrocities. Illicit weapons also contribute to domestic violence, trafficking and many other forms of lawlessness. Both RtoP and gender advocates are encouraged to consult regularly with UN agencies and civil society organizations focused on disarmament and security sector reform to help ensure that the negative impacts of illicit arms flows are recognized, highlighted and addressed long before these impacts rise to the level of mass atrocities.

vi. Finally, with the GA debate on the "third pillar" fast approaching, we should do everything possible to use this opportunity to explore and highlight the links between gender and RtoP. Nonetheless, attention to these complementary concerns should continue long after the debate. In 'The Role of Women in the RtoP Framework', the International Coalition for the Responsibility to Protect (ICRtoP) recommends the creation of an ongoing working group within the UN (separate from our own initiative in this area) to 'better integrate a gendered approach to the norm. ${ }^{\text {'47 }}$ Such a working group, especially if it is formed by the Secretary-General, or with significant involvement from the "Friends" of both SCR 1325 and RtoP, can play a major role in highlighting sector linkages and guiding future policy. ${ }^{48}$

\footnotetext{
${ }^{44} \mathrm{UN}$, "The role of regional and sub-regional arrangements in implementing the responsibility to protect", A/59/744 S/2005/183, (27 June 2011), para. 38.

45 "Monthly Action Points on Women, Peace and Security, Security Council: April 2012," NGO Working Group on Women, Peace and Security. See: http://womenpeacesecurity.org/media/pdf-MAP_April2012.pdf. (Accessed 5 April 2012).

${ }^{46} \mathrm{Ibid}$.

47 "The Role of Women in the RtoP Framework," International Coalition for the Responsibility to Protect. See: http://responsibilitytoprotect.org/index.php/women-and-conflict. (Accessed 6 April 2012).

${ }^{48}$ See also, "Women and the Responsibility to Protect," International Coalition for the Responsibility to Protect, Blog, (9 March 2012). See: http://icrtopblog.org/2012/03/09/women-and-the-responsibility-to-protect/. (Accessed 9 April 2012).
} 
As the RtoP framework evolves, it is more and more apparent that the international community should endorse discrete, tangible responsibilities not only to protect civilians from the commission of mass atrocity crimes, but, most importantly, to prevent such crimes from occurring in the first place. In order to do so effectively, RtoP policies need to consider women's contributions both as survivors of mass violence, and as agents of stability and change at all levels of engagement. ${ }^{49}$ The RtoP framework can be more effectively implemented with the full integration of women whose multifaceted roles can range from being leaders of conflict prevention and resolution activities to providing assistance to survivors of conflict and ex-combatants. ${ }^{50}$

\section{Conclusion}

The broad purposes of the "background concept note" are to highlight the gender links in the RtoP framework, promote women's participation in all preventive and reactive capacities, and ensure that the RtoP framework is more responsive to conflict-related sexual violence. The intent of this particular chapter is to stimulate discussion on how women's integration can strengthen the broad RtoP framework, to provide some background on how gender issues have been addressed in the recent history of RtoP starting from 2009, and to share recommendations that can raise the visibility of these issue linkages within the policy community. With the GA debate coming up in summer 2012, this note can hopefully serve as background for states as they compose their statements and positions on ways to strengthen the RtoP "third pillar". We urge all delegations and other stakeholders involved with RtoP to incorporate an awareness that effective protection of populations from mass atrocity crimes includes enacting policies that incorporate the skills and experiences of women in diverse circumstances, with particular concern for women in often neglected traditional and rural communities.

\footnotetext{
${ }^{49}$ Stammes, "The Responsibility to Protect", p. 21.

${ }^{50}$ Ibid., pp. 22-23.
} 


\title{
Sanctions, Trials and Peace: Promises and Pitfalls of the Responsibility to Protect's Civilian Dimension
}

\author{
CAROLINE FEHL
}

\author{
Introduction
}

The RtoP, brainchild of UN diplomats, American scholars and Canadian politicians, is still a young international norm, yet it has already taken on a life of its own unforeseen by its intellectual parents. The most striking evolution within the concept has been the continuous shift in emphasis from military to non-military responses to humanitarian crises, both at the conceptual level and in the implementation of RtoP in recent crises.

Conceptually, the "civilization" of RtoP started almost upon its inception, when the "International Commission on Intervention and State Sovereignty" (ICISS), rather than the "International Commission on Humanitarian Intervention" originally proposed by its Canadian sponsors, was convened in 2001. The name change was a political concession signalling that humanitarian intervention remained a highly controversial concept which needed to be reconciled with - rather than simply override - the principle of state sovereignty. ${ }^{387}$ In its final report, the Commission sought to achieve this reconciliation by conditioning sovereignty on a state's fulfilment of its protective tasks, but also by striking a balance between military and civilian tools for implementing RtoP. The hard historical core of the concept - the "Responsibility to React" to humanitarian emergencies with military interventions - was cushioned with a call for civilian crisis responses and with the invention of pre- and post-crisis "sister responsibilities": the "Responsibility to Prevent" and the "Responsibility to Rebuild". ${ }^{388}$ Further discussions and refinements of the concept then followed the path laid out by the ICISS report in emphasizing civilian crisis management, as well as responsibilities other than crisis reaction, as part of the RtoP. Most notably, the UNSG's Report "Implementing the Responsibility to Protect", released in 2009, introduced a three-pillar structure that shifted attention to states' responsibilities vis-à-vis their own populations ("pillar one"), to the non-confrontational supportive role of the international community with regard to this primary responsibility ("pillar two") and to the importance of non-military crisis responses as part of the reactive "pillar three". ${ }^{389}$

The conceptual development toward a stronger civilian component of RtoP is not a case of mere academic quibbling, but reflects a real and growing scepticism vis-à-vis military interventions under the cloak of humanity among large parts of the international community, not only in the Global South. ${ }^{390}$ This scepticism has largely inhibited humanitarian interventions in a long row of recent crises - with Libya perhaps the exception that proves the rule - and has driven states to look for alternative responses to mass atrocities, such as mediation, sanctions, or international criminal tribunals.

While interest in the civilian dimension of the Responsibility to Protect has thus been growing at a conceptual and practical level, it is striking that this has thus far generated little in-depth analysis and debate, compared to the controversy surrounding humanitarian intervention. For instance, the ICISS

\footnotetext{
387 A. Bellamy, "The Responsibility to Protect and the Problem of Military Intervention", International Affairs, Vol. 84, No. 4 (2008), pp. 615-639, here p. 620.

${ }^{388}$ International Commission on Intervention and State Sovereignty (ICISS) The Responsibility to Protect. Report of the International Commission on Intervention and State Sovereignty (International Development Research Centre, 2001); see also ibid. Bellamy.

${ }^{389}$ UN General Assembly, "Implementing the Responsibility to Protect. Report of the Secretary-General", A763/677, (12 January 2009); see also D. Chandler, "R2P or not to R2P? More Statebuilding, Less Responsibility", Global Responsibility to Protect, Vol. 2, No. 1-2 (2010), pp. 161-166.

${ }^{390}$ A. Bellamy, "Realizing the Responsibility to Protect", International Studies Perspectives, Vol. 10, No. 2 (2009), pp. 111-128; Chandler, "R2P or not to R2P”; T. Reinold, "The Responsibility to Protect - Much Ado About Nothing?", Review of International Studies, Vol. 36, Special Issue S1 (Evaluating global orders), pp. 55-78.
} 
report singles out the Responsibility to Prevent as the most important element of RtoP, yet gives more than three times the space to the discussion of humanitarian intervention. ${ }^{391}$

The sparse treatment of RtoP's civilian aspects both in official documents and in the academic literature could be read as indicating, quite simply, that no discussion is needed because the civilian dimension is self-evident and unproblematic. ${ }^{392}$ In fact, some critics of humanitarian intervention claim that prevention, post-conflict peacebuilding and civilian crisis management have been added to the RtoP mix precisely because of their uncontroversial nature - as a strategy of "selling" intervention to the sceptics. ${ }^{393}$ While this may well have been a motivation, this chapter argues that the seemingly broad agreement about RtoP's civilian dimension is in fact unjustified. Non-military strategies prominently advertised as part of the RtoP "toolbox" have many inherent problems and pitfalls that RtoP advocates have neglected for too long. A more critical discussion of these issues is therefore needed - if we are to take RtoP's civilian elements seriously as more than a sales pitch.

More specifically, the following analysis focuses on two civilian strategies which are prominently cited in the RtoP literature and have been widely used in recent state practice: economic and other forms of sanctions, and the prosecution of perpetrators in international criminal courts and tribunals. Both sanctions and trials are widely cited as promising alternatives to military intervention in a humanitarian crisis, for instance in the ICISS report: "by far the most controversial form of [..] intervention is military, and a great part of our report necessarily focuses on that. But we are also very much concerned with alternatives to military action, including all forms of preventive measures, and coercive measures sanctions and criminal prosecutions - falling short of military intervention. ${ }^{394}$

In this quote, sanctions and trials are framed as early steps on an escalation ladder of coercive crisis responses that precede, and ideally render unnecessary, military intervention. This escalation logic is most clearly expressed with regard to sanctions, for instance in the argument that sanctions are an important tool of RtoP because "there remains a need [...] for a tool lying 'between words and war.' "' 395 But also the criminal prosecution of perpetrators is often discussed under the heading of the "Responsibility to React", based on the argument that "[t]he strongest direct legal weapon to employ against those initiating unlawful violence is to arrest, try, and if properly convicted, punish them in a competent criminal court". ${ }^{396}$

Yet, neither sanctions nor trials are thought to be limited to the crisis response stage. Efforts to prevent the escalation of crises, RtoP proponents argue, can rely on timely threats of sanctions, ${ }^{397}$ as well as on the deterrent effect of criminal prosecutions: 'the threat to seek or apply international legal sanctions has [...] become a major new weapon in the international preventive armoury. [...] [T]he establishment of specialist tribunals to deal with war crimes committed in specific conflicts [...] will concentrate the minds of potential perpetrators of crimes against humanity on the risks they run of international retribution. ${ }^{398}$ Lastly, the prosecution of major crimes is also seen as a key building block of RtoP's "Responsibility to Rebuild". 399

In summary, sanctions and trials are presented as true "multipurpose" instruments in the RtoP toolbox, which the international community can wield with great effect, both within its "pillar three" responsibility of crisis response and in pre- and post-conflict contexts. Yet, does this ideal picture match with the empirical reality? The following analysis casts doubt on this claim.

\footnotetext{
${ }^{391}$ Bellamy, "The Responsibility to Protect and the Problem of Military Intervention”, p. 621.

${ }^{392}$ For an exception to the general disinterest in civilian aspects, see e.g. A. Bellamy, "Conflict Prevention and the Responsibility to Protect”, Global Governance, Vol. 14, No. 2 (2008).

${ }^{393}$ Chandler, "R2P or not to R2P", p. 163.

${ }^{394}$ ICISS, The Responsibility to Protect, p. 8.

395 G.J. Evans, The Responsibility to Protect: Ending Mass Atrocity Crimes Once and for All (Brookings, 2008), p. 114.

${ }^{396}$ Evans, The Responsibility to Protect, p. 115.

${ }^{397}$ Evans, The Responsibility to Protect, p. 94.

${ }^{398}$ ICISS, The Responsibility to Protect, p. 24.

${ }^{399}$ Evans, The Responsibility to Protect, p. 163.
} 


\section{Sanctions and trials - lessons from research and practice}

\section{Effectiveness and unintended consequences of sanctions}

The fact that sanctions are still accorded a prominent place in discussions on RtoP must surprise anyone familiar with decades of academic debate about the effects of various forms of sanctions. A first wave of research on the issue, conducted from the late 1960s to the early 1980s, focused on the question of whether and under what conditions economic sanctions such as trade embargoes could actually attain their - humanitarian or other - political aims. ${ }^{400}$ The findings were largely negative: while sanctions induced modest behavioural change in some cases, more often they remained without visible effects or even hardened the target's opposition to outside pressure. ${ }^{401}$ As early as 1989 , one analyst therefore drew the sobering conclusion: 'the view that these measures are an ineffective tool of statecraft has become almost axiomatic, ${ }^{402}$

Their limited effectiveness was not even the weightiest argument advanced against sanctions, however. The comprehensive economic embargoes imposed on the Former Yugoslavia, Haiti and particularly Iraq in the early 1990s triggered a wave of new research and a heated political debate about the grave negative humanitarian impact of global sanctions regimes. The shocking realisation that international sanctions had caused the death of hundreds of thousands of Iraqi children gave rise to calls for "targeted" or "smart" sanctions aimed more precisely at political elites. ${ }^{403} \mathrm{UN}$ members heeded these calls by launching three reform processes in the late 1990s, the Interlaken Process on Targeted Financial Sanctions, the Bonn-Berlin Process on Arms Embargoes and Travel and Aviation Related Sanctions, and the Stockholm Process on the Implementation of Targeted Sanctions. As a result of these and other discussions, comprehensive economic sanctions have disappeared from the arsenal of the UNSC, which has instead imposed a growing number of sector-specific trade embargoes, arms embargoes, financial sanctions, aviation and travel bans. ${ }^{404}$

The notion that sanctions need to be "smart" has by now become a firm international consensus, which is also reflected in the RtoP literature. ${ }^{405}$ Yet, studies evaluating the success of smart sanctions imposed to date have yielded mixed results at best. On the upside, there is clear evidence that targeting sanctions better has dampened their negative humanitarian effects. The downside of this development, however, is that the political effectiveness of smart sanctions in making targets change their behaviour has been even more limited than that of the old comprehensive regimes. ${ }^{406}$ Arms embargoes, one of the most popular forms of targeted sanctions, receive particularly bad grades in this regard. ${ }^{407}$

\footnotetext{
${ }^{400}$ E.g. D.A. Baldwin, Economic Statecraft (Princeton University Press, 1985); M.S. Daoudi \& M.S. Dajani, Economic Sanctions: Ideals and Experience (Routledge, 1983); M.P. Doxey, Economic Sanctions and International Enforcement (Oxford University Press, 1971); J. Galtung, "On the Effects of International Economic Sanctions: With Examples from the Case of Rhodesia”, World Politics, Vol. 19, No. 3 (1967), pp. 378-416; G.C. Hufbauer \& J.J. Schott, Economic Sanctions in Support of Foreign Policy Goals (Peterson Institute for International Economics, 1983).

${ }^{401}$ Galtung, "Effects of Economic Sanctions".

${ }^{402}$ K.R. Nossal, "International Sanctions as International Punishment", International Organization, Vol. 43, No. 2 (1989), pp. 30122, here p. 301.

${ }^{403}$ D. Cortright \& G.A. Lopez, The Sanctions Decade: Assessing UN Strategies in the 1990s (Lynne Rienner, 2000); M. Craven, "Humanitarianism and the Quest for Smarter Sanctions", European Journal of International Law, Vol. 13, No. 1 (2002), pp. 43-61; J. Gordon, “A Peaceful, Silent, Deadly Remedy: The Ethics of Economic Sanctions”, Ethics E⿱ International Affairs, Vol. 13, No. 1 (1999), pp. 123-142.; J. Mueller \& K. Mueller, "Sanctions of Mass Destruction”, Foreign Affairs, Vol. 78, No. 3 (1999), pp. 43-53; T.G. Weiss, D. Cortright, G.A. Lopez \& L. Minear, (Eds), Political Gain and Civilian Pain: Humanitarian Impact of Economic Sanctions (Lanham: Rowman \& Littlefield, 1997).

${ }^{404}$ M. Brzoska, "From Dumb to Smart? Recent Reforms of UN Sanctions", Global Governance, Vol. 9, No. 4 (2003), pp. 519-535; Watson Institute for International Studies: Background paper on targeted sanctions, prepared by the Targeted Financial Sanctions Project for the Workshop on United Nations Sanctions, 16-17 July 2004.

${ }^{405}$ Evans, The Responsibility to Protect, p. 114.

${ }^{406}$ D.W. Drezner, "Sanctions Sometimes Smart: Targeted Sanctions in Theory and Practice", International Studies Review, Vol. 13, No. 1 (2011), pp. 96-108; A. Torstensen \& B. Bull, “Are Smart Sanctions Feasible?”, World Politics, Vol. 54, No. 3 (2002), pp. 373. 403. 38, J. Gordon, "Smart Sanctions Revisited”, Ethics EI International Affairs, Vol. 25, No. 3 (2011), pp. 315-335.

${ }^{407}$ M. Brzoska, "Measuring the Effectiveness of Arms Embargoes", Peace Economics, Peace Science and Public Policy, Vol. 14, No. 2 (2008), pp. 1-32; D. Tierney, "Irrelevant or Malevolent? UN Arms Embargoes in Civil Wars", Review of International Studies, Vol.
} 
In addition, even smart sanctions are not immune to the problem of unintended consequences. Even partial trade embargoes and aviation bans can affect the well-being of the general population, and the institutionalization of humanitarian safeguards and impact monitoring remains weak and patchy in contemporary sanctions regimes. ${ }^{408}$ Like comprehensive embargoes, blockades of individual economic sectors can also lead to the "criminalization" of the target society through smuggling and corruption.

A particularly grave problem can result from the imposition of arms embargoes which are "impartial" on paper but effectively benefit the stronger side within an asymmetric conflict. The paradigmatic example was the UN arms embargo imposed on the Former Yugoslavia during the Bosnian War. Since the Serbs controlled the Former Yugoslav army and domestic arms industry and the Croats received clandestine arms shipments from friendly governments over the Adriatic Sea, the landlocked Bosnian Muslims were hit hardest by the officially neutral embargo - with well-known consequences. ${ }^{409}$ But also more recent arms embargoes imposed in the name of RtoP have been criticized for inadvertently skewing conflicts in favour of the stronger side. In the Darfur crisis, the UNSC imposed an arms embargo on all non-state actors in Darfur in an apparently impartial manner. Yet, since it did not cover the Sudanese government, the measure did not interfere with the government's arms supply to the "non-state" Janjaweed militia and thus effectively disadvantaged the Darfuri rebels. ${ }^{410}$ Similarly, in the recent Libya crisis, the UN as well as the EU imposed arms embargoes on the whole country that were meant to hit both government and rebel forces. Yet, the idea that this measure could curtail the fighting after years of foreign arms supplies to Gaddafi, including billions of euros worth of arms shipments from EU members, was naive. Rather than stopping the violence, the embargo threatened to reinforce the crushing superiority of government troops over the rebels - and thus to undermine the goals of the military intervention conducted at the same time in the name of the RtoP. ${ }^{411}$

As these examples illustrate, arms embargoes are particularly problematic when imposed after the fullscale escalation of a conflict. Arguably, a much more stringent European arms export control policy against the Libyan dictator at an earlier stage could have reduced his capacity to terrorize the civilian population. Yet, as one commentator points out with resignation, 'there is not a single case where an arms embargo was introduced sufficiently early to prevent the aggressor faction from actually initiating civil war' [author's emphasis]. ${ }^{412}$

Trials as an instrument of peace

The treatment of international criminal courts and tribunals as instruments of the RtoP rests on the assumption that the criminal prosecution of perpetrators can help to prevent, end, and alleviate the consequences of mass atrocities. At first sight, this proposition receives considerable support in the specialized literature on international criminal justice. The argument that prosecutions deter potential future perpetrators - and thus prevent the occurrence of atrocities - can be traced back to the very origins of the international criminal justice system, to the Nuremberg tribunals following World War II. It has since accompanied every step in the expansion of the system, from the establishment of the Yugoslavia tribunal to ongoing investigations of the ICC. In addition to this long-term deterrent effect, international criminal justice has also been credited with serving a specific deterrent function: by dissuading perpetrators from committing further crimes, by undermining their domestic power bases and by forcing them into

31, No. 4 (2005), pp. 645-664; A. Vines, “Can UN Arms Embargoes in Africa be Effective?”, International Affairs, Vol. 83, No. 6 (2007), pp. 1107-1122.

${ }^{408}$ R. Geiss, "Humanitarian Safeguards in Economic Sanctions Regimes: A Call for Automatic Suspension Clauses Periodic Monitoring, and Follow-up Assessment of Long-Term Effects", Harvard Human Rights Journal, 18 (2005), pp.167-199; Gordon, "Smart Sanctions".

${ }^{409}$ Tierney, "Irrelevant or Malevolent", p. 658.

${ }^{410}$ K.A. Rodman, "Darfur and the Limits of Legal Deterrence”, Human Rights Quarterly, Vol. 30, No. 3 (2008), pp. 529-560, here

p. 543. The embargo was later extended to government forces active in Darfur, but not to the government as a whole.

${ }^{411}$ C. Fehl, Ein hausgemachtes Dilemma. Der Bürgerkrieg in Libyen erteilt Europa einige unangenehme Lehren, HSFK.

Standpunkt No. 7/2011 (Peace Research Institute Frankfurt, 2011).

${ }^{412}$ Tierney, "Irrelevant or Malevolent", p. 651. 
negotiations, it is claimed, trials can serve as a peace-making instrument at the height of a crisis. ${ }^{413}$ Lastly, scholars argue that the legal Aufarbeitung of major crimes can help consolidate peace and advance reconciliation by teaching democracy and the rule of law to post-conflict societies. ${ }^{414}$

While these widespread arguments are in line with the presentation of international criminal justice as an instrument of peace, they are, unfortunately, all highly contested. The long-term deterrent effect of international tribunals is notoriously difficult to measure and to insulate from other factors. ${ }^{415}$ More fundamentally, critics attack the theoretical rationale of the argument from different directions. While some doubt that génocidaires are primarily guided by rational cost-benefit calculations, others point out that the high selectivity of international criminal justice - due to its limitation to the gravest crimes and to the political difficulty of enforcing arrest warrants - drastically reduces incentives for rational individuals to eschew the commission of atrocities. ${ }^{416}$

Regarding the usefulness of criminal prosecutions as part of a post-conflict peace-building strategy, some critics argue that trials unfold the greatest "demonstration effect" precisely on those audiences which are already convinced of the value of democracy and the rule of law. ${ }^{417}$ Furthermore, criminal prosecution is only one among many alternative forms of transitional justice - ranging from trials to truth commissions and traditional rituals of healing and forgiveness - that are being discussed as valuable pathways toward post-conflict reconciliation. ${ }^{418}$ The literature gives little reason to conclude that international trials are an inherently superior stabilization tool after major conflicts.

While preventive and post-conflict uses of criminal prosecutions in the service of the RtoP are thus debatable, by far the gravest criticism is directed against the use of trials in ongoing conflicts, that is, as part of the international community's "pillar three" responsibility to respond to humanitarian crises. To perpetrators who have already committed crimes and who are still in a position of power, many critics argue, the threat of prosecution provides no incentive to lay down arms, but rather a strong incentive to defend their power with all available means. Criminal prosecutions in ongoing conflicts can thus escalate and extend, rather than de-escalate and shorten conflicts. ${ }^{419}$ This infamous "peace versus justice" dilemma is not bound to manifest itself in every conflict investigated by international courts. Yet, there are clear indications that ICC investigations have complicated efforts to broker peace deals and aid the civilian population in the Ugandan and Darfuri civil wars.

In Uganda, the ICC got involved following a self-referral: The Ugandan government asked the court to investigate the situation in Northern Uganda, where it was fighting a consumptive civil war against the Lord's Resistance Army (LRA). This self-referral, observers believe, was primarily intended to deflect international criticism of the negative humanitarian impacts of a recent government offensive against the rebels and of abuses committed by government soldiers. In addition, it allowed President Yoweri Museveni to exempt the LRA leadership from an amnesty law that had been passed earlier against his opposition to facilitate peace talks. Despite the ICC's investigations and issuing of arrest warrants against

\footnotetext{
${ }^{413}$ P. Akhavan, "Beyond Impunity: Can International Criminal Justice Prevent Future Atrocities?", The American Journal of International Law, Vol. 95,No. 1 (2001), pp. 7-31; Rodman, "Darfur", pp. 532-533; L. Vinjamuri, "Deterrence, Democracy, and the Pursuit of International Justice”, Ethics E International Affairs, Vol. 24, No. 2 (2010), pp. 191-211.

${ }^{414}$ H. Kim \& K. Sikkink, "Explaining the Deterrence Effect of Human Rights Prosecutions for Transitional Countries", International Studies Quarterly, Vol. 54, No. 4 (2010), pp. 939-63.

${ }^{415}$ For an exceptional attempt to measure the long-term deterrent effects of domestic human rights trials, see Kim \& Sikkink, "Explaining the Deterrence Effect".

${ }^{416}$ F. Mégret, "Three Dangers for the International Criminal Court: A Critical Look at a Consensual Project", Finnish Yearbook of International Law, Vol. 12 (2001), pp. 193-247, here p. 203; M.A. Drumbl, "Collective Violence and Individual Punishment: The Criminality of Mass Atrocity", Northwestern University Law Review, Vol. 99, No. 2 (2004/05), pp. 539-610; J. Ku \& J. Nzelibe, "Do International Criminal Tribunals Deter or Exacerbate Humanitarian Atrocities?", Washington University Law Review, Vol. 84, No. 4 (2006), pp. 777-833.

${ }^{417}$ Vinjamuri, "Deterrence", p. 198.

${ }^{418}$ E.g. M. Aukerman, "Extraordinary Evil, Ordinary Crime: A Framework for Understanding Transitional Justice”, Harvard Human Rights Journal, Vol. 15 (2002), pp. 39-97; W. Lambourne, "Transitional Justice and Peacebuilding after Mass Violence", International Journal of Transitional Justice, Vol. 3 (2009), pp. 28-48.

${ }^{419}$ Rodman, "Darfur"; M.P. Scharf, "Justice Versus Peace", in S.B. Sewall \& C. Kaysen, (Eds) The United States and the International Criminal Court: National Security and International law (Rowman \& Littlefield, 2000), pp. 179-94; J. Snyder \& L. Vinjamuri, "Trials and Errors. Principle and Pragmatism in Strategies of International Justice”, International Security, Vol. 28, No. 3 (2003/04), pp. 5 44.
} 
five LRA commanders - heavily criticized by local peace activists -, talks between the conflict parties continued, and a peace agreement was drawn up by 2008. However, the LRA leadership, which had demanded guarantees against the enforcement of the ICC warrants throughout the negotiations, ultimately never signed it. ${ }^{420}$

In Darfur, ICC investigations followed a referral by the UNSC and have focused primarily on government officials. Ignoring warnings by analysts that "ending criminal violence in Darfur will require some compromises with international criminal justice", ${ }^{221}$ the court issued an arrest warrant against Sudan's President Omar Al-Bashir in 2009. At the time, commentators feared that this step could derail not only peace talks in Darfur itself, but also the Comprehensive Peace Agreement between North and South Sudan. ${ }^{422}$ While these extreme consequences have not materialized, this might in part be due to the fact - evident to Bashir - that neither the West nor African states have an appetite for actually enforcing the warrant. In any case, despite partial peace deals between the government and some Darfuri rebel factions, both sides continue to resort to violence.

A more immediate consequence of the warrant was the Sudanese government's decision to expel foreign aid organizations responsible for about $50 \%$ of the aid to civilians in the region on the grounds that they could collaborate with the ICC. ${ }^{423}$ Most were readmitted months later, yet it was civilians in Darfur who suffered the consequences of this power game between Bashir and the international community.

The symbolic politics of sanctions and trials

Given the evident problems with using sanctions and trials as instruments of peace, why do they still occupy such a prominent place in discussions of RtoP's civilian dimension, and why do they tend to be used precisely when the risk of unintended consequences is highest, as an acute response strategy at the height of crisis? The political science literature on sanctions and trials offers thought-provoking answers to both of these puzzles, too.

As early as 1967, Johan Galtung pointed out the "expressive function" of sanctions:

'If economic sanctions do not make a receiving nation comply, they may nevertheless serve functions that are useful in the eyes of the sending nation(s). [...] There is the value of at least doing something, of having the illusion of being instrumental, of being busy in time of crisis. When military action is impossible for one reason or another, and when doing nothing is seen as tantamount to complicity, then something has to be done to express morality [emphasis in original] [...]. If the sanctions do not serve instrumental purposes, they can at least have expressive functions. ${ }^{.424}$

According to this argument, shared and elaborated also by other theorists, (Western) governments use sanctions as a less costly substitute for military intervention, not because they expect them to affect the target's behaviour, but to demonstrate resolve to a domestic public concerned about violence against innocent civilians abroad. ${ }^{425}$ This dynamic also explains why sanctions that could work better at an early

\footnotetext{
${ }^{420}$ T. Allen, Trial Justice. The International Criminal Court and the Lord's Resistance Army (Zed Books, 2006), pp. 72-127; K.P. Apuuli, "The ICC's Possible Deferral of the LRA Case to Uganda”, Journal of International Criminal Justice, Vol. 6 (2008) pp. 801-813; S.M.H. Nowen \& W.G. Werner, "Doing Justice to the Political: The International Criminal Court in Uganda and Sudan", European Journal of International Law, Vol. 21, No. 4 (2010), pp. 941-969, here pp. 946-949. For the argument that ICC investigations helped the peace negotiations, see N. Grono \& A. O’Brian, "Justice in Conflict? The ICC and Peace Processes" in N. Whaddell \& Phil Clark, (Eds.) Courting Conflict? Justice, Peace and the ICC in Africa (Royal African Society, 2008), pp. 13-20. ${ }^{421}$ Rodman, "Darfur", p. 556.

${ }^{422}$ E.g. J. Flint \& A. De Waal, "To Put Justice before Peace Spells Disaster for Sudan”, The Guardian (6 March 2009); A. Natsios, "Waltz with Bashir: Why the Arrest Warrant against Sudan's President will Serve Neither Peace nor Justice”, Foreign Affairs, (23 March 2009).

${ }^{423}$ M. Kersten, "Sudanese President Charged with Genocide: Some Initial Thoughts on Why it Matters", Justice in Conflict, (12 July 2009). See http://justiceinconflict.org/2010/07/12/sudanese-president-charged-with-genocide-some-initial-thoughts-on-whyit-matters/. (Accessed 28 March 2012).

${ }^{424}$ Galtung, "Effects of Economic Sanctions", p. 411.

${ }^{425}$ T.C. Morgan \& V.L. Schwebach, "Fools Suffer Gladly: The Use of Economic Sanctions in International Crises", International Studies Quarterly, Vol. 41, No. 1 (1997), pp. 27-50; T. Whang, "Playing to the Home Crowd? Symbolic Use of Economic Sanctions in the United States", International Studies Quarterly, Vol. 55, No. 3 (2011), pp. 1-15.
} 
stage as crisis prevention tools - such as arms embargoes - are much more likely to be used at the height of crisis, when public pressure to "do something" is highest.

An example that well illustrates the use of sanctions as a symbolic substitute for military intervention is the stance of the German government in the Libyan crisis. Torn between allied pressure to contribute to crisis management and the (perceived) opposition of the German population to German involvement in another military campaign, the government did not participate in the Western military campaign against Gaddafi, but became a leading proponent of UN and EU sanctions against Libya, also insisting on the strict enforcement of the arms embargo when its allies had long begun to doubt the wisdom of this measure. ${ }^{426}$ In a parliamentary debate, Foreign Minister Guido Westerwelle justified this policy by arguing that "the alternative to a military intervention is not to do nothing, not to stand by and watch, but to increase the pressure, to impose and tighten sanctions". ${ }^{427}$

In a similar way, the search for symbolic alternatives to military intervention also appears to have contributed to the creation and increasingly frequent resort to mechanisms of international criminal justice. According to historians, Western policy-makers' desire to "do something" about the Bosnian tragedy in response to massive domestic public and media pressure, while at the same time avoiding a risky military campaign, played a central role in the creation of the International Tribunal for the Former Yugoslavia (ICTY). The creation of the permanent ICC is often interpreted as a more long-term response to the same kind of domestic pressure. ${ }^{428}$ Even the leader of the US delegation to the Rome Conference on the ICC Statute paid tribute to this factor:

'[I]t is simply no longer tenable for the democratically elected political leaders or among the publics they serve to tolerate impunity for the commission of such international crimes. [...] There are many different mechanisms that the international community is exploring and using to respond to genocide, crimes against humanity, and war crimes. [...] The permanent International Criminal Court is needed at one extreme of this spectrum of mechanisms. ${ }^{429}$

The apprehension that ICC investigations could serve as symbolic substitutes for military interventions has been widely discussed - and has been confirmed, in the eyes of many observers, by the Security Council's decision to refer the Darfur situation to the ICC without taking any more robust action. ${ }^{430}$

That international criminal justice has thus been instrumentalized as a substitute for military intervention is not only the fault of RtoP advocates, however. As Leslie Vinjamuri has convincingly showed, proponents of international criminal justice themselves - from justice NGOs to the prosecutors and presidents of international courts themselves - have increasingly emphasized the peacemaking effect of prosecutions, rather than principled demands for "doing justice", to broaden international support for these measures. While the peace argument thus serves a marketing strategy for justice advocates, it also suits activists interested in "selling" the RtoP concept to intervention-sceptic audiences. We can thus speak of a mutual instrumentalization of RtoP and justice advocates.

While there are thus good reasons to assume that sanctions and trials can be - and are - used as a symbolic substitute for military intervention, they may serve quite a different symbolic function in other

\footnotetext{
${ }^{426}$ Fehl, Hausgemachtes Dilemma.

${ }^{427}$ G. Westerwelle, „Regierungserklärung von Bundesaußenminister Guido Westerwelle vor dem Deutschen Bundestag zur aktuellen Entwicklung in Libyen (UN-Resolution)“, Berlin, (18 March 2011) [author's translation]. See http://www.bundesregierung.de/Content/DE/Regierungserklaerung/2011/2011-03-18-westerwelle$\underline{\text { libyen,layoutVariant=Druckansicht.html. }}$ (Accessed 9 September 2011).

${ }^{428}$ K. Anderson, "The Rise of International Criminal Law: Intended and Unintended Consequences", European Journal of International Law, Vol. 20, No. 2 (2009), pp. 331-358; J. Crawford, "The ILC Adopts a Statute for an International Criminal Court”, The American Journal of International Law, Vol. 89, No. 2 (1995), pp. 404-16; A. Neier, War crimes (Times Books, 1998); C. Rudolph, "Constructing an Atrocities Regime: The Politics of War Crimes Tribunals", International Organization, Vol. 55, No. 3 (2001), pp. 655-91.

${ }^{429}$ D.J. Scheffer, "Staying the Course with the International Criminal Court", Cornell International Law Journal, Vol. 35, No. 1 (2002), pp. 47-100, here pp. 51-52.

${ }^{430}$ Akhavan, "Beyond Impunity"; M. Happold, "Darfur, the Security Council, and the International Criminal Court", International and Comparative Law Quarterly, Vol. 55, No. 1 (2006), pp. 226-36; Rodman, "Darfur”, T.W. Smith, "Moral Hazard and Humanitarian Law: The International Criminal Court and the Limits of Legalism”, International Politics, Vol. 39, No. 2 (2002), pp. 175-192.
} 
cases: that of legitimating military intervention. As the Ugandan example shows, a government may be interested in ICC investigations and prosecutions of a rebel group to delegitimize its opponents and to claim a higher moral justification for its violent fight against that group: after all, it is merely "enforcing the will of the international community" ${ }^{431}$ But also for outside actors preparing to intervene in a conflict under the auspices of the RtoP, sanctions and trials serve an important legitimating function: their use before the authorization of armed force demonstrates to intervention sceptics that all other means have been exhausted. The escalation logic cited at the outset of this article can thus be re-read as a symbolic strategy of war legitimization. Sanctions and trials are irreplaceable instruments in the civilian RtoP toolbox not so much because of their superior effectiveness, but because they are the only truly coercive measures short of war. Viewed in this way, the "need for something between words and violence" flows above all from the need to demonstrate the ultimate necessity of violence.

Whether sanctions or trials are used as symbolic substitutes for military intervention or as symbolic steps toward legitimating violence - the important thing to realize is that none of these functions have anything to do with the purported beneficial effects they can achieve on the ground, in the target country. If (ab)used in this way, sanctions and trials do not constitute a truly free-standing civilian component of the RtoP, but merely serve secondary functions in relation to the core of the concept, military humanitarian intervention. The critics' argument that the civilian aspects of RtoP are not to be taken seriously would then be justified.

Yet, do we need to draw such a radical conclusion? Does the realization that sanctions and trials are more likely to impress Western publics than alter the strategic calculations of their targets suggest that we should scrap these instruments altogether from the RtoP toolbox? Not necessarily. One important argument in their favour is that in the long run and indirectly, the symbolic effects of sanctions and trials may still contribute to altering the international and domestic social environment in which atrocities are being committed, and thus contribute - even if in very small steps - to reducing global violence. By communicating disapproval with a particular kind of action, both measures confirm the validity of the norms that the behaviour is violating, and serve to brand the violator as an outcast of the international community. The outcasts' desire to regain their international as well as domestic social standing, to confirm their identity as members of a larger moral and legal community, can constitute a powerful, albeit slow-working, force for change. Constructivist International Relations theorists have discussed this mechanism with regard to the domestic enforcement of international human rights norms, in which "shaming" and other forms of social pressure have been found to play a powerful role. ${ }^{432}$ Furthermore, even if the target itself remains unimpressed, sanctioning atrocities in some form can reinforce the strength of human rights norms at the global level and thus contribute to decreasing violence in an even more indirect and long-term fashion. In a somewhat different language, political theorists relate to very similar ideas when they refer to the "expressive function" of punishment, whereby a society communicates and reaffirms its core norms both to the perpetrator and to all of its members. ${ }^{433}$

These beneficial symbolic effects may seem quite intangible, compared to the high expectations that are placed on the immediate, coercive peacemaking effect of sanctions and trials. But, as David Baldwin argues with regard to sanctions, their use as symbolic signalling devices is a perfectly valuable policy tool, the usefulness of which must be evaluated not only on its own terms, but in comparison with available alternatives. 'Even when the expectation of success is very low, the use of sanctions is justified if there is no policy alternative with a higher expectation of success. ${ }^{434}$ In light of the preceding discussion, two additional conditions should be attached: firstly, that the use of sanctions or trials is unlikely to have unintended negative consequences for the civilian population, and secondly, that decision-makers resist the temptation to present these symbolic signalling strategies as coercive tools functionally equivalent to

\footnotetext{
${ }^{431}$ Nowen \& Werner, "Doing Justice”.

${ }^{432}$ E.g. T. Risse, S.C. Ropp \& K. Sikkink, (Eds.) The Power of Human Rights: International Norms and Domestic Change (Cambridge University Press, 1999).

${ }^{433}$ E.g. B. Wringe, "Why Punish War Crimes? Victor's Justice and Expressive Justifications of Punishment", Law and Philosophy, Vol. 25, No. 2 (2006), pp. 159-191.

${ }^{434}$ D.A. Baldwin "The Sanctions Debate and the Logic of Choice”, International Security, Vol. 24, No. 3 (1999/2000), pp. 80-107, here p. 92.
} 
military intervention - in order to deflect public pressure for action. In practice, this is admittedly a very fine line to walk.

\section{In lieu of a conclusion: Lessons for analysts and policy-makers}

It is high time that RtoP advocates engage more honestly with critical findings about the effectiveness of sanctions and trials as peacemaking instruments, which have long been debated in specialized academic communities but have remained insulated from an RtoP debate focused on humanitarian intervention. Above all, this means scaling down expectations as to what sanctions and trials can do in the service of the Responsibility to Protect.

In particular, there are grave reasons to doubt that either of them can be used with immediate effect as a tool of crisis management, under the international community's "third pillar" responsibility to react to manifest violations of the RtoP principle. Neither sanctions nor trials are likely to function effectively as a "coercive tactic" that manipulates violent actors' strategic incentive. Both measures can have unintended negative consequences for peace, and both are routinely used as convenient symbolic substitutes for military intervention in situations when public pressure to act is high, yet when intervention is considered too costly.

The theoretical case for both strategies is somewhat better with regard to preventive and post-conflict uses: a timely arms embargo, imposed at the earliest sign of systematic oppression, may help to prevent the escalation of a crisis; the growing activism of the ICC - provided its sentences are enforced - may yet strengthen the long-term deterrent effect of international criminal justice. The greatest promise that both strategies hold for the realization of the RtoP, however, lies in openly recognizing their primarily symbolic effect - not as alibis for eschewing military action, but as normative appeals that strengthen the RtoP in the long run, by "shaming" and isolating perpetrators and by reaffirming the international community's commitment to human rights. The benefits to be gained are intangible and small, but much more realistic than the proposal to deescalate an ongoing crisis with sanctions and trials.

More concretely, what does this mean with regard to the use of sanctions and trials in a given humanitarian crisis? Given the small chances for effecting a direct behavioural change, the most important rationale underlying any decision on sanctions or criminal prosecutions must be to anticipate, avoid, and monitor unintended impacts on the population to be protected - economic hardships as well as undesirable manipulations of conflict dynamics through arms embargoes and criminal prosecutions. With regard to economic sanctions, proposals for instituting better impact monitoring mechanisms have long been on the table. ${ }^{435}$ In the case of arms embargoes, their effect on conflict dynamics is very hard to estimate in advance. These measures should therefore be used extremely selectively in the context of ongoing conflicts, their impact on power relations between conflict parties should be closely monitored.

Criminal prosecutions as a tool of crisis management have an additional disadvantage, compared to sanctions. While sanctions can be lifted if they are found to have a negative impact on the conflict, indictments cannot. There is thus a good case for preferring sanctions over trials as symbolic tools of condemnation in the context of an ongoing conflict. The pursuit of justice should be delayed until after the end of a conflict if there is any risk that it could undermine peace negotiations. Self-referrals, which are particularly prone to political instrumentalization by the conflict parties, should be avoided altogether.

Importantly, this is not the same as saying that justice has no value of its own. To the contrary, both RtoP and international criminal justice advocates should recognize that peace and justice are independent pursuits which are often in conflict, at least within short time horizons, and require careful balancing. A deferral of criminal investigations may be regrettable in a "purist" view of criminal justice. Yet, it is not irreconcilable with retributivist ethics - and does not undermine the long-term deterrent, norm-teaching and post-conflict reconciliation goals of prosecuting mass atrocities.

\footnotetext{
${ }^{435}$ E.g. Geiss, "Humanitarian Safeguards".
} 


\section{Index}

2005 World Summit

4-D Approach

$8,11,29,80,81,88$

Arab Spring

Abdel-Elah Al-Khatib

Abdullah al-Senussi

Accountability

Adriatic Sea

Afghanistan

Africa

African Union

Airborne Capabilities

Alassane Ouattara

Alien Tort Claims Act

American Convention on Human Rights

Amnesty International

Angola

Arab League

Argentina

Armoured personnel carriers

Arms Embargo $\quad 20,30,75,77,78,97,98,101,103$

Business and Peace

Bab-al-Aziziyah

Ban Ki-moon

Barefoot Infantry

Beijing

Ben Ali

Benghazi

Blue helmet

Bonn-Berlin Process on Arms Embarooes and Travel and Aviation Related Sanctions

$29,48,55,73,76,80$

52,54

$19,30,98,100$

7,9

9

84

82

64

78

28

23,26

28

28

80

51

Bosnia

Brazil

Bukavu

Bunia

Burma

Burundi

Business

Capacity Development

$9,13,80,81,82,83,84,85,86$

Capstone Doctrine

Chad

Chapter VI

Chapter VII

Chapter VIII

China $3,5,7,9,23,27$,

Christian Realists

$27,30,32$

84

$48,75,77,78$

27, 49

$19,20,98$

9, 48

50

51

57,74

19,57

Civil Protection Orders

Civil Society

11

50

28

70

$40,68,70,76$

$17,18,22$

Civilian Crisis Management

Civilian Protection Missions

Cold War

Committee on Economic, Social and Cultural Rights 68

Committee on the Elimination of Discrimination

Against Women

67,91
Committee on the Elimination of Racial Discrimination

Companies

$81,82,83,84,85,86$

Comprehensive Peace Agreement

100

Convention Against Torture

64,65

Corporate Security Responsibility

$7,80,81$

Corporate Social Responsibility

$7,80,82$

Côte d'Ivoire

$7,47,57,73,82,83,90$

Criminal Prosecution

9

Cruise Missiles

CSDP

7,30

Damascus

52

Darfur

$7,49,50,98,99,100,101$

DeBeers

83

Democracy

Democratic Republic of Congo

9, 99

Deterrent Effect

$17,49,91$

Dual Key

96, 98, 99, 103

East Asia

19

Economic Growth

52

Economic Interests

85

27

Economic Sanctions

ECOWAS

8

Effectiveness of Sanctions

$7,17,26,51$

Egypt

103

European Court of Human Rights

28, 81

European Union

61,64

Expectations/Capacities Gap

Facebook

Faith Based Organizations 20

Fighter Jets $\quad 53$

Financial Sanctions $\quad 97$

Foreign Aid Organizations $\quad 100$

Former Yugoslavia 97, 98, 101

Francis Deng $\quad 47$

Friends of RtoP 93

Gaddafi $\quad 48,52,73,75,76,78,98,101$

Gender 9,87

Gender-Based Violence $\quad 16$

Génocidaires $\quad 99$

Genocide Convention 59, 63

Georgia $\quad 57$

German Criminal Law $\quad 59$

Germany 14

Global Action to Prevent War and Armed Conflict 10,87

Global Interests 16

Global Responsibility to Protect 10, 95

Global Sanctions Regimes $\quad 97$

Global South 52, 95

Global Witness 82

Globalization $\quad 8$

Ground Forces 9

Guido Westerwelle 101 
Hardeep Singh Puri $\quad 77$

Hobbes $\quad 30$

Hu Jintao $\quad 27$

Human Rights Law $\quad 54$

Human Rights Norms $\quad 102$

Human Rights Watch $\quad 78$

Humanists

Humanitarian Intervention 95, 96, 102, 103

Illicit Arms

95, 96, 102, 103

India

$9,30,48$

Inter-American Court of Human Rights

64

INTERFET

7,51

Interlaken Process on Targeted Financial Sanctions97

International Coalition for the Responsibility to

Protect

2, 88, 93

International Commission on Humanitarian Intervention

International Commission on Intervention and State Sovereignty

7, 28, 80, 95

International Covenant on Civil and Political Rights 64,67

International Criminal Court $\quad 7,10,37,58,59,60$, 99, 100, 101, 102, 103

International Criminal Justice 98, 99, 100, 101, 103

International Criminal Tribunals 95, 99

International Humanitarian Law $\quad 51$

International Justice $\quad 16$

International Law $\quad 82$

International Legal Sanctions 96

International Relations 8

Iraq $\quad 97$

Ivo Daalder $\quad 78$

Jacobo Árbenz Guzmán $\quad 85$

James Stavridis $\quad 78$

Janjaweed 98

Japan $\quad 30$

Jean Ping $\quad 78$

Johan Galtung 100

Joshua Arap Sang $\quad 82$

Juan Mendez $\quad 10$

Jus Cogens $\quad 68$

Kavitha Suthanthiraraj $\quad 10$

Kenya 60, 82, 84

Kofi Annan $\quad 15,18$

Land-Invasions $\quad 52$

Laurent Gbagbo $\quad 73,84$

Lebanon 7, 28, 85

Legitimacy $\quad 8,9,12,13,16,17,18,19,20,21,22$, $23,24,25,26,32$

Li Jijun

Libya $\quad 3,6,7,8,9,13,18,23,26,29,47$, $48,50,51,52,54,80,82,84,90,91,93,95,98$, 101, 109

Lord's Resistance Army

$7,54,99,100$

Macedonia

Margot Wallström

Mass Atrocity Response Operations 9, 47, 50, 52, 54

Medecins Sans Frontières $\quad 78$

Media 8, 82

Mediation $\quad 95$

Military Information Support Operations $\quad 53$

Military Intervention 8

Military Modernization 29

Mine-Clearing $\quad 27$

MINUSTAH 7, 28

Misrata 78

Mission Creep $\quad 75$

Mubarak 81

Mujajiriya $\quad 50$

Multinational Corporations $\quad 83,85$

Multi-Track Dialogue 33

Mutual Instrumentalization $\quad 101$

National Defense University 29

National Transitional Council 76

NATO $6,7,8,9,17,18,19,20,21,23$, $26,30,33,47,48,50,51,52,53,54,80$

Neo-colonialism 24

Neo-militarism $\quad 73$

New York Times 52, 80, 82, 83, 85

NGOs $\quad 5,101$

Nigeria 84

No-Fly Zone $\quad 73,74,75,78,90$

Non-refoulement $\quad 55,64,65,70$

Nuremberg Tribunals 98

Office for the Coordination of Humanitarian Affairs $7,48,49$

Oil and Natural Gas Company of India 83

Omar Al-Bashir $\quad 61,100$

Operation Artemis 18, 51

Operation Deliberate Force 20

Oxfam 20

Pacific Region $\quad 52$

Pakistan 53

Peacekeeping 4, 9, 15, 27, 28, 88, 103

People's Liberation Army 7, 27

Pillar One $\quad 8,95$

Pillar Two 8, 95

PLA Air Force 29

Political Will 15, 17, 23, 24

Post-Conflict Peacebuilding 96

Post-Conflict Reconciliation 99, 103

Post-Conflict Societies 99

Pre-Trial Chamber 60,61

Prevention of Genocide 6, 10, 47

Preventive Diplomacy $\quad 8$

Protection of Civilians $\quad 5,8,47,48,49$

Public Pressure 101, 103

Qing Empire $\quad 31$

Radio Télévision Libre Des Mille Collines 7,84

Ramesh Thakur $\quad 73$

Realpolitik 27

Regional Organizations $\quad 9,13,17,18,19,20,21$, 22, 23, 24, 25, 26, 27, 29, 88

Regular Economic Activity 85

Reinhold Niebuhr $\quad 13,14$ 
Resistance Movements

Responsibility to Prevent

Responsibility While Protecting

28, 74, 76, 77, 95, 96

Responsibility to React

$3,95,96$

95,96

103

Retributivist Ethics

101

Rome Conference

Rome Statute

RtoP "toolbox"

$58,59,60,61$

Rule of Law

Russia

$9,23,29,48$

Safaricom

Sahel

Saif al-Islam

eawer

89,90

Sexual and Gender-Based Violence

$87,88,89,90,92,94$

Sexual Violence

Shared Sovereignty

Sierra Leone

Smart Sanctions

$7,49,51$

Social Change

97, 98

Social Pressure

Somalia

South Africa

Sovereignty

Sovereignty as Responsibility

Special Operations Forces

Sri Lanka

Stockholm Process on the Implementation of

Targeted Sanctions

Strategic Airlift

Strategic Culture

Sudan

Sun Tzu

Sustainable Economies

Symbolic Signalling Strategies

Syria

$13,23,26,47,48,52,57,91,93$

Targeted Sanctions

Tehran

Thailand

Thomists

Timely and Decisive Action

Tort Law

Trade Embargoes

Transitional Justice

Transparency

Travel Bans

Tripoli

Trust-Building

102

$17,53,57,74$

48,85

$8,23,24,30,31,95$

8,17

53,54

57

$2,28,100$
Truth Commissions

Uganda

$54,99,100$

Unmanned Aerial Vehicles

United Fruit Company

United Kingdom

$5,20,21$

United Nations
Charter
$8,17,18,19,29,68,69,76$

Department of Peacekeeping Operations 28, 48

Emergency Peace Service

$51,52,67,75,78$

Human Rights Council

$10,15,87,95$

P5

12

Resolution 1325

$87,89,93$

Resolution 1674

Resolution 1820

Resolution 1973

Resolution 1975

Resolution 2000

$6,8,48,53,75,77,90$

90

90

Resolution 2009

90

Security Council 7, 9, 21, 27, 30, 34, 68, 75, 76, 79, 80, 87, 89, 90, 91, 93, 97, 98, 100

System

$10,13,15,17,18,93$

UNAMID

UNAMSIL

$7,19,50$

UNIFIL

UNOCI

UNPROFOR

7,28

$7,47,50,90$

UNSMIL

19,20

United States

90

Victims of Rape

$11,13,14,101$

Vodafone

87

War Economy

81

Wikileaks

Women as Mediators

Women, Peace and Security

$7,87,93$

Women's Participation $\quad 87,88,89,91,92,93,94$

Women's Skills $87,88,89$

Working Group on the Prevention of Odious Debt 86

World Summit Outcome Document 34, 55, 57, 73

World Trade Organization 7, 33

World War II 98

Xiang Xiaoling 29

Xinjiang $\quad 30$

Xizang $\quad 30$

Yao Yunzhu 33

Yemen 53, 93

Yoweri Museveni 99

Zero Expectation Policy 53 


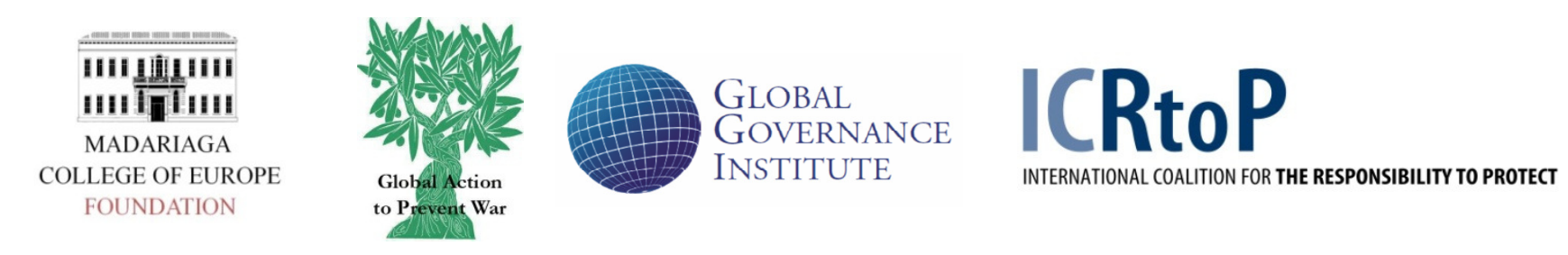

These chapters are a response and contribution to the challenges of the third pillar of the Responsibility to Protect (RtoP) principle. This pillar focuses on the international responsibility to take timely and decisive action to prevent and halt genocide, ethnic cleansing, war crimes and crimes against humanity in those instances where a state is unable or unwilling to protect its own population. As RtoP moves further away from discussions on norms towards operationalization, and following the concerns raised by the intervention in Libya, further thinking and clarity needs to be developed on the capacities needed for a timely and decisive response under pillar three. This book is a contribution to this end.

Contributors: Eamon Aloyo; David Curran; Caroline Fehl; Daniel Fiott; Joachim Koops; Melina Lito; Ruben Reike; Sheri Rosenberg; Robert Schütte; Kate Seaman; Conor Seyle; Ekkehard Strauss; Peiran Wang; Robert Zuber.

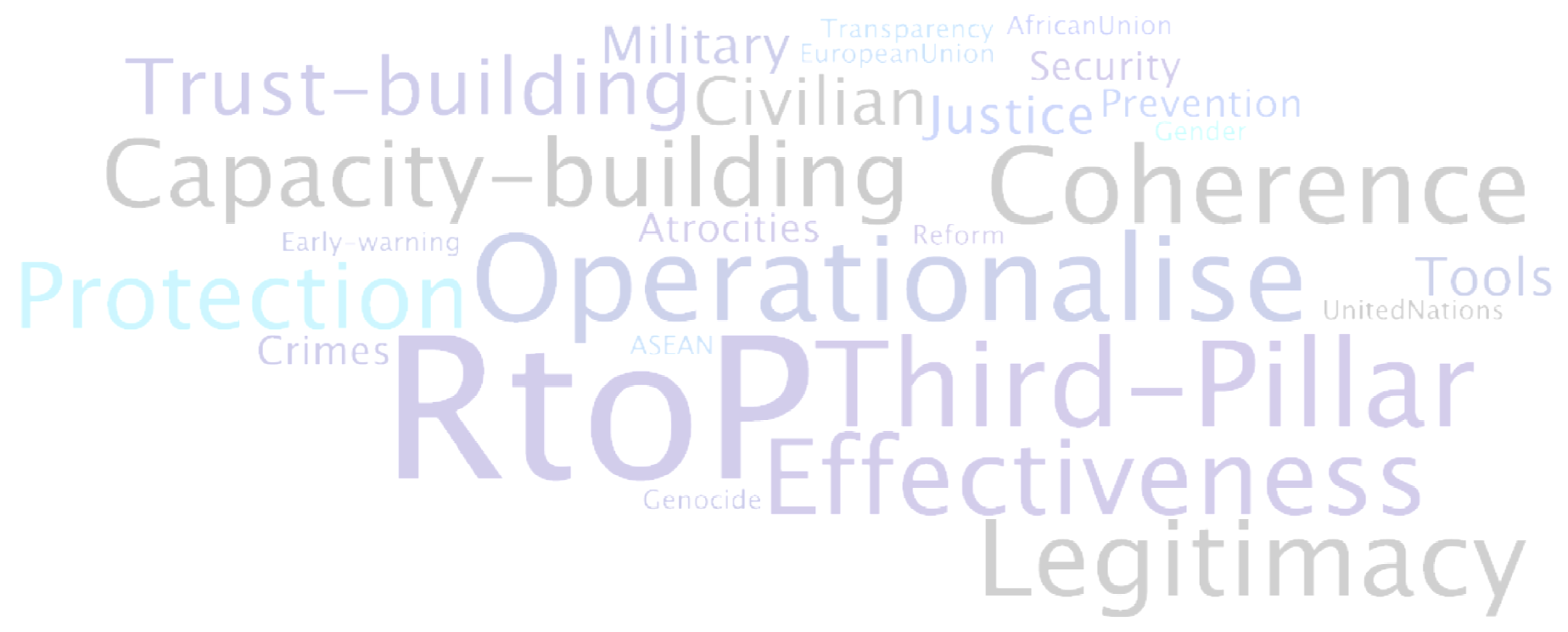

